\title{
Borboleta: um sistema de telessaúde para auxílio à atenção primária domiciliar
}

Rafael José Peres Correia

\author{
DISSERTAÇÃO APRESENTADA \\ AO \\ Instituto De Matemática e Estatística \\ DA \\ Universidade De SÃo Paulo \\ PARA \\ OBTENÇÃO DO TÍTULO \\ $\mathrm{DE}$ \\ Mestre em CiÊnCIAS
}

\author{
Programa: Ciência da Computação \\ Orientador: Prof. Dr. Fabio Kon
}

Durante o desenvolvimento deste trabalho o autor recebeu auxílio financeiro do Instituto Microsoft Research-FAPESP de Pesquisas em TI

São Paulo, abril de 2011 


\title{
Borboleta: um sistema de telessaúde para auxílio à atenção primária domiciliar
}

\author{
Esta tese/dissertação contém as correções e alterações \\ sugeridas pela Comissão Julgadora durante a defesa \\ realizada por (Rafael José Peres Correia) em 08/02/2011. \\ O original encontra-se disponível no Instituto de \\ Matemática e Estatística da Universidade de São Paulo.
}

Comissão Julgadora:

- Prof. Dr. Fabio Kon (orientador) - IME-USP

- Prof. Dr. Flávio Soares Corrêa da Silva - IME-USP

- Prof. Dr. Arlindo Flávio da Conceição - UNIFESP 


\section{Agradecimentos}

Eu gostaria de agradecer primeiramente a Deus, afinal sem Ele no controle de minha vida eu provavelmente não estaria vivo, depois aos meus pais, amigos e aos colegas de laboratório. Devo também meu agradecimento ao meu orientador Prof. Dr. Fabio Kon, aos profissionais do CSEB, que foram vitais para o progresso desse trabalho, em especial o Dr. José Ricardo de Mello Brandão e Rubens Kon, e a todos ajudaram a galgar mais esse degrau na minha vida. 


\section{Resumo}

No sistema brasileiro de saúde, cabe aos Centros de Saúde o papel de órgão provedor de assistência médica primária. Para que esse papel seja cumprido com responsabilidade e eficácia, se mostrou fundamental a condução de programas públicos de atenção primária que envolvam visitas domiciliares aos pacientes. O objetivo desses programas, tais como o Estratégia de Saúde da Família (ESF), também conhecido como Programa de Saúde da Família (PSF), é o de melhorar a qualidade do serviço de saúde prestado à população por meio da aproximação entre equipes de saúde e a comunidade, permitindo, dessa forma, uma migração do paradigma de tratamento de doenças para o de promoção da saúde. No entanto, apesar da importância desses programas para a organização e articulação do sistema de atenção primária, as atividades de atenção domiciliar são normalmente conduzidas com pouco ou nenhum suporte de Tecnologia da Informação (TI).

Esta pesquisa de mestrado tem por objetivo mostrar a definição e o desenvolvimento de um sistema móvel que auxilie os profissionais de saúde na coleta de informações dos pacientes que usufruem dos serviços de saúde citados acima. O projeto recebeu o nome de Projeto Borboleta e durante o tempo desta pesquisa várias versões do software foram desenvolvidas. Essas versões geraram protótipos do sistema que foram submetidos a testes em campo e, a partir da avaliação realizada pelos profissionais de saúde, surgiram alterações diversas.

Outros objetivos desta pesquisa de mestrado foram analisar as soluções adotadas pela equipe de desenvolvimento, assim como mostrar as dificuldades encontradas no desenvolvimento do sistema, que funciona em um PDA ou smartphone, além de apresentar qual tem sido a resposta dos profissionais de saúde com o uso, mesmo em fase de teste, do sistema móvel.

Palavras-chave: Borboleta, Telesaúde, Computação Móvel. 


\section{Abstract}

In the Brazilian Health System, the healthcare centers have the role of primary health care providers. To successfully fulfill this responsibility with more dedication and effectiveness, the Brazilian government created public primary health programs of homecare where the health professionals visit the patient's homes. Those programs, as the Family Health Strategy (also known as Family Health Program), aim to raise the quality of health services provided by the centers to the neighboring community. This enables a new way of treatment of diseases and health care promotion. Nevertheless, those important programs have almost no Information Technology mechanisms helping them to manage the processes involved by the program.

This master research objective is to present a definition and development of a mobile system that helps the healthcare providers to collect relevant data on the patient status on the site of the homecare treatment. The project was named as the Borboleta Project and during, the development of this research, several versions were released. Those versions were tested as prototypes on a real situation until a more stable version fitted the health professionals needs.

Other objectives of this research were to analyze the solutions adopted by the development team, to describe the difficulties encountered by the team while working on this mobile system, and finally to show which were the feedbacks of the usage of the system on the field, during the test phase.

Keywords: Borboleta, Telehealth, Mobile Computing. 


\section{Conteúdo}

1 Introdução $\quad 3$

1.1 Atendimento Domiciliar . . . . . . . . . . . . . . . . . . . . 4

1.1.1 Processo da Atenção Primária Domiciliar . . . . . . . . . . . . . . . . . 4

1.1 .2 Proposta de Sistema de Informação . . . . . . . . . . . . . . . . 6

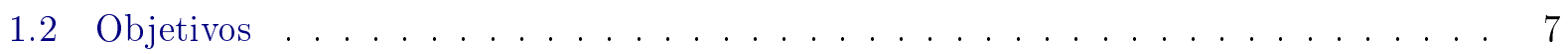

2 Trabalhos Relacionados $\quad 9$

2.1 Sistemas . . . . . . . . . . . . . . . . . . . . . . 9

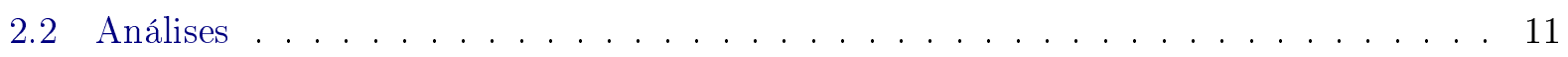

2.3 Padrões e Arcabouços . . . . . . . . . . . . . . . . . . . . . . . 12

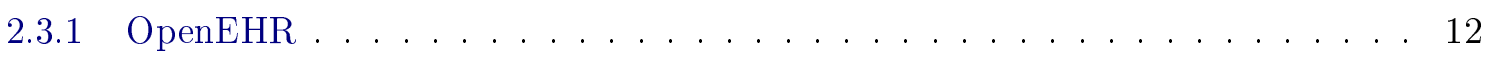

$2.3 .2 \quad$ Padrão HL7 . . . . . . . . . . . . . . . . . . . . . . . . . . . . . 14

3 O Projeto Borboleta $\quad 17$

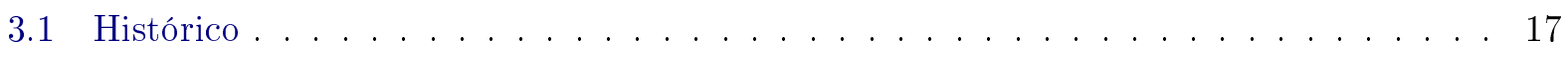

3.1.1 Funcionalidades do Módulo Móvel até 2007 . . . . . . . . . . . . . . 18

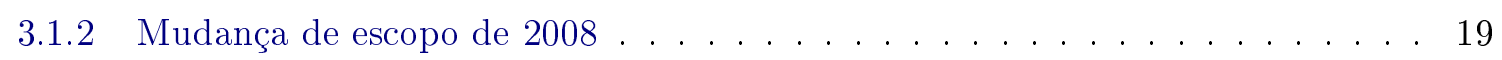

3.1 .3 Nova Interface . . . . . . . . . . . . . . . . . . . . . . . . . 19

3.2 Atenção Primária Domiciliar . . . . . . . . . . . . . . . . . 20

3.2.1 Roteiro do Encontro Domiciliar . . . . . . . . . . . . . . . . . . . 21

3.3 Entidades e Profissionais envolvidos . . . . . . . . . . . . . . . . 22

3.4 Outras Pesquisas do Projeto Borboleta . . . . . . . . . . . . . . . . . . 22

4 Tecnologias Utilizadas $\quad 25$

4.1 Evolução tecnológica . . . . . . . . . . . . . . . . . . . 25

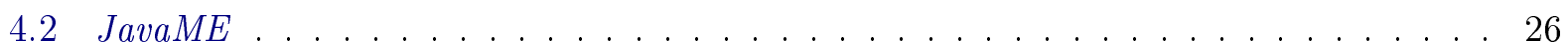

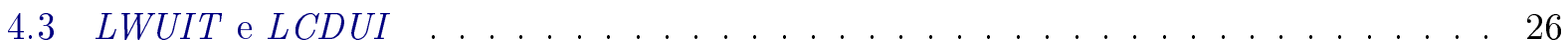

4.3 .1 Diferenças entre $L C D U I$ e o LWUIT . . . . . . . . . . . . . . . 27

4.4 Dispositivos Utilizados . . . . . . . . . . . . . . . . . . . . 30

5 Arquitetura $\quad 31$

5.1 Modelagem Conceitual . . . . . . . . . . . . . . . . . . . . . 31

5.2 Modelo Lógico de Dados . . . . . . . . . . . . . . . . . . . . . . 33

5.3 Arquitetura Geral do Sistema . . . . . . . . . . . . . . . . . . . . . . . . . . . . . . . . . . . . . . . . . .

5.4 Arquitetura dos Pacotes . . . . . . . . . . . . . . . . 36 
5.4.1 Pacote com as Classes de Dados e E/S . . . . . . . . . . . . . . . . 36

5.4 .2 Arquitetura do Pacote de Interface . . . . . . . . . . . . . . . . . 37

5.4 .3 Integração com o Sistema Central . . . . . . . . . . . . . . . . . . . . 39

$\begin{array}{lll}6 & \text { Implementação } & 43\end{array}$

6.1 Metodologia de Desenvolvimento . . . . . . . . . . . . . . . . . 43

6.2 Desenvolvimento da Interface Gráfica do Sistema Móvel . . . . . . . . . . . . . . . 44

6.2 .1 Construindo a nova interface . . . . . . . . . . . . . . . . 44

6.3 Dificuldades de Desenvolvimento . . . . . . . . . . . . . . . . . . . 45

6.4 Como o Borboleta funciona em campo? . . . . . . . . . . . . . . . 47

7 Conclusões e Trabalhos Futuros $\quad 55$

7.1 Contribuições e publicações durante o mestrado . . . . . . . . . . . . . . . 55

7.2 Trabalhos futuros . . . . . . . . . . . . . . . . . . 57

7.2.1 Proposta de um estudo do impacto do Borboleta . . . . . . . . . . . . . 57

7.3 Considerações Finais . . . . . . . . . . . . . . . . . . . . . 60

$\begin{array}{lll}\text { A Formulários APD } & 61\end{array}$

$\begin{array}{ll}\text { B Diagrama de navegação do Borboleta } & 67\end{array}$

$\begin{array}{ll}\text { Bibliografia } & 69\end{array}$ 


\section{Capítulo 1}

\section{Introdução}

O Sistema Único de Saúde brasileiro (SUS) [dS02] é estruturado em níveis e, em um deles, está o Centro de Saúde, que tem exercido com eficácia seu papel como órgão provedor de assistência primária à saúde dentro desse sistema. Concomitantemente, a Tecnologia da Informação vem sendo, cada vez mais, inserida em todas as áreas da Medicina e Saúde, auxiliando em novas descobertas e formas de oferecer uma assistência médica de melhor qualidade. Segundo Miller [MHG04], em uma pesquisa realizada com 1.200 médicos norte-americanos, por volta de $96 \%$ deles utilizam algum meio tecnológico no seu dia-a-dia, desde o acesso à Internet até o uso de PDAs e Sistemas de Prontuário Eletrônico. Sistemas de Prontuário Eletrônico $\left[\mathrm{BEG}^{+}\right.$03] são responsáveis por guardar os registros médicos (prontuários) dos pacientes em meios digitais [DSD97, dFM03]. Tais ferramentas agregam valor ao serviço de saúde e podem reduzir custos, conforme é mostrado pelo estudo de Wang $\left[\mathrm{WMP}^{+} 03\right]$. Segundo esse estudo, o uso de um sistema de prontuário eletrônico em larga escala tem aspectos positivos, dentre eles, a economia de recursos.

O Governo brasileiro, por meio do Ministério da Saúde, tem um programa que provê cuidados médicos, chamado Saúde da Família (PSF)[DdAaB00], e por mais de uma década, desde a sua criação, tem provado sua eficácia em oferecer um melhor serviço de saúde à população, reduzindo a ocorrência de várias doenças e diminuindo a mortalidade infantil. Outros centros de saúde podem ter outros programas de atenção primária, todos usando o PSF como base e expandindo seus conceitos e detalhamento. Um caso assim é o do Centro de Saúde Escola Samuel Pessoa (CSEB) que tem um programa de Assistência Primária Domiciliar (APD) que define protocolos com procedimentos que devem ser feitos e um mínimo de dados a serem coletados num prontuário. Por sua vez, os procedimentos definem o que os profissionais de saúde precisam fazer ao visitar um paciente que tem dificuldade de locomoção, quais são as medidas e como elas devem ser coletadas.

Nesse contexto de saúde pública, criou-se uma aliança entre o Centro de Saúde Escola Samuel Pessoa (CSEB), da Faculdade de Medicina da Universidade de São Paulo, e o Departamento de Ciência da Computação do Instituto de Matemática e Estatística, também da Universidade de São Paulo, para desenvolver um sistema móvel que auxiliasse os profissionais de saúde e atendesse às especificidades desses programas. Foi assim que nasceu o Projeto Borboleta [CKK08], que tinha como objetivo o desenvolvimento de um sistema móvel para auxílio aos profissionais que trabalham no Centro de Saúde e que realizam visitas domiciliares a pacientes que têm dificuldades de locomoção. O projeto iniciou-se com a meta comum do Grupo de Sistemas Distribuídos do IME-USP e do Centro de Saúde Escola Butantã da FM-USP de prover um sistema que aumente a qualidade do serviço prestado pelo Centro de Saúde, oferecendo uma forma mais ágil e simples de acessar, 
visualizar e registrar dados dos pacientes que recebem cuidados pelo Centro. A meta do projeto era desenvolver um sistema de Prontuário Eletrônico integrado, com um módulo para PDA ou telefones celulares inteligentes e módulos para mineração de dados que facilitem a coleta e análise de grandes volumes de informações médicas de um banco de dados centralizado.

O sistema Borboleta pode ser definido como um sistema de Telesaúde [KWD06]. Tal conceito deriva de Telemedicina [WCP06], que significa prover e trocar informações relativas a cuidados médicos à distância. Wootton [WCP06] explica que o prefixo "Tele" vem do grego e significa "à distância". Assim, usando as raízes gregas da palavra, Wootton apresenta a definição de Telemedicina como sendo medicina à distância. Esse conceito engloba atividades como diagnósticos, tratamentos e prevenção de doenças. Telesaúde, porém, não tem uma definição de consenso na comunidade. Entretanto, segundo Kevdar et al. [KWD06], seu significado gira em torno do uso de Telemedicina em lugares não institucionais, como atendimentos domiciliares. Segundo Oliveira et al. [dO07], o termo Telesaúde é o uso de telemática em saúde, que é promover saúde, controlar doenças e instruir o paciente ou a comunidade, em contextos de saúde pública.

\subsection{Atendimento Domiciliar}

O Centro de Saúde é também responsável por prover serviços de saúde preventiva à comunidade. Existem vários serviços prestados pelos centros, um deles, que está ligado ao foco deste trabalho, é o serviço de assistência domiciliar para pessoas com dificuldades de ida até o Centro de Saúde oferecido pelo CSEB, cujo programa é chamado de Atenção Primária Domiciliar (APD). Esse programa é mais complexo do que o PSF pois são prestados mais serviços e a situação clínica do paciente é acompanhada com maior precisão. Nesse programa são coletadas mais informações, fornecendo uma base com nível de detalhamento mais apurado para a tomada de decisões.

\subsubsection{Processo da Atenção Primária Domiciliar}

O processo de atendimento domiciliar inicia-se ainda no Centro de Saúde, onde os profissionais selecionam pacientes que serão atendidos naquele dia. A escolha dos pacientes a serem atendidos é feita por meio de pré-agendamentos, realizados durante a visita anterior da equipe de saúde, ou se o paciente, ou um responsável, entram em contato com o Centro de Saúde. São agendados por volta de três ou quatro atendimentos por período (manhã ou tarde), número que varia conforme a complexidade dos casos. Antes da saída dos profissionais, eles obtêm as pastas contendo os prontuários anteriores que serão atendidos naquele período e, no caminho, é feito um breve estudo da situação do primeiro paciente, a partir dos dados das visitas anteriores. Devido à quantidade de casos e a regularidade dos atendimentos, muitos dos usuários do serviço de saúde já são bem conhecidos da equipe dos profissionais e, por isso, basta apenas uma rápida consulta ao último prontuário. Mesmo assim, o tempo gasto com a busca das pastas e da ficha certa consome um tempo considerável, tempo que poderia ser gasto com outras atividades.

Chegando ao local do atendimento, dois dos profissionais - geralmente a equipe é formada por três pessoas - prestam os serviços ao paciente, enquanto um observa e preenche algumas informações do atendimento que está ocorrendo. Os profissionais, geralmente, revezam-se ao longo do atendimento, dependendo da situação e da especialidade de cada um. Terminado o atendimento, algumas notas adicionais são passadas para o formulário em papel e, então, a equipe deixa o lugar e 
se dirige para o próximo paciente ou para o Centro de Saúde, caso o período de atendimento tenha terminado.

Quando a equipe chega ao Centro de Saúde, os atendimentos coletados são divididos entre os profissionais para que terminem de preencher os formulários, que são arquivados. Porém, devido às atividades da rotina do Centro de Saúde e ao volume de informações que precisam ser coletadas, muitas vezes o preenchimento das fichas demora, o que contribui para dois problemas: perda de informação e dados incorretos. Ambos os motivos podem ocorrer pelo simples fato de as informações dependerem da memória humana para ser preenchidas e, quanto maior for o intervalo de tempo entre a visita e o completo preenchimento da ficha, maior a probabilidade desses problemas acontecerem. Segundo relatos dos profissionais de saúde, esse intervalo entre o atendimento e o preenchimento é, em média, de três dias. Porém, às vezes ocorrem casos em que o tempo chega a uma semana. Além disso, existe o tempo de preenchimento do formulário em papel, que poderia ser utilizado para outros serviços. A Tabela 1.1 mostra o tempo médio gasto com essa atividade segundo as nossas observações em campo..

\begin{tabular}{|c|c|}
\hline Tipo da Visita & Tempo Gasto \\
\hline Paciente Novo & $30-40$ minutos \\
\hline Tratamentos & $15-20$ minutos \\
\hline Assistência Eventual ou Curativo & $10-15$ minutos \\
\hline
\end{tabular}

Tabela 1.1: Tempo gasto no preenchimento dos formulários de papel

Os dados apresentados na Tabela 1.1 foram coletados no segundo semestre de 2007 por dois meses. Os profissionais de saúde marcaram o tempo gasto no preenchimento a ficha de papel segundo o tipo de cada visita. Pode-se notar que um grande tempo era gasto com os preenchimentos dos formulários das visitas. Por exemplo, um simples curativo, levava de dez a quinze minutos para ter os dados devidamente registrados no formulário. Uma meta do Borboleta é justamente diminuir esse tempo, que poderia ser usado em outras atividades. Outra meta é reduzir o intervalo entre a visita e o seu registro. Antes do Borboleta, os profissionais de saúde nos informaram que era normal passar três dias para que uma visita fosse devidamente cadastrada. Com o uso de dispositivos móveis e implementando uma interface gráfica fácil e rápida de preencher é possível fazer o registro durante a própria visita.

A Figura $1.1^{1}$ mostra a primeira página do formulário de um atendimento de enfermagem da APD. Já a Figura $1.2^{1}$ mostra a terceira página do formulário de atendimento para novos pacientes. Observando os campos, sua disposição e configuração na página, vemos que é um formulário extenso para ser preenchido, com muitos campos que precisam ser transcritos à mão. Além disso, existem formulários com várias páginas, como a do novo paciente.

Outros exemplos são mostrados nas Figuras 1.3 e $1.4^{1}$. Nota-se também o excesso de espaço, que dá liberdade para a escrita da informação que o profissional julgar necessária, porém a grande quantidade de dados a serem coletados prejudica a agilidade e a facilidade de se obter um certo tipo de informação.

\footnotetext{
${ }^{1}$ Os formulários em papel apresentados nas Figuras 1.1, 1.2, 1.3 e 1.4 podem ser vistas em tamanho ampliado no apêndice A.
} 

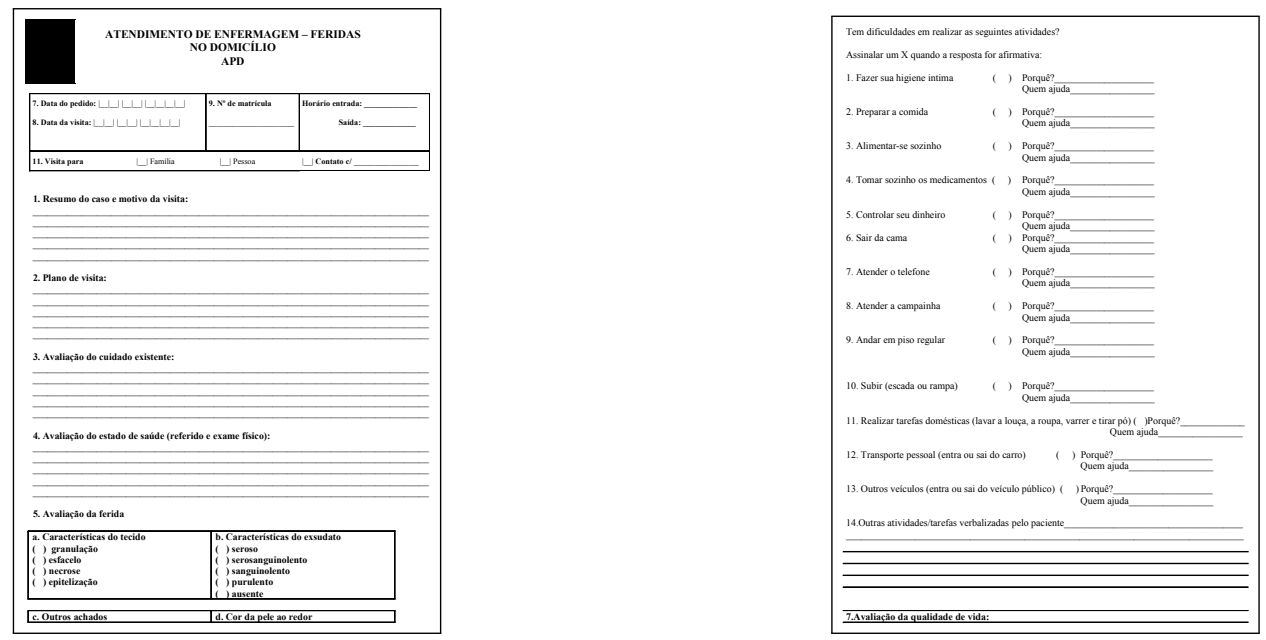

Figura 1.1: Formulário de Atendimento de Enfer-Figura 1.2: Formulário de Atendimento para Novo magem

Paciente

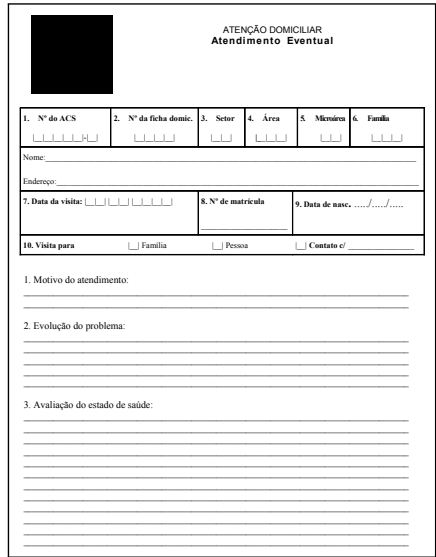

Figura 1.3: Formulário de Atendimento Eventual

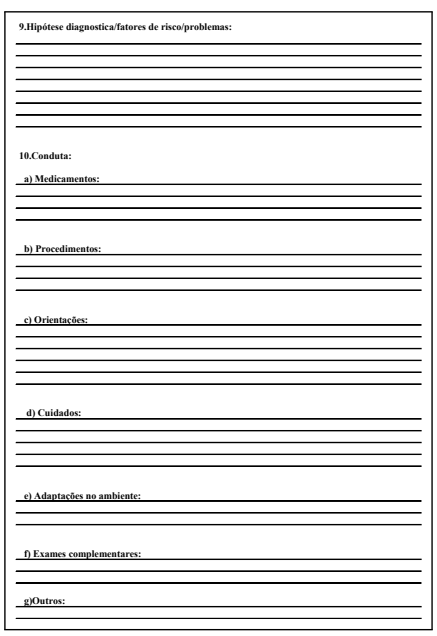

Figura 1.4: Formulário de Atendimento Continuidade do Tratamento

\subsubsection{Proposta de Sistema de Informação}

Com o uso de um formulário eletrônico, pode-se otimizar a interação dos profissionais da equipe de saúde durante a coleta de dados e, assim, ganhar tempo no preenchimento do formulário. Além disso, por ser um sistema digital, arquivar essas informações e realizar consultas em cima dessa base de dados se torna mais simples que no papel. Assim sendo, fazer uma análise gerencial sobre os dados coletados e tomar decisões para otimizar ainda mais o processo de atendimento domiciliar pode vir a ser uma alavanca para que os serviços prestados pela equipe de saúde ocorram com maior qualidade e, talvez, em maior número.

Diante desse cenário, o Projeto Borboleta buscou desenvolver uma solução que, por meio de dispositivos móveis, PDAs e celulares inteligentes, fornecesse uma ferramenta para auxiliar os profissionais de saúde no atendimento domiciliar. O sistema foi projetado para ser usado no Programa de Atenção Primária Domiciliar (APD), programa que atende as localidades próximas ao CSEB, como a Favela São Remo, no bairro do Butantã, região oeste da cidade de São Paulo. Nosso objetivo para o módulo Móvel foi que ele se tornasse um sistema móvel de Prontuário Eletrônico de Paciente, como o exemplo de Bates et al. [BEG $\left.{ }^{+} 03\right]$. 


\subsection{Objetivos}

Esta pesquisa de mestrado teve como objetivo analisar as ferramentas e tecnologias móveis disponíveis que possam ser utilizadas para auxiliar a equipe de Atendimento Primário Domiciliar do Centro de Saúde. Seu objetivo principal foi desenvolver um sistema de código aberto móvel que, de acordo com as especificações da equipe de saúde, suprisse as necessidades de melhoria na qualidade e na eficácia no provimento do atendimento primário domiciliar, e que abrisse espaço para o desenvolvimento de uma ferramenta de Prontuário Eletrônico de Paciente Móvel. Nossa meta foi solucionar três grandes problemas dos formulários em papel.

O primeiro, já citado anteriormente, é a perda de informação devido ao tempo de inicio de preenchimento e até mesmo pela simples não coleta de informação. Um sistema de prontuário eletrônico com o foco em atendimento domiciliar, se bem alinhado com as necessidades do contexto, agiliza a coleta de informação e, também, permitisse uma coleta mais minuciosa.

O segundo, também já descrito anteriormente e relacionado com o primeiro, são os erros gerados pelo mesmo motivo da perda de informação. Estudos anteriores, como o de Stengel et al. [SBW ${ }^{+}$04], concluíram que o uso de dispositivos móveis podem trazer um aumento na qualidade e quantidade dos prontuários.

O terceiro foi dificuldade de gerenciar e minerar dados que estão em papel, pelo simples fato de não ter um sistema informatizado. Com o Borboleta, a gestão do serviço de atendimento domiciliar estará munida de mais informação que auxiliará na melhora da qualidade desse programa.

Para resolvemos tais dificuldades, resolvemos adotar a implementação de um sistema de Prontuário Eletrônico em um dispositivo móvel. Os pontos focais desta pesquisa são a apresentação e discussão referentes a arquitetura e interface com o usuário, nesse caso, os profissionais de saúde. Tais pontos foram fundamentais para que os objetivos fossem alcançados. 


\section{Introdução}




\section{Capítulo 2}

\section{Trabalhos Relacionados}

Computação Móvel é um assunto que tem gerado várias discussões e trabalhos na comunidade, sendo elas relacionadas diretamente a ciência da computação ou outra área, por exemplo a médica. Mesmo assim, um sistema de Prontuário Eletrônico Móvel para o auxílio à Atenção Primária Domiciliar, segundo nossa pesquisa, é algo inovador. Porém, há uma série de trabalhos relacionados à nossa proposta, boa parte deles diz respeito a aplicações móveis aplicadas à saúde. A seguir citaremos e analisaremos alguns trabalhos que tem relacionamento com a ideia do Borboleta. Para facilitar a análise, dividimos os trabalhos em três grupos. Começando pelos sistemas, descritos na Seção 2.1. Depois algumas análises de bibliografia sobre pesquisas na área (Seção 2.2) e por fim padrões e arcabouços na Seção 2.3.

\subsection{Sistemas}

A partir do momento em que a computação móvel ficou mais popular no ambiente de saúde, muitos sistemas foram desenvolvidos, mas um dos pioneiros foi o Projeto Constelação, de Labkoff [LSB ${ }^{+}$95], que foi implantado primeiramente no Hospital da Mulher da Universidade de Harvard, na cidade de Boston, e no Massachusetts General Hospital, também em Boston. Em 1993, esse sistema proveu dados médicos para os profissionais de saúde. O projeto alcançou um considerável sucesso, o que levou à popularização do uso de PDAs nos ambientes médicos. O seu objetivo era trazer informações de referências bibliográficas e textos que auxiliassem os médicos em suas tomadas de decisões.

Carrol et al. [CTHOC07] também analisa como o uso de uma aplicação móvel pode ajudar na redução de discrepâncias encontradas em diagnósticos. Os autores desenvolveram um estudo comparativo entre os formulários em papel e os dados coletados por intermédio de uma aplicação móvel voltada à atenção ao programa neonatal. O intuito era verificar se os dados eletrônicos tinham mais ou menos discrepância com relação aos dados coletados no papel. No geral, verificou-se um decréscimo nesse aspecto (de 61,7\% para 51,2\% de erros na coleta de dados com formulários em papel e o eletrônico).Além desse estudo, Blaser et al. $\left[\mathrm{BSM}^{+} 04, \mathrm{BSB}^{+} 07, \mathrm{LBB}^{+} 07\right]$ mostram que o uso de tecnologias de informação pode reduzir erros nas prescrições. Blaser analisa como, um sistema de TI, poderia ser desenvolvido para minimizar os problemas nas cartas de prescrição médica. Esse sistema foi desenvolvido para o Centro Médico de Marburgo (Alemanha) e vários desafios foram apresentados pela equipe de Blaser. Apesar de não se tratar de uma aplicação móvel, esse sistema apresenta objetivos semelhantes ao Borboleta: minimizar erros de prescrição, agilizar a coleta de 
dados médicos e servir de base para uma melhor gestão do serviço de saúde. Lenz et al. [LBB $\left.{ }^{+} 07\right]$ verificam pontos importantes no projeto a forma de interação com o usuário (interface gráfica) e a arquitetura de sistema heterogênea, fruto de dados heterogêneos vindos de áreas de trabalho heterogêneas. Da mesma forma, esses aspectos o Borboleta [ $\left.\mathrm{DCL}^{+} 10, \mathrm{CdCK}^{+} 09\right]$ também observa como cruciais para a adoção do software e, consequentemente, para melhoria da qualidade do serviço de saúde prestado. Porém, o fator do Borboleta ser um sistema de Prontuário Eletrônico Móvel traz dificuldades adicionais, basicamente o hardware e o visor, que limita a gama de alternativas para o desenvolvimento de uma aplicação mais robusta e acessível.

Fátima dos Santos et al. [dFdSAdS ${ }^{+} 06$ ] mostra uma aplicação de Telesaúde aplicada na cidade de Belo Horizonte, Minas Gerais. BHTelehealth, implantado em 2004, visa a ajudar os grupos de auxílio à família nas atividades medicinais, de enfermagem e odontológica. O projeto interliga centros de saúde na cidade mineira e, segundo é mostrado, tem adquirido uma aceitação muito boa entre os usuários, ponto que é mostrado pelo crescente número de atendimentos que passa pelo sistema. Outro aspecto observado pelo trabalho de Fátima dos Santos é o fato da aceitação. Um sistema sem a aceitação do usuário não vai ajudar para a melhoria do serviço que ele procura auxiliar. Essas questões, aplicadas ao Borboleta, nos deixam mais preocupados com a assimilação do projeto que, apesar de estar sendo implementado segundo as diretivas dos usuários, pode mostrar dificuldades de implantação em seu inicio. Novamente, outra razão para justificar uma preocupação grande com a interface com o usuário do sistema (profissionais de saúde). O projeto BHTelehealth tem similaridades com parte do projeto Borboleta, no entanto, pelo que foi mostrado no trabalho, o projeto BHTelehealth não incorpora a assistência primária domiciliar, que é o foco do projeto Borboleta, além de não fazer menção ao uso de prontuários eletrônicos. Assim, não sabemos qual o foco dos dados do BHTelehealth e se chegam a ter a mesma precisão que buscamos alcançar com o nosso projeto.

Huang descreve, em seu trabalho, um protótipo de sistema móvel para o uso em áreas médicas usando os recursos multimídia dos dispositivos [Hua09]. Sua tese mostra um ambiente de desenvolvimento similar ao do Borboleta utilizando JavaME e a biblioteca LWUIT [SUN08] como base para o desenvolvimento na plataforma móvel. No trabalho de Huang, pode-se notar um foco muito grande em duas áreas do trabalho: a arquitetura de rede onde a aplicação móvel se encontra (apresentado como MJCF - Mobile Java Communication Framework - desenvolvido pela Ericsson) e a camada multimídia. A aplicação móvel funciona em sincronia com uma aplicação web, porém com recursos limitados. Nela os profissionais de saúde tem acesso à lista de tarefas a serem realizadas e registrar um parecer sobre a situação do paciente que foi agendado para aquela tarefa. Note que o conceito de Encontro aqui é simplesmente uma tarefa do profissional de saúde. Outra diferença, analisando os esquemas de arquitetura apresentados no trabalho, é que a aplicação móvel requer o uso constante de uma rede para acessar os dados necessários. O conceito do Borboleta de funcionar independente da rede é um diferencial entre os sistemas e um requisito forte para o nosso trabalho, já que nas favelas onde são feitos os encontros domiciliares não existe rede sem fio disponível. A Figura 2.1 mostra a arquitetura do sistema de Telemedicina que Huang apresenta. Podemos ver a semelhança com o Borboleta (apresentada na Figura 5.3 na Seção 5.3), com algumas poucas alterações, como a comunicação direta do sistema móvel com o servidor (que no caso do Borboleta é escrito em Ruby on Rails). 


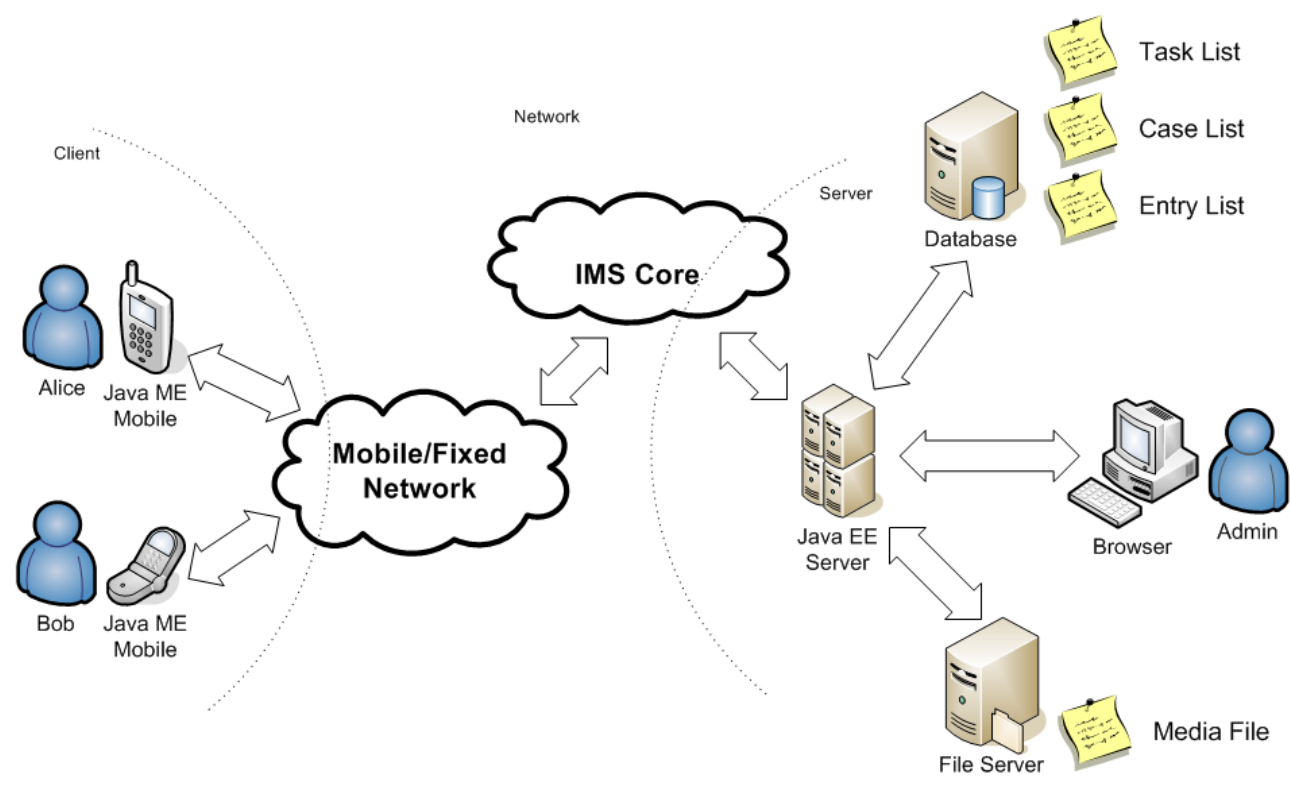

Figura 2.1: Arquitetura do Sistema de Telemedicina de Huang [Hua09]

\subsection{Análises}

Para demonstrar a importância do uso de tecnologia móvel na área da saúde, Koch et al. [Koc06] fizeram uma revisão sistemática da literatura sobre Telesaúde domiciliar até 2006 e relatam que a maioria das publicações $(72 \%)$ é sobre monitoramento remoto de doenças específicas, como o trabalho de Gonçalves et al. [GFAG08], 10,9\% é sobre telemedicina e 4,5\% sobre sistemas de informação e homecare. Isso mostra que existe uma preocupação com sistemas como o Borboleta, que se encaixa na divisão de sistemas de informação e homecare, mas que ainda existe muito espaço a ser explorado. Ainda mais pelo fato do Borboleta ser aplicado ao ambiente de Telesaúde e medicina preventiva no contexto de programas de saúde pública.

Baumgart [Bau05] expõe como as aplicações para PDA podem ser usadas com eficácia no ambiente médico para ajudar nos diagnósticos e nas prescrições. Ele também aponta o uso de dispositivos móveis no ambiente de ensino de medicina. Nesse contexto PDAs se tornaram uma boa opção para ajudar os alunos a obterem informações com maior facilidade. No uso em clínicas e hospitais Baumgart et al. analisa algumas aplicações do uso de dispositivos móveis, entre elas, referência a medicamentos, agendamento de paciente, acompanhamento e suporte a decisões. O estudo não inclui sistemas com o mesmo foco que o Borboleta: um sistema móvel de Prontuário Eletrônico. No entanto, acreditamos que um sistema como o Borboleta, ainda mais se integrado a um sistema central de prontuário eletrônico como o SAGUISaúde [ $\left.\mathrm{DCL}^{+} 10\right]$ pode trazer benefícios muito significativos para enfermeiros, médicos, gestores do Centro de Saúde e, principalmente, pacientes.

Zeni et al. [ZBdPPM04] analisam várias aplicações e utilizações de dispositivos móveis e redes sem fio em ambientes hospitalares. Apesar de ser voltado para outro ambiente, esse trabalho mostra o crescimento do uso de PDAs e redes sem fio na área de Saúde. De forma similar, Ammenwerth et al. [ABBH00] fazem um estudo sobre o uso de dispositivos móveis e sua comunicação. Enquanto Oliveira et al. [dO07] mostra aplicações e conceitos do uso de Telemedicina e algumas questões como sigilo das informações do paciente e tópicos relacionados à ética, principalmente no uso de dados multimídia nos prontuários. Tais pontos são importantes para o nosso trabalho visto que também 
passaremos por problemas semelhantes e estar alinhado com essas pesquisas nos ajudam a tomar decisões e adotar formas de trabalho que desviam ou minimizam esses problemas.

Prgomet et al. [PGW09] analisa a literatura procurando o impacto do uso de dispositivos móveis em hospitais. Esse estudo analisa a bibliografia procurando por sistemas móveis que auxiliam profissionais de saúde em ambientes hospitalares, especificamente. Prgomet divide seu estudo em três tipos de aplicações dos aparelhos: facilitar a resposta dos médicos, prevenção de erros em diagnósticos e ajudar no acesso a dados e na sua manutenção. Sua conclusão é que os sistemas desenvolvidos para plataforma móvel traz grandes benefícios para quem está utilizando.

Outra análise interessante é sobre o uso de Prontuário Eletrônico. DesRoches et al. [DCR ${ }^{+} 08$ ] ponderam sobre o uso de Prontuário Eletrônico nos Estados Unidos e os resultados apontam que, dos médicos que usam esses sistemas, 93\% ficaram satisfeitos com a adoção e com a melhora de qualidade dos serviços de saúde. Assim intuimos que um sistema de prontuário eletrônico aplicado e otimizado ao atendimento domiciliar pode trazer ganhos significativos para a qualidade e eficiência do serviço.

Shivute et al. [SMO08] escreve sobre várias iniciativas e implementações do uso de Tecnologia de Comunicação e Informação em vários países da Africa, inclusive com o uso de PDAs para fazer coleta de informações de pacientes que estão fora do alcance de um hospital ou centro médico. Esse sistema foi implantado em Uganda e, segundo Shivute, aprimora o nível gerenciamento dos serviços de saúde e usa eficiência.

\subsection{Padrões e Arcabouços}

Sá et al. [dSCA07] fizeram uso da computação em seu sistema de acompanhamento psicoterápico de tratamentos específicos. Desenvolveu-se um arcabouço para ambientes móveis, como PDAs e TabletPCs, cobrindo tarefas terapêuticas, tanto para o terapeuta quanto para o paciente. A ideia de ter um dispositivo móvel para o acompanhamento do progresso do quadro de um paciente é similar à do Borboleta. No entanto, o Borboleta não se aplica somente ao ambiente psicoterápico mas, sim, a um contexto mais amplo de atendimento primário de saúde.

O Borboleta utilizou como base dois arcabouços de software criados especificamente para a manipulação de informações de saúde: o OpenEHR e o HealthLevel 7. Ambos contribuiram com ideias de modelagens para certas situações. A seguir descreveremos com maiores detalhes esses dois padrões e como eles influenciaram o projeto.

\subsubsection{OpenEHR}

O OpenEHR [BH07b, BH07a], desenvolvido pela fundação OpenEHR mantida pela University College London e Ocean Informatics, provê especificações, padrões e implementações abertas para sistemas de saúde. É baseado no conceito de arquétipos, isto é, apresenta soluções testadas para problemas conhecidos. Com a proposta da criação de arquétipos, é dado ao sistema uma flexibilidade para evoluir e crescer baseado num modelo de referência.

Mezaroba e Nicoleit [MN10] descrevem algumas características do OpenEHR, que os levaram a adotá-lo em seu projeto, como justamente a divisão do padrão OpenEHR em dois níveis de arquitetura, o primeiro é o modelo de referência e o segundo o modelo de arquétipos. O primeiro 
modelo é composto por estruturas genéricas que podem ser representadas por arquétipos, que são utilizados no nível posterior.

Com a utilização de arquétipos, é possível desenvolver novos conceitos e evoluir conceitos já existentes com maior facilidade, já que os arquétipos possibilitam a extensão de seus conceitos. Segundo Mezaroba, essa abordagem oferece uma maior manutenibilidade ao sistema.

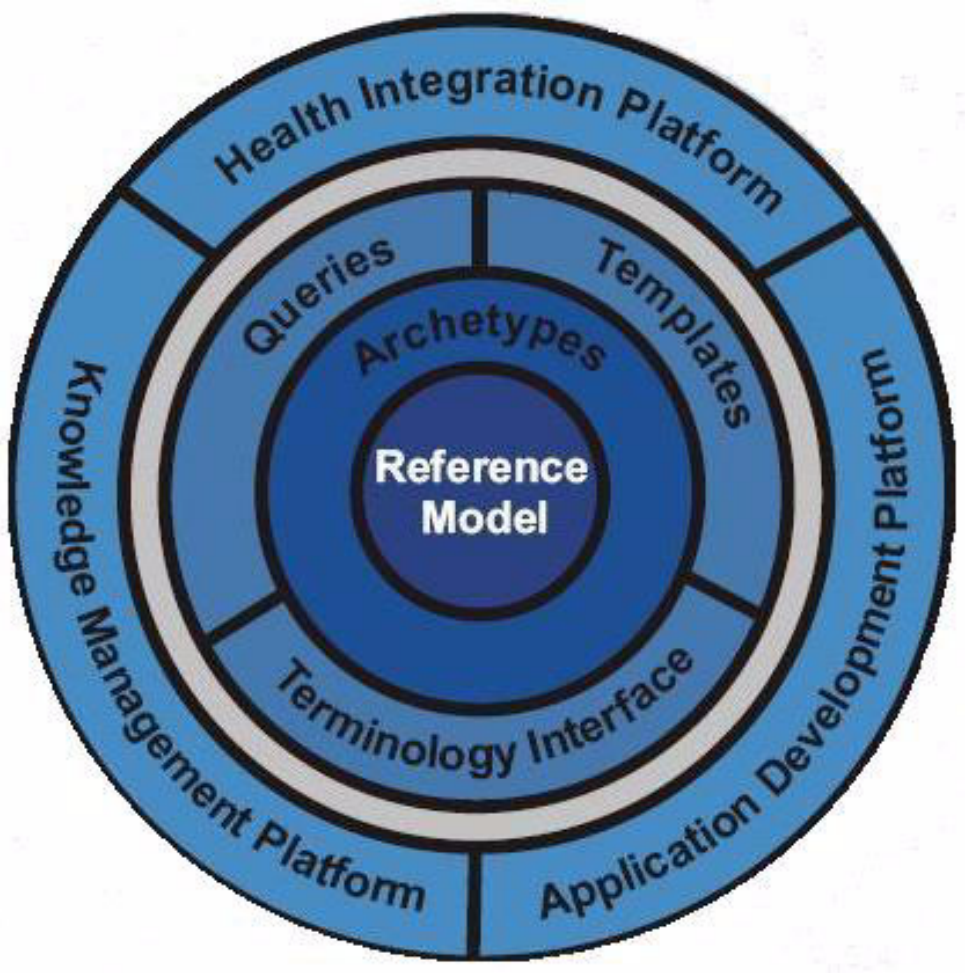

Figura 2.2: Projeto de Especificação do OpenEHR

A Figura 2.2 mostra como é feita a especificação dentro do OpenEHR ${ }^{1}$. O Diagrama mostra as interações entre as partes do projeto. Podemos notar o centro como sendo o modelo de referência e logo acima os arquétipos. A partir desse ponto, as aplicações podem usar a coleção de arquétipos oferecidas pelo padrão e extendê-los ou simplesmente utilizá-los em um template (que seria o prontuário propriamente dito). A OpenEHR Fundation tem um repositório de arquétipos disponível para consulta e programas para a consulta e edição desses arquétipos. A Figura 2.3 mostra uma ferramenta implementada em JavaSE ${ }^{2}$ que edita os arquétipos fornecidos pela OpenEHR.

No caso da Figura 2.3, o arquétipo que está sendo editado é chamado de Evento. Ele representa um evento médico ocorrido em uma data. Esse conceito é similar ao do Encontro definido pelo Borboleta (Seção 5.2). O conceito de Encontro nos arquétipos do openEHR é um conjunto de eventos. Diferenças como essas se dão pela necessidade de adaptação dos conceitos à realidade do projeto. O Borboleta não utiliza arquétipos como base da modelagem do sistema, pois era um conceito novo e não tinhamos certeza da aplicabilidade dele no contexto de computação móvel. Porém pode se ver semelhanças entre as modelagens.

\footnotetext{
${ }^{1} \mathrm{O}$ diagrama foi retirado do livro openEHR Architecture: Architecture Overview[BH0b]

${ }^{2}$ Essa ferramenta é desenvolvida pela Universidade de Linköpings http://www.imt.liu.se/mi/ehr/
} 


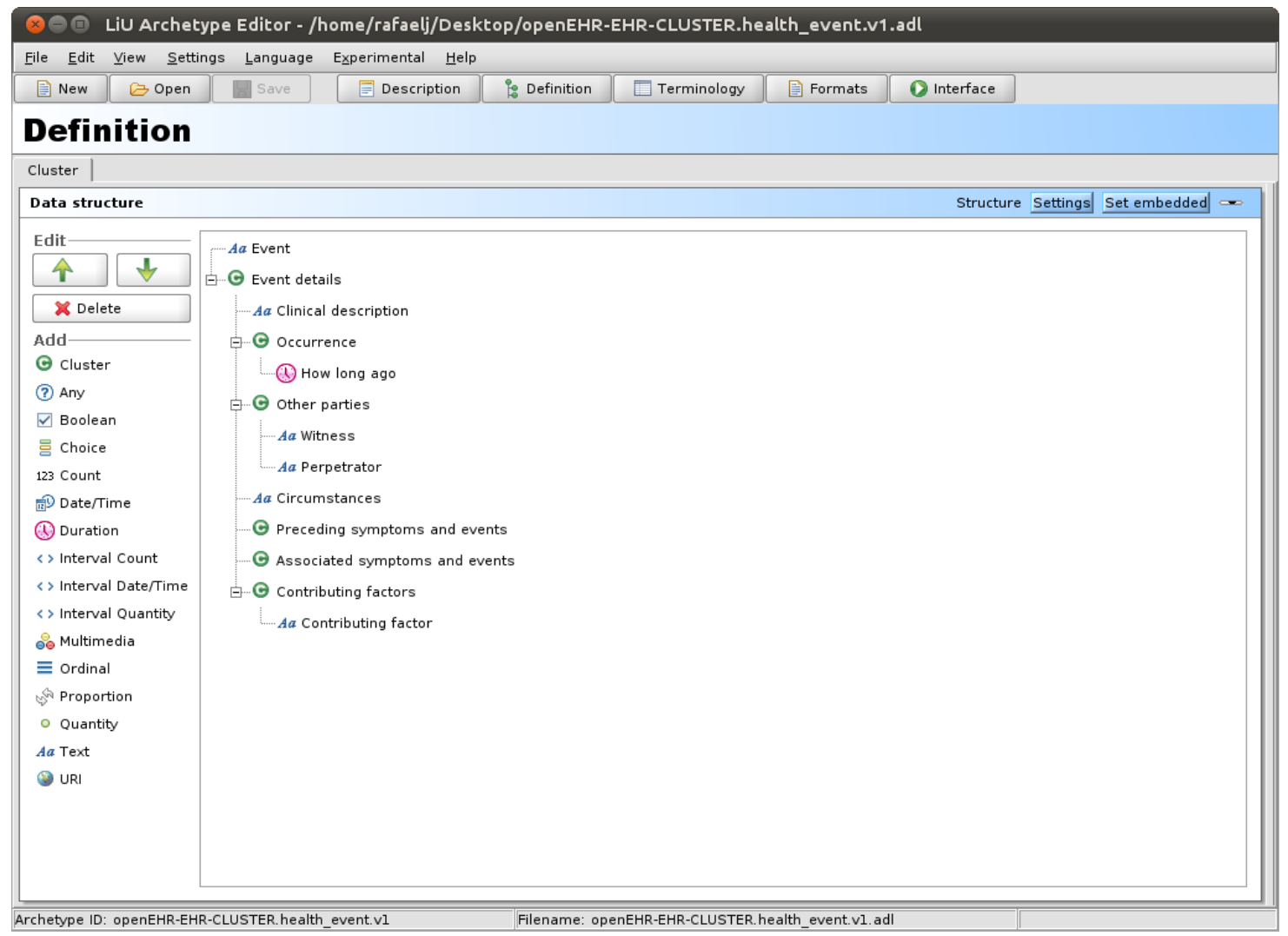

Figura 2.3: Interface de Edição de Arquétipos

\subsubsection{Padrão HL7}

O Health Level Seven (HL7) [Bee98] é um padrão que nos ajudou muito na concepção do modelo do Borboleta. Voltado para a sincronização de dados médicos entre sistemas de Prontuário Eletrônico, ele tem um escopo mais centralizado no paciente e possui uma parte financeira muito forte. Segundo Beeler [Bee98], a HL7 Fundation tem como objetivo criar um arcabouço e um padrão para troca de informações de saúde e dados clínicos. A última versão é a RIM 2.34 de Novembro de 2010 e é disponibilizada em vários formatos. Desde 1998, o padrão HL7 vem definindo seus conceitos por meio de uma metodologia baseada no seu modelo, o HL7 Versão 3 MDF (Message Develpment Framework).

A Figura 2.4 mostra as entidades do padrão HL7; podemos ver que o conceito gira em torno tudo que é algo palpável. O Borboleta não pegou todo esse conceito abrangente. Preferimos nos concentrar na parte de paciente e pessoa; assim, não carregamos todos os dados que não fazem sentido para o escopo para o qual desenvolvemos. No caso do banco de dados presente no dispositivo móvel, observamos que temos apenas três classes (vide Seção 5.2), Paciente, SocioEconomico e Cuidador que podem ser mapeadas na estrutura de Entidades do HL7 apresentada na Figura 2.4, porém com menos informação e de forma mais concisa.

O diagrama de classes da Figura 2.5 mostra como são representados as Açôes. Segundo o HL7, ações são, por exemplo, exames, diagnósticos, procedimentos e assim por diante. Podemos ver que eles não tratam eventos (que no Borboleta chamamos de Encontro) como a classe central do modelo e sim as ações. Os eventos são montados como uma composição, ActRelationship, e não têm um relacionamento direto com o paciente e nem com os participantes. Mais uma vez, a forma de tratarmos os dados é mais simples e seguiu a orientação dos especialistas de saúde. A simplicidade 


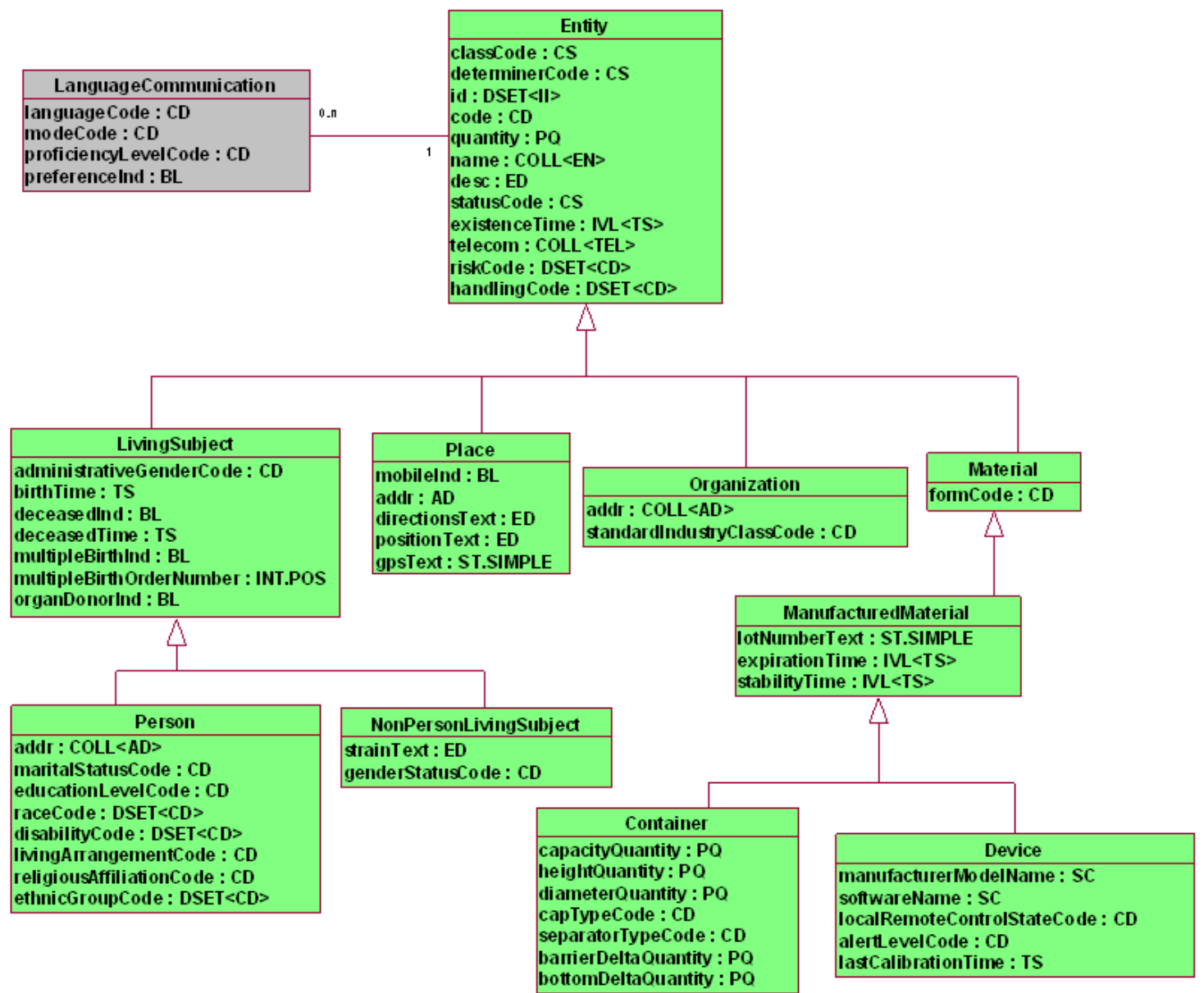

Figura 2.4: Diagrama de Entidades do HL7

do nosso modelo se dá pelo fato de restringirmos o escopo ao uso em Centros de Saúde e, no caso do dispositivo móvel, fechamos o escopo ainda mais para o nível de encontros domiciliares. 


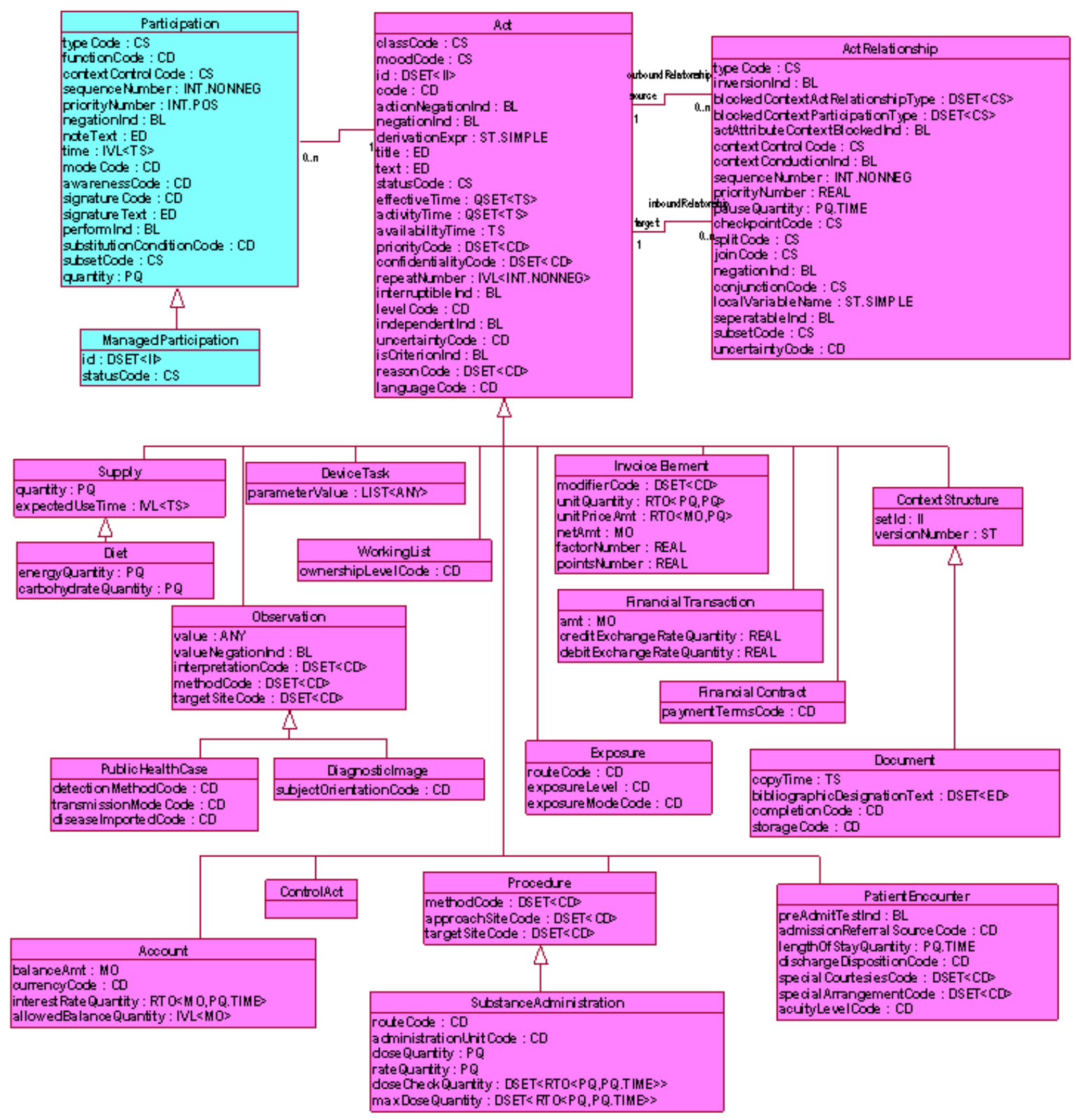

Figura 2.5: Diagrama de Ações do HL7 


\section{Capítulo 3}

\section{O Projeto Borboleta}

Como apontado na Seção 1.2, esta pesquisa visa a analisar ferramentas e arcabouços que possam trazer ganhos para o desenvolvimento de um sistema que auxilie no serviço de atendimento primário domiciliar prestado pelo centro de saúde. Por essa razão, é interessante dar mais informações sobre o Projeto Borboleta como um todo. Primeiramente um breve histórico do projeto (Seção 3.1), depois um detalhamento maior sobre o atendimento domiciliar (Seção 3.2), em seguida - Seção 3.3 - quais são as entidades envolvidas e, finalmente, outras pesquisas realizadas sobre o projeto Borboleta (Seção 3.4).

\section{$3.1 \quad$ Histórico}

A história do projeto Borboleta se inicia em 2002 quando o Centro de Saúde Escola do Butantã (CSEB) e o Instituto de Matemática começam o desenvolvimento de ferramentas móveis para o uso no programa de APD. Em 2005, num primeiro contato com três institutos, IME-USP, CSEB e o grupo de Telesaúde do Hospital Universitário (HU) da Faculdade de Medicina da USP, definiu-se algumas diretivas e funcionalidades que seriam necessárias para a ferramenta. Em nível abstrato definiu-se que:

1. Base de dados móvel integrada com a base central dos pacientes - A equipe de atendimento deve ter acesso aos dados relevantes referentes ao paciente que está sendo atendido e depois os novos dados coletados deverão ser sincronizados com o banco de dados central.

2. Acesso a material de referência - $\mathrm{O}$ acesso à base de referência aumenta a qualidade do serviço prestado, portanto definiu-se a necessidade de programas de referência, Tabela CID [Org04], bulário de medicamentos, manuais de padronização de conduta, valores de referência de exames e outros documentos e páginas na WEB.

3. Acesso interconsulta com especialista - Esse recurso visa o aumento da resolutividade do atendimento domiciliar conectando a equipe com especialistas, por exemplo, Fisioterapeutas, Fonoaudiólogos. Esse contato ajuda a esclarecer dúvidas, elucidar diagnósticos e compartilhar decisões relativas ao caso do paciente.

4. Sistema de apoio à decisão e lembretes para a equipe de saúde - Nos sistemas informatizados na área de saúde vem crescendo o uso de sistemas de apoio à decisão que, 
a partir de confrontar as informações passadas a ele, como sexo, idade, origem do paciente, fatores de riscos, doenças anteriores, sinais e sintomas atuais, oferecem sugestões de hipóteses diagnósticas, exames complementares indicados, entre outras coisas. Uma ferramenta com essa característica pode trazer para um programa de assistência domiciliar um grande auxílio, melhorando a qualidade e a efetividade do serviço.

5. Envio de mensagens e lembretes para os pacientes - Uma ferramenta com esse recurso traria uma grande ajuda para o paciente, auxiliando-o a lembrar do horário de medicamentos, consultas no centro de saúde ou hospital.

6. Mapeamento de rotas e domicílios - Este módulo seria usado para mapear os domicílios que são atendidos pela APD e auxiliar no trajeto a cada uma das casas dos pacientes.

7. Acesso dos pacientes às informações - Esta funcionalidade visa prover o acesso a informação dos pacientes atendidos pela APD, para os próprios pacientes.

Essas definições macros servem de base para o desenvolvimento conceitual do projeto. Algumas delas já estão no escopo atual do projeto, outras estão reservadas para trabalhos futuros. Em 2005 e 2006, o Borboleta foi desenvolvido por alunos de graduação durante as disciplinas de Laboratório de Programação Extrema, oferecidas pelo IME. Alguns alunos fizeram do Borboleta seu tema de trabalho de conclusão de curso de graduação. Nesse período, o sistema atingiu um certo nível de maturidade e é considerado como os primórdios do Borboleta, pois, até então os profissionais de saúde não tinham tido um contato mais direto com o sistema e o feedback da equipe de desenvolvimento não tinha como meta apresentar uma versão estável para o cliente final, os profissionais de saúde. A primeira versão disponibilizada para teste dos profissionais do centro de saúde foi liberada em março de 2007 e também foi desenvolvida durante a disciplina de Laboratório de Programação Extrema. Usamos esse marco para definir o que chamamos de primórdios do sistema pois, até então, o desenvolvimento feito não tinha sido validado nem discutido com os usuários do sistema.

\subsubsection{Funcionalidades do Módulo Móvel até 2007}

Até 2007, o Borboleta consistia, praticamente, do módulo Móvel, Desktop e Web. Os dois últimos módulos eram uma ponte entre o sistema instalado no dispositivo móvel e a base de dados, e não tinham muita relevância. Assim o foco sempre foi o módulo Móvel. Com a primeira meta, em 2007, de ser colocado em fase de teste no cliente, iniciou-se ciclos de implementação e feedbacks por parte do mesmo. A versão de 2007 tinha seguintes as funcionalidades, que serão descritas na Seção 5.1.

\section{Dados do Paciente}

\section{Dados Sócio-Econômicos}

3. Agenda de Visita

\section{Registro de nova visitas}

5. Acesso ao Histórico das Visitas

6. Catálogo de Doenças 


\section{Catálogo de Medicamentos}

Mesmo tendo essas várias funcionalidades, na época, algumas delas estavam muito aquém do que os profissionais de saúde precisavam para usar o borboleta móvel em campo. Essas deficiências foram sendo mapeadas ao longo das versões do Borboleta ao longo de 2007 e incorporadas ao sistema. Muitas delas eram relacionadas a forma com que os dados eram apresentados e coletados. Campos que eram de texto livre foram substituídos por campos onde se pode escolher uma opção dentro uma lista de valores pré-estabelecidos. Outros eram dados que eram complexos demais para serem colocados no momento, por exemplo a associação entre Medicamentos e Visitas, então foram deixados lado para dados que eram mais simples.

\subsubsection{Mudança de escopo de 2008}

Quando as alterações foram implementadas ao Borboleta o projeto estava mais maduro e a equipe dos profissionais de saúde viram que o projeto poderia ir além do que um simples sistema de coleta de dados e ir em direção a um alvo maior, ser um sistema Móvel de Prontuário Eletrônico. Então a equipe de desenvolvimento, juntamente com a equipe de Saúde remodelaram todo o conceito do projeto e de apenas um simples sistema móvel nasceu a necessidade de dois sistemas. O primeiro que seria o sistema de prontuário eletrônico que funcionaria em dispositivos móveis. O segundo que seria um sistema central de registro dos prontuários dos pacientes. Portanto, como houve alteração no conceito do projeto uma alteração conceitual no sistema foi realizada [ $\mathrm{DCK}^{+} 08$ ].

Essa mudança de escopo e, consequentemente, de modelagem norteou todo o desenvolvimento do Borboleta durante o ano de 2009. Concomitantemente, o sistema central do centro de saúde foi desenvolvido, e chamado de SAGUISaúde. Assim, uma forma mais robusta e agradável de acessar os dados exportados pelo Borboleta foi criado. Obviamente o SAGUISaúde não é um mero suporte ao Borboleta, mas todas as suas funcionalidades e seu escopo não fazem parte da discussão deste trabalho.

\subsubsection{Nova Interface}

Ao terminar as implementações do Borboleta em 2009, a equipe de saúde realizou testes de usabilidade no sistema móvel e o feedback que foi dado à equipe de desenvolvimento apontou vários problemas. Conceitualmente, o sistema estava robusto com todos os aspectos apresentados pelos profissionais de saúde, porém a usabilidade estava bem comprometida. O Borboleta foi desenvolvido em J2ME [SUN09] e até o final de 2009 ele usava a biblioteca padrão para criação de interfaces gráficas no J2ME, conhecida como LCDUI. Os principais problemas apontados relativos à interface estão citados na lista a seguir:

- Muita troca de tela - Quase toda a troca de formulário se faz utilizando um menu inferior, fora o fato de que quase todas as ações também se dão utilizando o mesmo menu, o que deixa muito ruim a interação com o usuário, no caso de formulários mais dinâmicos e/ou muito grandes.

- Falta de padronização entre as telas - Pelo fato do LCDUI ser dependente do dispositivo e da máquina virtual, cada uma interpreta e monta os formulários de forma diferente. Isso atrapalha demais a adaptação do grupo de profissionais de saúde. 
- Falta de componentes - A LCDUI é muito limitada por ter o objetivo de funcionar até em celulares mais rústicos e com poucos recursos, então ela provê muito poucos componentes e possui restrições bem fortes em relação a como montar os formulários.

Então, começamos a buscar alternativas para melhorar a interface humano-computador (IHM) do sistema móvel. A equipe decidiu por adotar a biblioteca gráfica LWUIT [SUN08]. Primeiramente, por usar a linguagem Java, que já era utilizada pelo sistema anteriormente. Segundo, pois resolve os principais problemas de interface encontrados. Essa alteração de biblioteca de interface foi implementada durante os últimos meses de 2009 e início de 2010. Atualmente, o Borboleta está em fase de teste e aprimoramento de seus recursos. É importante relembrar que este texto tratará principalmente de dois avanços conquistados pelo Borboleta: as alterações arquiteturais nos módulos correspondentes à modelagem de dados e a IHM.

\subsection{Atenção Primária Domiciliar}

Como o sistema do Borboleta é voltado para o Programa de Atenção Primária Domiciliar, oferecido pelo Centro de Saúde Escola (CSEB), é importante descrever um pouco sobre o programa, seus objetivos, público alvo, procedimentos e as informações que precisam ser coletadas, que é onde entra o Borboleta.

Primeiramente, vamos trazer uma definição simplificada do que é o serviço de Atenção Primária Domiciliar (APD). Duarte e Diogo [dODD00] caracterizaram as denominações de atendimento domiciliar: Visita domiciliar, Assistência domiciliar e Internamento domiciliar, transcritos resumidamente a seguir.

- Visita domiciliar - Atendimento domiciliar realizado pelo profissional de saúde e/ou equipe com objetivo de avaliar demandas do paciente e familiares, bem como do ambiente em que vivem e estabelecer plano assistencial voltado à recuperação e/ou reabilitação do paciente, visando a sua autonomia e a maximização de sua independência. As visitas são pontuais ou realizadas sistematicamente, sendo programadas conforme necessidade do paciente e disponibilidade do programa em que está ligada. A equipe interprofissional fornece orientações relativas aos cuidados necessários, que serão realizados pelo denominado cuidador (pessoa responsável pelo cuidado no contexto domiciliar).

- Assistência domiciliar - Compreende atividades assistenciais exercidas por profissional de saúde e/ou equipe interprofissional no local de residência do paciente. Engloba visitas programadas em que determinados procedimentos técnicos são realizados pelos elementos da equipe. A periodicidade das visitas depende da complexidade assistencial requerida. Conta-se também com o cuidador como responsável pela continuidade da assistência em domicílio.

- Internamento domiciliar - Atendimento domiciliar que exige algum grau de incorporação tecnológica e disponibilidade de assistência médica e de enfermagem 24 horas por dia, com monitorização constante da evolução clínica do paciente e das reações familiares, propiciando intervenção precoce em eventuais intercorrências.

O Programa de APD compreende as atividades Visita domiciliar e Assistência domiciliar. O 
objetivo do programa é oferecer, no domicílio ações, primárias de promoção, prevenção e reabilitação para aqueles indivíduos impedidos de acessar o serviço de saúde no centro de saúde.

Os pacientes que são inclusos no programa são pessoas que tem impedimento físico ou mental para acessar o serviço e que necessitam de cuidados primários de saúde. Para auxiliar no processo de inclusão dos pacientes no programa, bem como no planejamento do cuidado, é adotado os conceitos contidos na Classificação Internacional de Funcionalidade, Incapacidade e Saúde [Org01] (CIF) proposto pela Organização Mundial de Saúde (OMS) em 1989 e utilizado por Scholz [Sch99], a qual estabelece a seguinte taxonomia e nomenclatura.

- Deficiência (impairment) - representa qualquer perda ou alteração de estrutura, função psicológica, fisiológica ou anatômica. Caracterizando-se por perdas ou alterações, temporárias ou permanentes, incluindo existência ou ocorrência de anomalia, defeito ou perda de membro, órgão, tecido ou outra estrutura corporal, considerando também função mental.

- Incapacidade (disability) - é qualquer restrição ou perda da capacidade, decorrente de qualquer deficiência, de realizar atividade, dentro dos limites considerados normais para uma pessoa numa dada condição. A incapacidade caracteriza-se por excessos ou insuficiências no comportamento ou desempenho de atividade considerada normal. Estas perturbações podem ser temporárias, irreversíveis e progressivas ou regressivas. A incapacidade pode surgir em conseqüência direta da deficiência ou como resposta do indivíduo - sobretudo psicológica - a deficiências físicas, sensitivas e outras.

- Desvantagem (handicap) - refere-se ao prejuízo social sofrido pelo indivíduo, resultando de deficiência ou incapacidade que limita ou impede desenvolver atividades no meio social, considerando necessidades pessoais, sociais ou profissionais, julgadas como normais em relação à sua idade, sexo, fatores sociais e culturais.

O trabalho no Programa de Atenção Primária Domiciliar tem como orientação a integralidade das ações. A prática tem sido direcionada mais às deficiências e incapacidades, e menos às desvantagens; entretanto, estas últimas se sobrepõem de uma maneira bastante peculiar no atendimento domiciliar, pelo contato direto com a realidade, nos remetendo à necessidade de buscar ampliação do referencial teórico-prático, para dar conta de parte desta complexidade.

Como um paciente é incluso no programa? Primeiramente é realizado um pedido, que pode ser feito de duas forma: interamente (pelos profissionais do Centro de Saúde) ou externamente (por algum agente comunitário ou pessoa que entre em contato com o CSEB). O pedido é analisado pelos especialistas e assim se determina se o caso compete, ou não, para a entrada na APD.

\subsubsection{Roteiro do Encontro Domiciliar}

Na Seção 1.1.1, foi colocado brevemente como funciona o processo do enconto. Nesta seção, descreveremos em mais detalhes o processo da visita em si. O nível de detalhamento, porém, não entrará em assuntos que não tem relação ao tema do trabalho.

Quando um paciente está cadastrado no Programa da APD, ele já está apto a receber visitas. As visitas são agendadas previamente pela equipe do centro de saúde. No caso do CSEB, existem dois períodos (de mais ou menos 4 horas) na semana onde são programados os encontros. Os encontros são agendados com os pacientes, ou responsáveis, e a partir daí é feito um roteiro. Dependendo 
da complexidade dos casos, são colocados dois, três ou quatro visitas no mesmo período, e assim é montado um roteiro.

A cada encontro, os profissionais da equipe de saúde realizam procedimentos e coletam informações dos pacientes e tomam atitudes, como encaminhar o paciente para um exame laboratorial ou prescrever um medicamento. No final da visita, é dado uma data imprecisa de retorno da equipe de saúde ao domicílio do paciente, por exemplo 2 semanas. Isso mostra o compromisso de retorno e quando, aproximadamente, a equipe voltará à residência. Em média, as visitas duram cerca de 45 minutos, podendo variar de caso a caso. Após o encontro, os integrantes discutem o caso e tomam nota de mais algumas informações sobre o caso. Os dados coletados vão para o prontuário dos pacientes visitados.

\subsection{Entidades e Profissionais envolvidos}

O Projeto Borboleta é uma iniciativa de basicamente dois grupos, o primeiro é o Centro de Saúde Escola Samuel Pessoa (CSEB) da Faculdade de Medicina e do Grupo de Sistemas Distribuídos do Instituto de Matemática e Estatística, ambos da Universidade de São Paulo. Do grupo de profissionais de saúde que contribuiram para esta pesquisa vamos nomear algumas pessoas que contribuiram para o desenvolvimento. O Dr. José Ricardo de Mello Brandão foi o responsável da equipe médica designado para realizar a interação entre a equipe de desenvolvimento e os profissionais de saúde. Ele é o principal especialista do projeto na área de atendimento domiciliar e conhece todo o processo das visitas. Outra pessoa crucial para o bom andamento do projeto foi o médico sanitarista Rubens Kon, que durante o desenvolvimento dos estudos desta pesquisa, era o Diretor do Centro de Saúde e ajudou bastante na idealização do projeto, no incentivo para que as pesquisas de campo fossem realizadas e nas definições de metas. Outra área envolvida no projeto foi a área de TI do Centro de Saúde, cuja pessoa responsável era Norma Colucci, auxiliada pelo Thiago Augusto Duarte de Freitas, que ajudaram a passar os dados dos sistemas legados para a base de dados do SAGUISaúde.

Além do CSEB e do IME outros grupos contribuiram grandemente para que o Borboleta se torne, cada vez mais, um sistema de software robusto. Um exemplo é o grupo de desenvolvimento de software da Universidade Federal de São Paulo - campus São José dos Campos - que tem como foco a inserção de outras mídias no Borboleta, como fotos e vídeos. Outro exemplo é a Escola de Artes, Ciências e Humanidades (EACH/USP) que, juntamente ao centro de saúde, querem estudar o impacto do uso da tecnologia móvel nesse âmbito do atendimento primário domiciliar.

\subsection{Outras Pesquisas do Projeto Borboleta}

Um tema como Sistema Móvel para Atendimento Primário Domiciliar não tem apenas uma linha de pesquisa, que no caso deste texto é sobre a arquitetura e desenvolvimento do sistema móvel em si, mas tem várias frentes de pesquisa e estudos que, obviamente, transcendem a área de computação e sistemas. A seguir listaremos alguns temas que o grupo do Borboleta desenvolve a partir de informações colocadas pelos membros das respectivas linhas de pesquisa no portal do projeto (hhtp://ccsl.ime.usp.br/borboleta).

- Prontuário eletrônico móvel para atenção primária de saúde - O principal objetivo tec- 
nológico do projeto é o desenvolvimento de um sistema eficiente e robusto para o armazenamento de informações de saúde multimídia (dados numéricos, textuais, fotos, áudio e vídeo) em um sistema móvel executado em telefones celulares a ser aplicado em programas de saúde pública. O objetivo é aumentar a qualidade do serviço público de saúde oferecido no âmbito do SUS através da agilização e da otimização do acesso a informações de saúde dos pacientes atendidos por programas de atendimento domiciliar como o Programa Saúde da Família e outros.

- Modelagem conceitual do atendimento primário de saúde no âmbito do SUS - Desenvolvimento e validação do modelo conceitual de um sistema de informação para a atenção primária à saúde. Este modelo pretende, por um lado, incorporar as especificidades deste nível de atenção do sistema de saúde, permitindo que o sistema de informação ultrapasse uma apreensão excessivamente genérica do trabalho em saúde. Por outro lado, a disponibilidade de um modelo deste tipo auxilia no diálogo entre a equipe de desenvolvimento e a equipe de saúde, além de facilitar a manutenção de coerência na construção dos diferentes componentes do sistema.

A responsabilidade deste desenvolvimento tem permitido, como um ganho secundário, consolidar dentro do CSEB uma equipe dedicada às questões da Informação e Comunicação em Saúde, que articula setores com atividades relacionadas, mas que mantinham uma prática um tanto fragmentada. Os setores de Informática, de Arquivo e Informação (SAMI) e o de Comunicação, Informação e Vigilância em Saúde (CIVIS) têm operado, sob a coordenação do Diretor Técnico do Serviço, como Grupo de Comunicação e Informação, responsável por coordenar todas as ações relacionadas ao Projeto Borboleta.

- Banco de dados evolutivos em métodos ágeis - A modelagem de dados em métodos ágeis pressupõe a evolução do banco de dados durante o processo de desenvolvimento devido às frequentes mudanças de requisitos das aplicações. O desafio é maior quando o banco de dados tem que atender simultaneamente a várias aplicações. A solução atual em métodos ágeis para evolução de banco de dados utiliza refatorações e define um período de transição, durante o qual tanto o esquema velho quanto o novo funcionam em paralelo e os dados são replicados por meio de um processo síncrono. Este tema de pesquisa tornou possível o desenvolvimento de uma ferramenta para manter atualizados esses esquemas e facilitar a evolução dos bancos de dados.

- Algoritmos e protocolos de criptografia para telefones celulares - No Projeto Borboleta, as informações dos prontuários médicos, que trafegam entre dispositivos móveis conectados sem fio, necessitam de tratamento da privacidade e a segurança da informação. Como os PDAs possuem baixo poder de processamento e conexões de baixa largura de banda, exigem algoritmos especiais em termos de velocidade e nível de segurança altas. Por isso, estudamos métodos de acordo de chaves autenticados baseados em curvas elípticas, que possibilitam a privacidade e segurança dos dados do Borboleta.

- Sincronização de bancos de dados móveis - O acesso ao banco de dados do centro de saúde pelos PDA é impraticável, devido ao alto custo do serviço de transferência de dados, instabilidade de sinal e indisponibilidade do serviço em regiões remotas. A alternativa viável é a 
replicação parcial dos dados nos dispositivos móveis. Com essa réplica dos dados, os profissionais de saúde podem se deslocar até as residências e realizar seu trabalho. Nesse momento, operações de leitura e escrita são efetuadas sobre os dados da réplica. Posteriormente, quando o profissional voltar ao centro de saúde, será necessário um processo de integração dos dados do dispositivo móvel com o banco de dados central. Este trabalho visa desenvolver algoritmos e protocolos que identifiquem e solucionem conflitos de dados durante o processo de integração da maneira mais automatizada possível.

- Transmissão eficiente de dados multimídia através de redes sem fio com telefones celulares - Investigação sobre a capacidade efetiva de transmissão IP de telefones celulares inteligentes; concentra-se na caracterização dos atributos de latência e de banda passante que podem ser alcançados em transmissão de dados multimídia sobre redes IEEE 802.11.

- Mineração de dados em informações de saúde - Estamos estudando o uso de técnicas de mineração de dados para a busca de padrões em bases históricas de atendimentos de saúde. Esses padrões podem revelar informações de natureza epidemiológica e orientar planos de prevenção e resolução de problemas e questões de saúde.

- Interação Homem Máquina e Reconhecimento automático de voz - O reconhecimento automático de voz será utilizado para aumentar a interação homem/máquina e melhorar a entrada para mineração de dados. Primeiro, o desenvolvimento de esquemas de navegação inteligentes em dispositivos móveis incorporarão comandos de voz, permitindo que os profissionais da saúde tenham mais tempo para se focar nas necessidades dos pacientes. Usaremos um sistema embarcado de reconhecimento de voz com um vocabulário reduzido. Segundo, para o suporte em mineração de dados, registros falados e histórias detalhadas serão coletadas e convertidas para texto. Atualmente, os dados são coletados a mão em papel. A conversão de voz para texto será feita usando um sistema de reconhecimento de voz com vocabulário ampliado com terminologia médica. 


\section{Capítulo 4}

\section{Tecnologias Utilizadas}

O Borboleta é um sistema desenvolvido para plataforma móvel. Para que tal trabalho fosse realizado, a equipe de desenvolvimento se valeu de várias tecnologias que se encontram disponíveis atualmente. Neste capítulo discutiremos as principais delas, as quais mais impactaram o desenvolvimento do projeto e que foram cruciais para chegar ao estado que se encontra atualmente.

\subsection{Evolução tecnológica}

Como mostra a Seção 3.1, o projeto Borboleta começou em 2002, sendo que seu desenvolvimento efetivo começou em 2005. O cenário para desenvolvimento de uma aplicação móvel robusta depende inteiramente do hardware onde tal aplicação pode ser desenvolvida. Começando a análise por 1999, foram desenvolvidos os cartões de rede sem fio, WiFi, e displays de maior resolução. Assim, uma maior conectividade e capacidade de interação foi atribuída para os dispositivos. Também em 1999, foi criada a plataforma de desenvolvimento JavaME que, naquela época, chamava-se Java2 ME, que simplificou o desenvolvimento e aumentou o poder que uma aplicação móvel poderia ter.

Quando chegamos em 2005, dispositivos com maior poder de armazenamento, processamento e interação com o usuário foram criados. Valendo-se desse cenário, o Borboleta começou a ser desenvolvido. Até então, todo desenvolvimento era feito sobre dispositivos da Palm, cujo o sistema operacional era o PalmOS. Mesmo utilizando a plataforma JavaME os dispositivos da Palm se adequavam à necessidade do projeto. Foi então que o Windows Mobile entrou como alternativa e, com os dispositivos da fábrica $H T C$, o Borboleta pôde evoluir para um patamar de acessibilidade e conectividade superior ao que tinha com a plataforma Palm.

Foi então que em 2009, com a evolução do modelo de dados do Borboleta e com o surgimento de diversos problemas relacionados à interação dos profissionais de saúde com o sistema, a equipe de desenvolvimento procurou uma alternativa para tornar o uso do Borboleta mais amigável (isso é descrito na Seção 3.1). Das opções disponíveis, a plataforma JavaME continuou sendo a melhor, só que dessa vez com a utilização da biblioteca gráfica LWUIT. O fato de não precisar reescrever todo o código, já que apenas a IHC precisaria ser refeita, foi crucial para a decisão. Outro ponto foi a aceitação do JavaME por mais plataformas, que com a adoção do LWUIT se fixou apenas no Windows Mobile. Porém, em 2010, a plataforma SymbianOS, utilizando o dispositivo Nokia N97, se mostrou muito boa para a utilização do Borboleta. E, atualmente, o Borboleta pode ser instalado no Android; contudo, não foram feitos muitos testes nessa plataforma, que parece ser muito promissora. 


\subsection{JavaME}

A plataforma Java é, atualmente, uma das principais plataformas de desenvolvimento de aplicação. Ela fornece ferramentas e bibliotecas para sistemas corporativos e sistemas que funcionam em uma máquina pessoal. Com esse escopo de englobar o maior número de ambientes de execução possível foi que, em 1999, a Sun criou a plataforma Java2 ME, hoje conhecida como JavaME[SUN09]. A ideia de ter uma plataforma padrão para rodar aplicações móveis foi de grande valia para que mais e mais aplicações móveis fossem desenvolvidas.

Com o passar do tempo, a especificação foi ficando mais robusta e as possibilidades de desenvolvimento de aplicações móveis foram se ampliando. A princípio, a plataforma tem como objetivo funcionar tanto em aparelhos de celular com poucos recursos quanto em smartphones e PDAs. Esse escopo limita o uso de recursos avançados, por exemplo, uma câmera de vídeo embutida de em um smartphone. Assim, bibliotecas especializadas para cada uma das operações avançadas foram criadas. Tais bibliotecas são descritas e nomeadas em suas respectivas JSR (Java Specification Request).

Basicamente existem duas especificações para dispositivos móveis: CLDC (Connected Limited Device Configuration) e $C D C$ (Connected Device Configuration). A primeira é para dispositivos mais simples e a segunda, para dispositivos mais complexos (como smartphones e PDAs). O Borboleta usa a primeira especificação, pois a segunda, até 2009, não tinha uma máquina virtual implementada com resultados satisfatórios para a equipe de desenvolvimento. A Figura 4.1 mostra, resumidamente, a plataforma $J_{a v a}{ }^{1}$ e destaca as duas plataformas móveis.

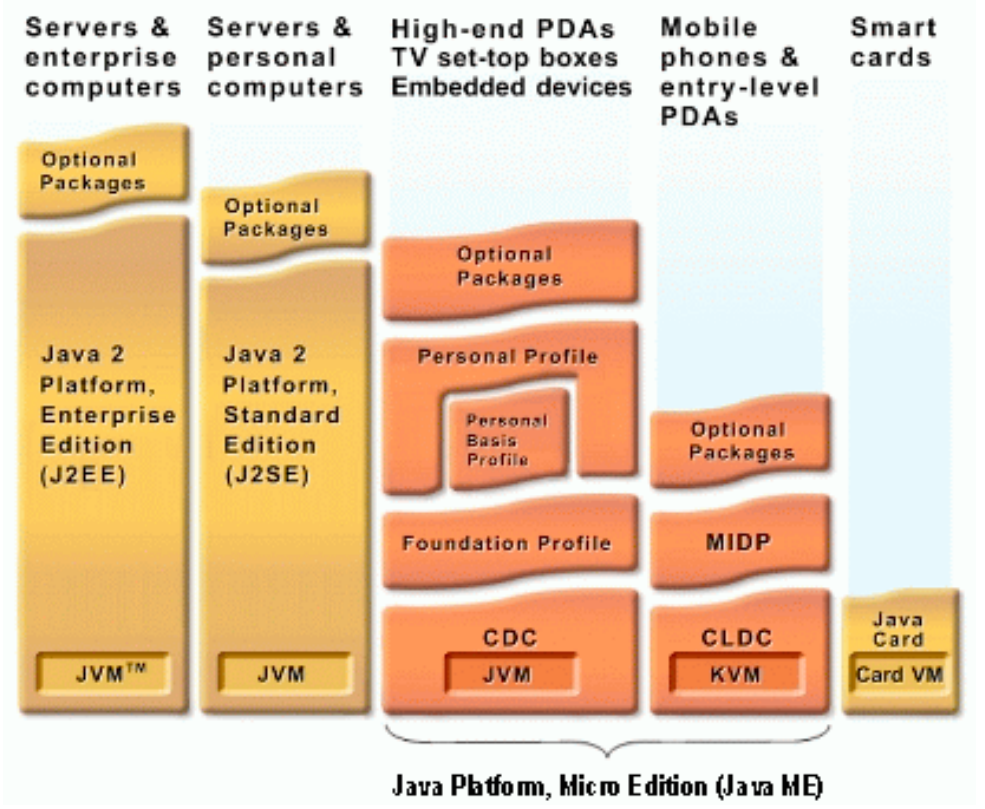

Figura 4.1: Plataforma Java

\section{$4.3 \quad L W U I T$ e $L C D U I$}

Nesta seção iremos apresentar duas bibliotecas usadas para desenvolver interfaces gráficas para dispositivos móveis. São elas a $L C D U I$ e a LWUIT. A biblioteca $L C D U I$ implementa um tipo

\footnotetext{
${ }^{1}$ Esta figura foi retirada do site http://www.oracle.com/technetwork/java/javame/tech.
} 
de interface simples, visualmente falando, com poucos componentes, fácil de se programar, porém muito limitada, justamente por não ter uma gama de recursos interessantes para serem usados em telefones celulares de baixo recurso computacional. Dado que o padrão JavaME se propõe a ser uma plataforma para qualquer dispositivo móvel, desde celulares de baixo custo até celulares inteligentes e PDAs, os recursos disponíveis em dispositivos mais robustos, tais como PDAs e celulares inteligentes, são subutilizados. Com o intuito de não perder totalmente a portabilidade do JavaME CLDC e poder usufruir de um poder gráfico melhor, decidimos adotar no Borboleta, no segundo semestre de 2009, uma nova biblioteca gráfica, a $L W U I T^{2}$.

A biblioteca LWUIT utiliza os recursos da classe Canvas disponível no JavaME para disponibilizar uma gama de recursos gráficos que se assemelham ao AWT e ao Swing do Java SE. Seguindo, assim, o padrão MVC [KP88], o LWUIT divide melhor as atribuições das classes de interface, que se seguidas adequadamente, melhora bem a clareza do código. Dessa forma, a LWUIT tem uma forma de desenvolvimento mais organizada e mais concisa que o LCDUI. A Figura 4.2, adaptada do trabalho de Krasner et al. [KP88], mostra um diagrama com as trocas de mensagens das classes que compõem o MVC.

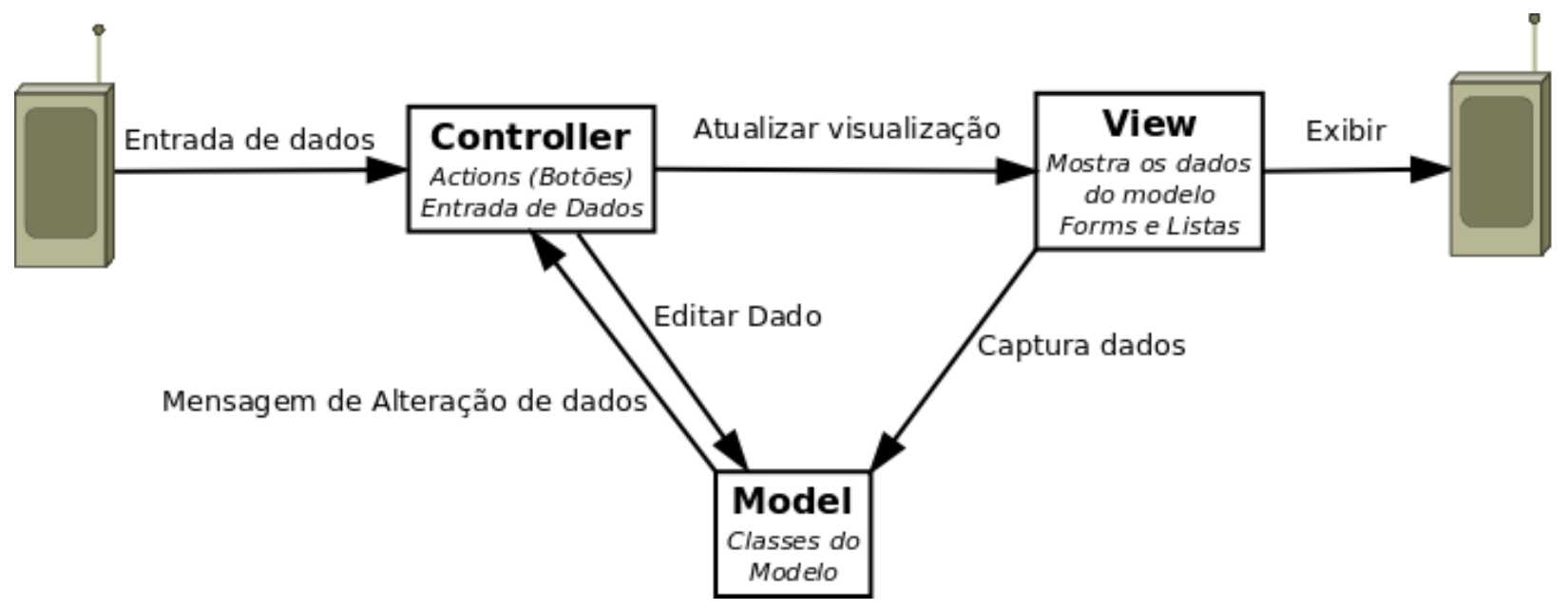

Figura 4.2: Diagrama $M V C$ adaptado a tecnologia móvel

Contudo, o fato da LWUIT desenhar no Canvas os formulários e componentes faz ela requer mais do dispositivo, então PDAs e celulares com baixo poder de processamento têm uma dificuldade maior em executar aplicações que a utilizam. A seguir, na Seção 4.3.1, mostraremos, com mais detalhes, algumas diferenças entre as duas bibliotecas.

\subsubsection{Diferenças entre $L C D U I$ e o $L W U I T$}

A biblioteca $L C D U I$ [SUN09] é a padrão para montar interfaces de formulários na plataforma Java ME. Ao montar um formulário, todo campo tem duas partes: um rótulo e um componente de entrada de dados. Os tipos de componentes disponíveis nesta biblioteca listaremos a seguir. Outro ponto da construção de interface usando essa biblioteca gráfica é que qualquer interação entre as telas é feita a partir de ações. Basicamente existem dois tipos de ações: ação de formulário e ação de componente. O primeiro é acessado a partir de um menu no rodapé do formulário e o segundo é

\footnotetext{
${ }^{2} \mathrm{~A}$ Lightweight User Interface Toolkit (LWUIT) é uma biblioteca de código livre e pode ser encontrada em https://lwuit.dev.java.net.
} 
acessado de várias formas diferentes dependendo do tipo de componente na qual a ação está ligada, por exemplo, a ação de selecionar um item de uma combobox.

A lista de componentes da $L C D U I$ é a seguinte.

- ChoiceGroup - Este componente é uma lista de itens selecionáveis. Nele, podem ser selecionados um ou mais itens, dependendo da configuração, e se for de seleção única ele pode tomar a forma de uma combobox.

- CustomItem - Este componente é um componente utilizado para ampliar a capacidade da $L C D U I$ e dar ao programador a oportunidade de implementar componentes customizados. Entretanto, ele limita bastante a forma de trabalhar com o componente, como exemplo, não conseguimos implementar, de forma satisfatória, um botão onde se possa clicar e gerar uma ação.

- DateField - Este componente cuida da manipulação de data.

- Gauge - Este componente serve apenas para a exibição. Ele mostra uma barra de progresso que é utilizada para exibir um valor numérico (exemplo, quantidade de bytes de uma mensagem transferidos pela rede).

- ImageItem - Este componente serve para exibir uma imagem.

- Spacer - Este componente apenas cria um espaçamento no formulário.

- StringItem - Este componente serve para exibir um valor em forma de caractere, por exemplo um campo informativo e que o usuário não tem acesso para alterar seu valor.

- TextField - Este componente serve para exibir e editar um valor em forma de caractere.

Já a biblioteca LWUIT [SUN08] utiliza a interface de gaming do Java ME que habilita desenhar diretamente num canvas. Isso possibilita a implementação de recursos bem mais avançados, já que não se precisa adaptar a limitações de componentes, pois não há componentes no canvas, apenas uma tela branca para ser desenhada. Sobre essa tela branca a LWUIT desenha, com um kit de ferramentas, e substitui o $L C D U I$ para criação de formulários. A forma de trabalhar com essa biblioteca é similar ao Swing do JavaSE, disponível para Desktop.

A LWUIT tem muitos componentes então iremos abordar apenas alguns que foram cruciais para que escolhêssemos essa biblioteca. Primeiramente abordaremos as cinco classes de componentes e depois as suas subclasses mais relevantes.

- Container - Os componentes que têm como Container sua superclasse são aqueles que podem armazenar outros componentes dentro de si, inclusive outros contêineres, um de seus principais atributos é o layout do contêiner que define como os componentes internos serão organizados. Dois exemplos de contêineres que foram cruciais para a implementação do Borboleta são Form e a TabbedPane. O primeiro, para a criação dos formulários contendo os campos a serem preenchidos ou exibidos. Já o segundo serviu para que pudéssemos organizar de uma forma mais limpa a variedade de informações e formulários, que antes precisavam ter seus próprios menus. A forma de organização por abas, implementada pela classe TabbedPane, foi muito bem recebida pelos usuários do sistema. 
- Label - As classes que estendem a classe Label servem para mostrar dados. Duas classes dessa árvore foram utilizadas pelo Borboleta e merecem destaque. A primeira é a própria classe Label, que é vastamente utilizada no sistema. A segunda é a classe Button, que implementa um botão que pode ser clicado pelo usuário e dispara uma ação. Com esse recurso, a utilização de menus para fazer ações relativas a campos caiu drasticamente, fora o fato de podermos utilizar conjunto de botões para criar telas de menus, por exemplo, a tela principal. Outros dois componentes derivam dos botões: CheckBox e RadioButton, ambos utilizados para montagens de formulários e captura e exibição de dados ao longo de todo o sistema.

- List - As classes que derivam de List representam listas. Dessas utilizamos a classe List e a classe ComboBox. A primeira foi utilizada para seleção de um ou mais elementos que entram no processo de cada formulário, por exemplo: selecionar quais os procedimentos realizados num atendimento domiciliar. Também foi utilizada para a exibição de dados em forma de lista. O componente ComboBox é uma lista de seleção única e foi utilizado em formulários ao longo do texto onde o usuário tinha que escolher uma opção dentre uma lista, por exemplo: nível de escolaridade do paciente.

- MediaComponent - Os componentes dessa árvore não foram muito utilizados pelo Borboleta até o presente momento. Existe uma linha de pesquisa no Borboleta que estuda a utilização de recursos multimídia nos prontuários gerados por ele. Essa linha de pesquisa tem como responsável o prof. Arlindo [dCaPaVPR $\left.{ }^{+} 08\right]$. Eles utilizam os componentes dessa árvore.

- TextArea - Os componentes TextArea e sua subclasse TextField são utilizadas ao longo de todo o sistema para a captura de dados texto. É nesses componentes (principalmente o TextField) que o usuário digita informações sobre o paciente e a visita. Nós tentamos evitar o uso desse tipo de componente ao máximo, pois a digitação nos dispositivos móveis (mesmo os que têm teclado embutido) é uma tarefa que prejudica a agilidade da entrada de dados. Porém, existem campos que não possuem um padrão simples de preenchimento e que o recurso de digitação é a única alternativa, por exemplo, o campo Anamnese, que faz parte do encontro.

Na Seção 5.4.2, as Figuras 5.6 e 5.7 mostram as diferenças entre LCDUI e LWUIT. O ganho de qualidade gráfica e recursos de interação é grande. Note que no topo da Figura 5.7, logo abaixo do título do formulário, está o componente TabbedPane, que incorpora no formulário de paciente três aspectos diferentes do seu cadastro. No LCDUI nós implementamos três formulários diferentes que eram acessados pelo menu inferior para ter o mesmo recurso, o que torna a utilização bem mais massante.

No entanto, utilizar a biblioteca LWUIT tem uma desvantagem principal. Primeiramente, ela aumenta consideravelmente o tamanho do binário; na versão 0.86 (onde utilizávamos $L C D U I$ ) o arquivo JAR tinha $350 \mathrm{~Kb}$. Já na versão 0.9 (primeira versão $100 \%$ utilizando $L W U I T$ ) o arquivo JAR tinha 1.1M. Este problema também é apontado por Huang [Hua09]. Em segundo lugar, Huang também escreve sobre a perda no desempenho do projeto. Nós não chegamos a sentir tanto problema com isso, pois nossos dispositivos têm um hardware mais robusto que o utilizado por Huang, porém, em certos momentos, o problema de desempenho aparece, principalmente ao carregar formulários muito grandes, como o do Encontro Domiciliar. 


\subsection{Dispositivos Utilizados}

Para um sistema móvel desenvolvido para smartphones e PDAs é importante saber quais os requisitos e em quais dispositivos podemos ter o software funcionando corretamente. Para isso, nesta Seção, colocaremos as características de hardware e software que os dispositivos precisam ter para serem capazes de executar o Borboleta sem problemas. Primeiramente, vamos listar os requisitos de hardware mínimos.

- Processador de no mínimo $200 \mathrm{MHz}$ - com menos do que isso o uso do Borboleta fica comprometido.

- Memória de 64 MBytes - os dados do Borboleta ocupam por volta de 30 a 40 MBytes, variando de acordo com o número de pacientes sincronizados.

- Placa de rede $W i F i$ - para que possam ser sincronizados os dados com o servidor central do Centro de Saúde.

- Display colorido de no mínimo 240x320 px.

Infelizmente, devido à utilização da biblioteca $L W U I T$, que exige recursos novos do JavaME $C L D C$, não podemos incluir os dispositivos da Palm entres os dispositivos compatíveis com o Borboleta. Isso se deve porque a Java Virtual Machine com os recursos multimídia, necessários para a LWUIT funcionar, não está implementada. Contudo, pudemos testar a compatibilidade com três dispositivos, os quais tornamos como padrão para o uso do Borboleta. Dois deles usam o sistema operacional Windows Mobile e o terceiro utiliza SymbianOS. A Tabela 4.1 mostra uma comparação entre os dispositivos utilizados no projeto.

\begin{tabular}{|c||c|c|c|}
\hline Característica & HTC Touch & HTC Tytn II & Nokia N97 \\
\hline \hline Processador & OMAP $850201 \mathrm{MHz}$ & $\begin{array}{l}\text { Qualcomm MSM7200 } \\
400 \mathrm{MHz} \text { ARM }\end{array}$ & $\begin{array}{c}\text { Single CPU } \\
434 \mathrm{MHz} \text { ARM11 }\end{array}$ \\
\hline Memória & 64 MBytes & $128 \mathrm{MBytes}$ & $128 \mathrm{MBytes}$ \\
\hline WiFi & Sim & Sim & Sim \\
\hline Display & 240x320 px, 65k-color & 240x320 px, 65k-color & $640 x 360 \mathrm{px}, 16 \mathrm{M}-$ color \\
\hline Sistema Operacional & Windows Mobile 6.5 & Windows Mobile 6.5 & Symbian OS 9.4 \\
\hline
\end{tabular}

Tabela 4.1: Dispositivos em que testamos o Borboleta

Dispositivos que usam o sistema operacional Android devem ser compatíveis com o Borboleta, já que existe uma máquina virtual para esse ambiente. Porém, nenhum teste nesta plataforma foi feito até o momento. 


\section{Capítulo 5}

\section{Arquitetura}

Durante o desenvolvimento do Borboleta, cuja a evolução cronológica foi descrita na Seção 3.1, foram pesquisados diversos recursos, plataformas e formas de abordagem que melhor se adequavam ao escopo do projeto. Tais aspectos tiveram impacto na forma com que a arquitetura do sistema foi projetada. A seguir, vamos analisar e descrever os seus principais conceitos e como eles foram aplicados dentro do sistema.

\subsection{Modelagem Conceitual}

O Borboleta é um sistema pioneiro e foi necessário desenvolver uma modelagem própria. Procuramos basear nosso modelo em dois padrões internacionais relevantes: o OpenEHR [BH07a] e o Health Level 7 (HL7) [Bee98]. Tomando como base os arquétipos do OpenEHR, definimos conteúdos dos pacientes como: dados do endereço, contatos, relacionamentos do paciente com o seu cuidador e até o conceito de Encontro. O padrão HL7 ajudou-nos a definir parte dos dados dos Encontros e dos Pacientes. Porém, no módulo móvel, não utilizamos toda a riqueza que esses modelos definem, pois não faz parte do escopo do sistema ter, por exemplo, dados de cobrança pelo serviço.

Inicialmente, a equipe de saúde e a equipe de desenvolvimento definiram algumas diretivas e funcionalidades que seriam interessantes para serem exploradas no escopo do Borboleta. A Figura 5.1 mostra um resumo do conceito do encontro.

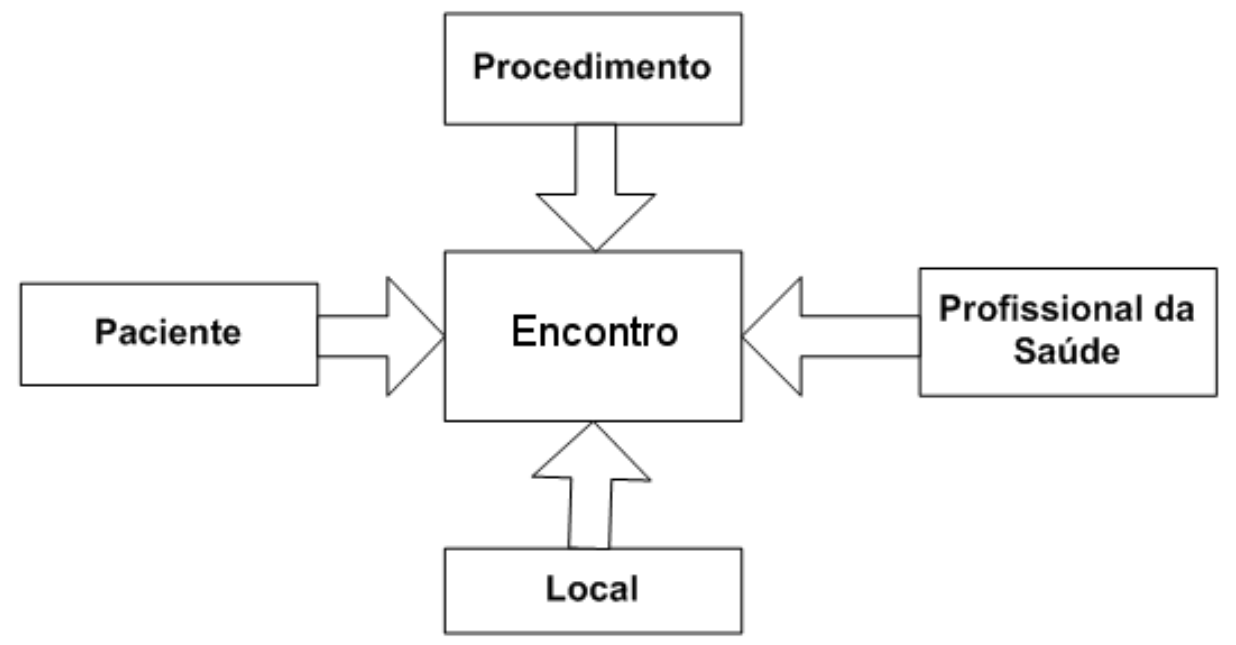

Figura 5.1: Macro modelo de definição de um encontro 
Encontros são os atendimentos prestados pelo centro de saúde de uma forma geral. Mas, por que chamar de encontro? Justamente, porque a palavra atendimento não reflete todas as possibilidades de serviços prestados pelo Centro de Saúde, assim sendo, os profissionais de saúde preferiram o nome "Encontro" para esta definição. Além da escolha do termo "Encontro", foram definidas funcionalidades abstratas a serem incorporadas ao Borboleta. Parte dessas funcionalidades já estão implementadas. A seguir estão uma listagem com as funcionalidades abstratas que estão implementadas ou serão implementadas no Borboletas, a descrição de cada funcionalidade pode ser encontrada na Seção 3.1.

1. Base de dados móvel integrada com a base central dos pacientes

2. Acesso a material de referência

\section{Acesso interconsulta com especialista}

4. Sistema de apoio à decisão e lembretes para a equipe de saúde

5. Envio de mensagens e lembretes para os pacientes

6. Mapeamento de rotas e domicílios

\section{Acesso dos pacientes às informações}

A partir dessas definições macros desenvolvemos servem de guia para o desenvolvimento do projeto. Algumas delas já estão no escopo atual, outras serão planejadas para versões futuras. As funcionalidades descritas a seguir, listadas na Seção 3.1, mostram as funcionalidades presentes no Borboleta.

- Dados do Paciente - Contém os dados cadastrais pessoais do paciente. Os campos mais importantes e obrigatórios desse cadastro são: a matrícula do paciente no centro de saúde, o nome do paciente, nome da mãe e o endereço da residência do paciente.

- Dados Socioeconômicos - Referem-se à situação financeira e social do paciente, como profissão, escolaridade, nacionalidade, religião. Esses dados podem influenciar no modo que um tratamento será conduzido, por exemplo, dependendo da religião o paciente não pode receber certos tratamentos. Esses dados também contém o documento de registro do paciente (Registro Geral, ou RG, fornecido pela Secretaria de Segurança Pública).

- Dados do Cuidador - Contém dados do cuidador responsável pelo paciente. O cuidador é uma pessoa que pode continuar o tratamento indicado para o paciente durante o período entre as visitas da equipe de saúde.

- Agenda de Visita - Contém a agenda com as visitas futuras aos pacientes programadas. Esta agenda é montada pelos profissionais baseando-se nos prazos passados para os pacientes na parte de Programação Final do Encontro.

- Registro de Nova Visitas - É o registro do que ocorreu durante um Encontro Domiciliar. Os dados coletados serão melhores descritos na Seção 5.2. Esta é a principal funcionalidade do Borboleta e onde se encontra o maior esforço de desenvolvimento até agora. 
- Acesso ao Histórico das Visitas - Provê um histórico dos Encontros realizados a um determinado paciente. Os Encontros identificados pelas datas em que foram realizados. Essa listagem é preenchida com os três Encontros mais recentes presentes no SAGUISaúde, ou Encontros recém cadastrados.

- Catálogo de Doenças - Contém o catálogo de doenças definido pela Organização Mundial de Saúde, Tabela CID-10[Org04].

- Catálogo de Medicamentos - Possui a lista de medicamentos disponíveis na farmácia do Centro de Saúde bem como as suas informações. Os medicamentos desse catálogo podem ser informados na Conduta de Medicamento no registro de uma Situação Clínica de um Encontro.

Essas são as funcionalidades que estão presentes atualmente no sistema móvel. Apesar delas terem sido mapeadas há alguns anos, muito do seu conteúdo foi radicalmente alterado para melhor atender às necessidades do cliente durante o tempo. A partir delas, trabalhamos para o levantamento do Modelo Lógico de Dados apresentado a seguir na Seção 5.2.

\subsection{Modelo Lógico de Dados}

Com a definição conceitual das funcionalidades e do foco do sistema pudemos traçar, junto com a equipe de saúde, um modelo de coleta de dados, onde tivemos como meta nos aproximar, ao máximo, do conceito de um prontuário eletrônico $\left[\mathrm{BEG}^{+} 03\right]$, voltado para o suporte à atenção primária domiciliar. Citando mais uma definição de Richard [DSD97, dFM03], do Instituto de Medicina da Academia Nacional de Ciências dos Estados Unidos, prontuário eletrônico do paciente é: "um registro eletrônico que reside em um sistema especificamente projetado para apoiar os usuários, fornecendo acesso a um completo conjunto de dados corretos, alertas, sistemas de apoio à decisão e outros recursos, como links para bases de conhecimento médico". Essa definição, assim como a de outras referências, tem como foco o paciente, afinal são os dados relativos a essa pessoa que serão armazeados. Porém, ao analisarmos o foco do sistema consideramos o mais aropriado que utilizar o Encontro como entidade central do sistema. Afinal, para nós, os eventos tem um peso maior no sistema do que os dados do paciente, mas obviamente não deixamos de lado tais informações. Relembrando a Figura 5.1 exposta na Seção 5.1 que mostra bem o Encontro como centro e foco do modelo de dados.

Primeiramente, vamos destacar o conceito de Encontro, que ficou explícito no modelo atual. Encontro é qualquer situação onde um paciente encontra-se com um profissional de saúde para realizar atividades relativas à saúde do indivíduo. A Figura 5.1 mostra quais as principais informações que dizem respeito ao Encontro.

De maneira geral, um Encontro é um evento onde um Profissional de Saúde realiza Procedimentos de saúde em um Paciente em um Local. No caso do Borboleta, o local é a casa do paciente e os profissionais de saúde são os responsáveis pelo dispositivo móvel, assim sendo, falta somente os dados do paciente que são sincronizados com o servidor central, que executa o sistema SAGUISaúde [DCK $\left.{ }^{+} 08\right]$. Em relação ao registro de paciente, os dados coletados são: os dados pessoais (nome, telefone, endereço, documentos, etc.), dados socioeconômicos e os dados do cuidador (uma pessoa responsável por auxiliar o paciente em seus afazeres cotidianos). 
No nosso modelo, o foco é a coleta de dados relacionada ao Encontro, que, no caso do Borboleta, foi especializado para Encontro Domiciliar, visando suprir as peculiaridades deste tipo de Encontro. Assim, fica explícito que Encontro Domiciliar é uma especialização de um conceito mais genérico, Encontro. A seguir, na Figura 5.2, está o diagrama relativo à tal modelagem.

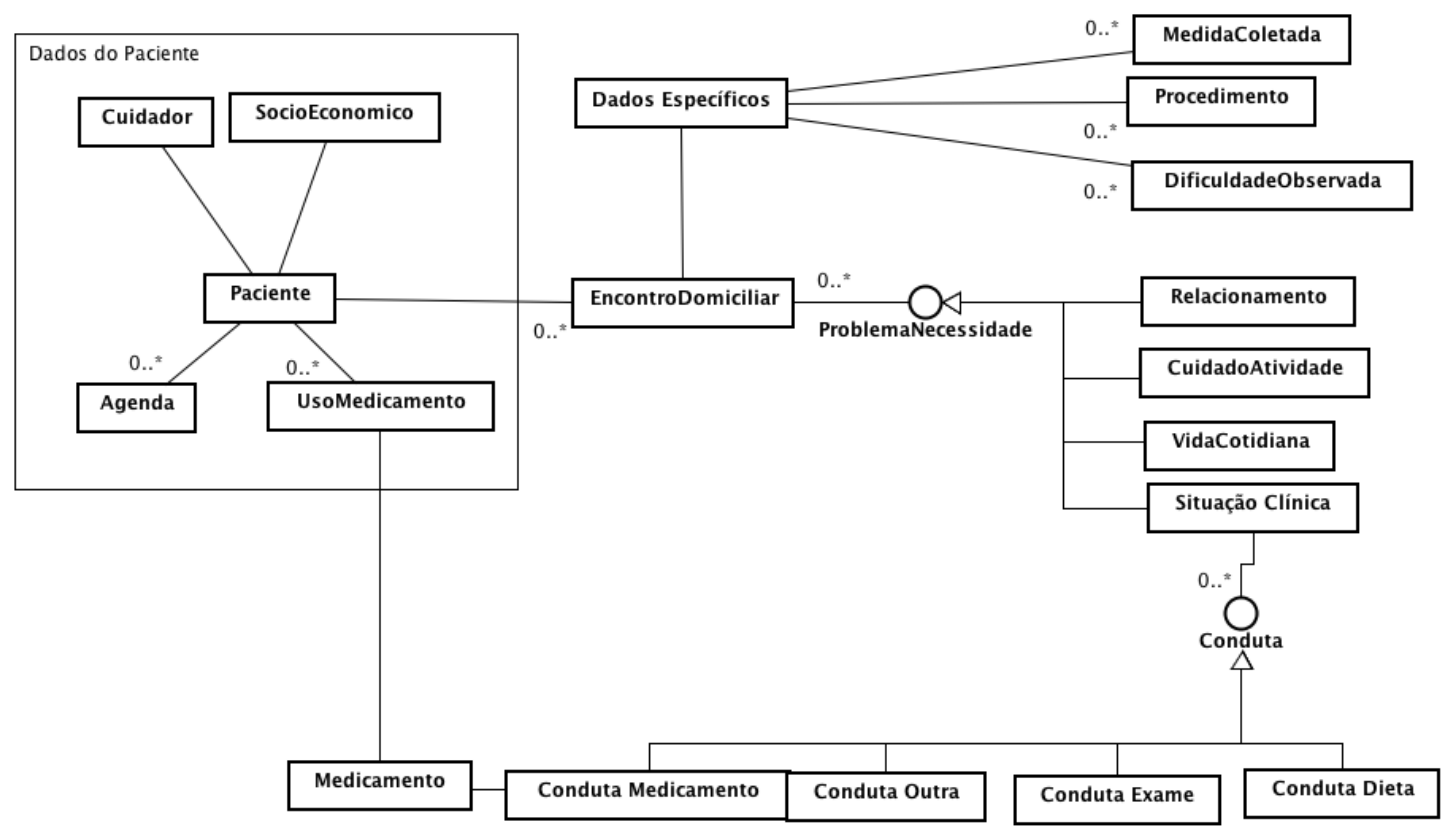

Figura 5.2: Diagrama de classes mostrando a modelagem atual do Sistema Borboleta

A primeira coisa a ser considerada à respeito da Figura 5.2 é a quantidade de dados que estão relacionados ao EncontroDomiciliar. Todas as classes que são coletadas no encontro estão fora do pacote que chamamos Dados do Paciente, a quantidade de classe é bem superior que a de dentro do pacote. Portanto, não é por acaso que o Encontro Domiciliar é o centro da modelagem do Borboleta. Conceitos, como Problema/Necessidade, são dados que permeiam e se relacionam com o Encontro Domiciliar. Especificamente, em se tratando de Problema/Necessidade, seu significado é o de relatar os problemas e as necessidades observadas pelos profissionais de saúde a respeito do paciente. Um dos tipos é a Situação Clínica que identifica um diagnóstico de doença avaliada pelos profissionais de saúde. Ela tem por objetivo representar os diagnósticos e as Condutas que foram tomadas para aquela Situação Clínica. Com isso, pode-se saber qual o diagnóstico que levou o profissional a decidir por uma certa conduta.

Além disso, outro tipo de Problema/Necessidade coletado são os Cuidados e Atividades que o paciente pratica, por exemplo: higiene pessoal, atividades de trabalho etc. Além desse tipo, é registrado a condição da Vida Cotidiana do paciente, como autonomia, relações sociais. Existe mais um tipo de Problema/Necessidade que se refere aos Relacionamentos que o paciente tem, sendo eles: relacionamento com cuidador e com a equipe de profissionais de saúde. O modelo foi construído com base em padrões como OpenEHR [BH07a], onde existe uma divisão clara entre dados coletados, Situação Clínica ou Vida Cotidiana, e ações a serem tomadas, denominadas de Condutas. Pode-se notar que as Condutas são composições de pequenas classes que representam as atitudes e recomendações que os profissionais receitaram para o paciente. Tal forma de trabalhar é semelhante ao padrão de arquétipos, porém adaptamos as ideias para que fossem mais simples implementá-las em uma plataforma móvel. 
Além dos Problemas/Necessidades coletados no Encontro Domiciliar existem mais dados específicos da visita realizada à casa do paciente. Eles são Procedimentos, Medidas e Dificuldades. Esses dados foram organizados como os Dados Especificos do Encontro Domiciliar, que representam o registro feito no ato do encontro específicos dele, como as medidas, procedimentos realizados e as dificuldades observadas. Na Figura 5.2, podemos notar que eles estão ligados à classe Encontro Domiciliar por meio da classe Dados Específicos, porém essa classe só foi colocada na figura para que ficasse clara a separação dos dados, na realidade os Dados Específicos relacionam-se diretamente com o encontro.

Seguindo as orientações dos profissionais de saúde, chegamos a essa modelagem conceitual implementada na versão mais recente do sistema. Acreditamos que tal passo seja crucial para que possamos alcançar nosso objetivo de ter um sistema de Prontuário Eletrônico apropriado para as especificidades da Atenção Primária Domiciliar praticada no Brasil. A seguir, iremos mostrar a Arquitetura do Projeto Borboleta, que juntamente com o Modelo Lógico, são a base para o desenvolvimento e sucesso do sistema.

\subsection{Arquitetura Geral do Sistema}

O Borboleta foi construído sobre a plataforma de desenvolvimento Java ME [SUN09] e, por isso, a linguagem utilizada é Java. Pela razão de Java ser orientada a objetos, toda a arquitetura é descrita com terminologias desse tipo de linguagem. Detalhes sobre o desenvolvimento do projeto em si serão abordados no Capítulo 6. Porém esses aspectos da linguagem influenciam na maneira que criamos o sistema. Além disso, o sistema móvel se relaciona com o SAGUISaúde [DCL $\left.{ }^{+} 10\right]$ onde os dados coletados são sincronizados. O processo total do uso do Borboleta segue o que é descrito na Figura 5.3.

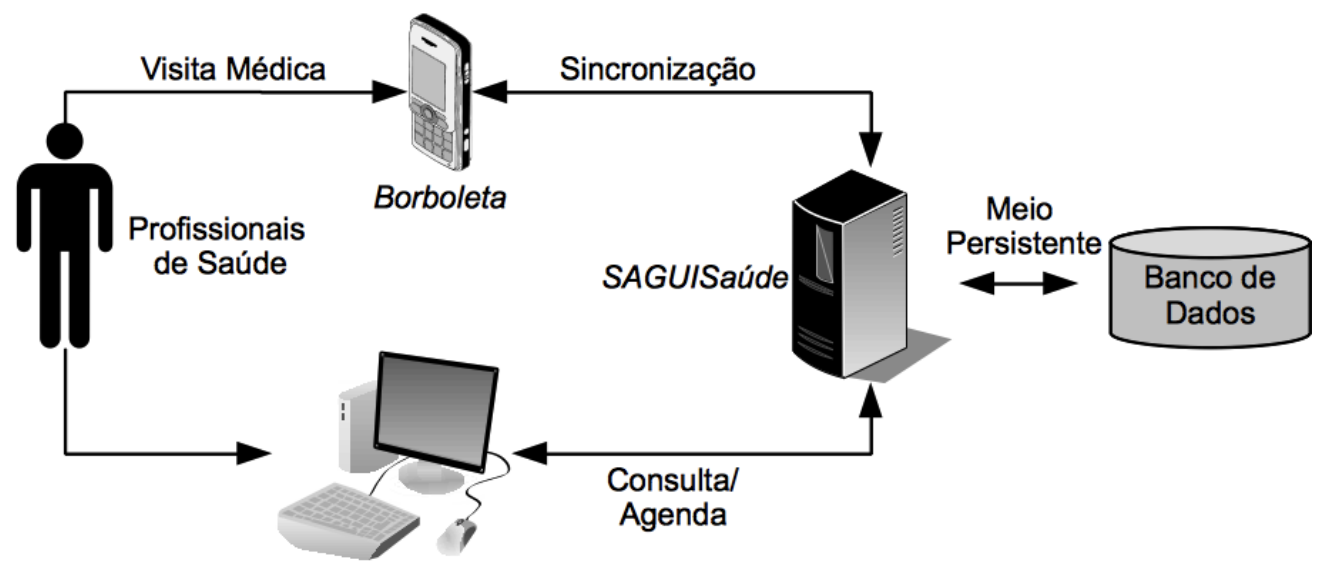

Figura 5.3: Fluxo do uso do sistema Borboleta e integração com o SAGUISaúde

O Projeto Borboleta como um todo pode ser dividido em duas aplicações basicamente: o SAGUISaúde e o Borboleta móvel (ou simplesmente Borboleta). O SAGUISaúde é um sistema central de gerenciamento do Centro de Saúde com o qual o Borboleta móvel faz interface e de onde ele extrai informações dos pacientes e exporta os encontros coletados nos encontros. O sistema móvel, foco deste trabalho, é instalado nos dispositivos e usados nos encontros. Internamente, ele se divide em pacotes e estes serão analisados na Seção 5.4 . 


\subsection{Arquitetura dos Pacotes}

A arquitetura interna do Borboleta, instalado nos dispositivos móveis, é dividida em pacotes. Nesta seção, vamos descrever os principais pacotes referentes à arquitetura do sistema móvel, como foram criados, porque foram criados dessa forma e se existe algum comentário a respeito de sua evolução.

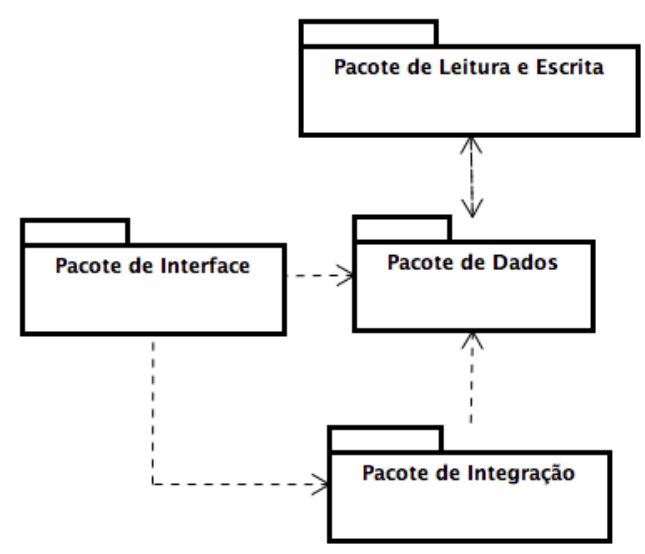

Figura 5.4: Interações entre os pacotes

Basicamente, o Borboleta tem seu desenvolvimento baseado em quatro pacotes principais: Pacote de Dados, Pacote de Interface do Usuário, Pacote de Integração com o Sistema Central (também chamado de sincronização) e Pacote de Gravação e Leitura de Dados. Essa divisão se deu para termos um melhor controle dos processos que envolvem o Borboleta, cada pacote tem uma funcionalidade específica e se relaciona com os outros, essas interações são mostradas na Figura 5.4. Examinaremos cada um dos pacotes nas seções seguir.

\subsubsection{Pacote com as Classes de Dados e E/S}

O pacote que contém as Classes de Dados é o centro do sistema móvel, como mostra a Figura 5.4, e os outros pacotes dependem diretamente dele. Toda a lógica e definições do Modelo Conceitual (Seção 5.2) estão espelhados nesse pacote. Qualquer alteração e/ou inclusão de conceitos que o Borboleta sofre pode gerar alteração no modelo de dados, cuja a implementação está nesse pacote. Isso mostra a importância dele. O diagrama de classes dele é o mesmo apresentado na Seção 5.2, Figura 5.2.

Junto ao pacote de dados implementamos a parte de Entrada e Saída de dados (E/S) com o RecordStore. O processo de gravação e leitura é demonstrado pelo Diagrama de Sequência da Figura 5.5. Podemos observar que todas as classes de dados, por exemplo Paciente, tem um método salvar o qual se encarrega de salvar seus dados e chamar os métodos salvar de seus dependentes e isso vai até as classes folhas, que não tem dependentes. O processo de gravação é disparado pela interface quando o usuário pede para salvar os dados alterados, como alteração dos dados do paciente e/ou inclusão de dados de um novo EncontroDomiciliar.

O processo de leitura acontece de forma semelhante ao processo de gravação porém sua origem não vem de uma solicitação do usuário. Os dados são carregados logo na inicialização do Borboleta, isso garante que não percamos tempo e nem recursos de energia com o processo de leitura. 


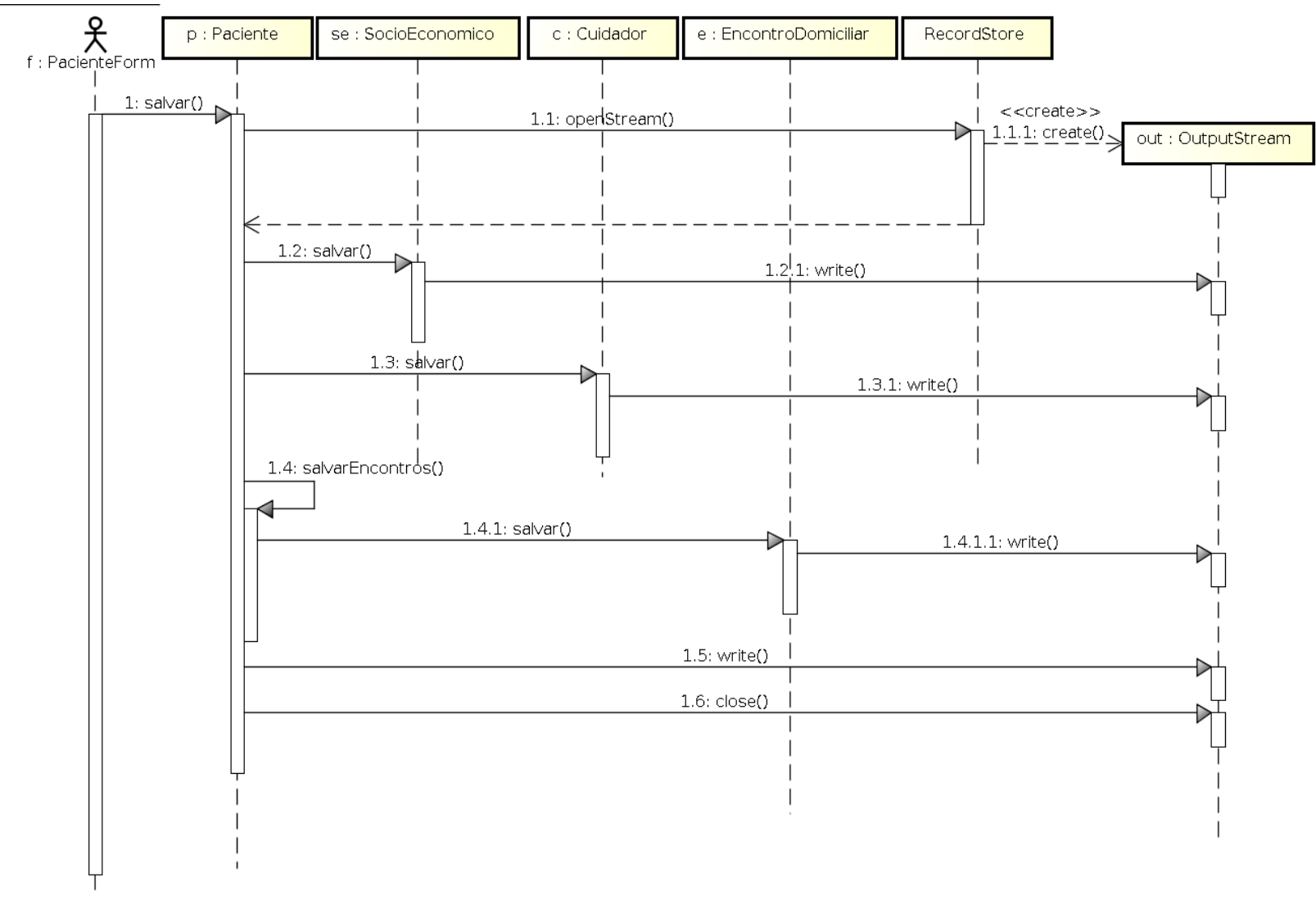

Figura 5.5: Sequência para gravação no RecordStore

O processo de leitura e gravação que o Borboleta faz não é o ideal, queremos dar um desacoplamento maior para essa camada, e até mesmo uma generalização com a parte de XML. Assim a camada de dados ficaria mais independente e não teria código relacionado a como escrever num stream de dados, algo que acontece hoje. Outra opção é estudar o uso de arcabouços de persistência móvel, como o Floggy [TLaMTRPL]. Isso será feito em versões posteriores com a refatoração de várias camadas do Borboleta.

\subsubsection{Arquitetura do Pacote de Interface}

Como se sabe, a interface de usuário de um sistema é um componente vital. Esse fator é ainda mais agravado quando se trata de aplicações móveis. Com tela, teclado e recursos gráficos reduzidos, o desenvolvimento de uma boa interface foi um desafio para a equipe técnica. Para minimizar e agilizar o processo de construção da interface nos valemos de técnicas usadas na metodologia de Programação eXtrema (XP) [BA04], como ter o cliente o mais próximo possível da equipe e, com o rápido feedback, o desenvolvimento é mais rápido e atinge melhor a expectativa do cliente. As práticas de XP foram usadas ao máximo, porém não foi possível aplicar todas elas, pois nem sempre tinhamos uma pessoa da equipe de saúde com a de desenvolvimento; mesmo assim a política de versões curtas ajudou a manter o feedback mais rápido.

Com relação à interface do usuário, o Borboleta estava usando a interface padrão da plataforma JavaME conhecida como LCDUI. Como mostra a Seção 4.3, essa biblioteca é muito limitada então decidimos migrar a interface com o usuário para a nova biblioteca LWUIT, que tem mais com- 
ponentes e dá mais liberdade para se criar formulários mais complexos. Não sabemos, ainda, se a biblioteca LWUIT irá suprir todas as nossas necessidades com relação à interface de usuário, porém é uma alternativa bem promissora para a padronização e evolução da interface do Borboleta. As Figuras 5.6 e 5.7 mostram duas telas capturadas do borboleta, a primeira quando usava a biblioteca LCDUI e a segunda usando a LWUIT.

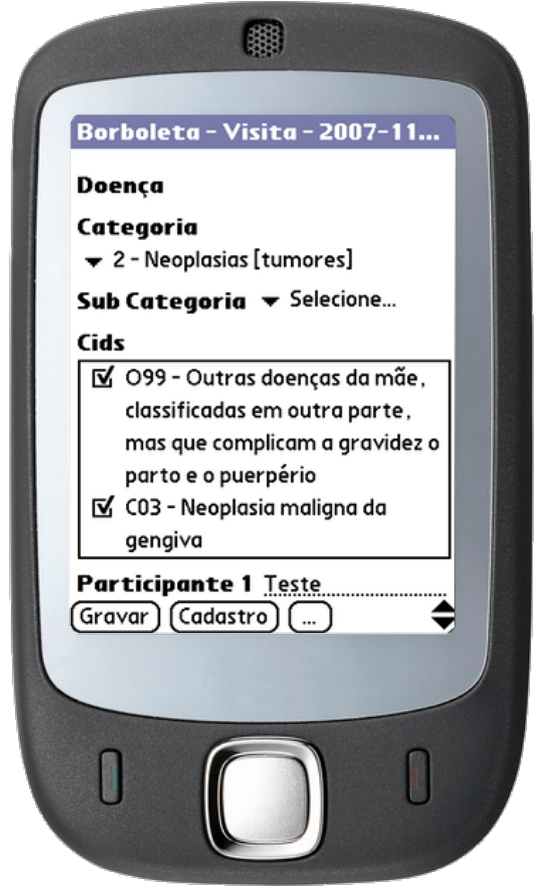

Figura 5.6: Tela do Borboleta usando a biblioteca $L C D U I$

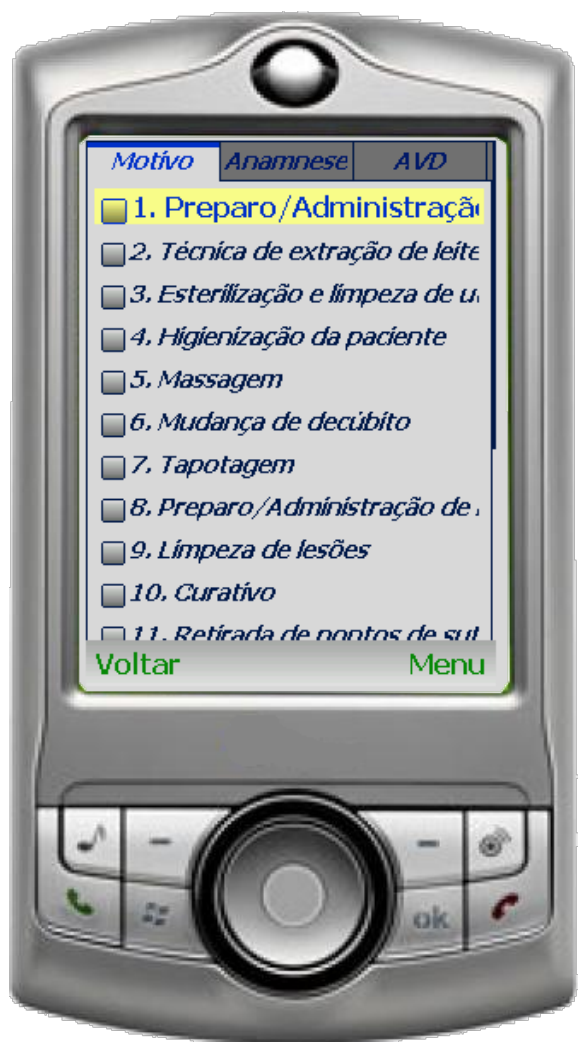

Figura 5.7: Tela do Borboleta usando a LWUIT

Além das questões de metodologia de desenvolvimento de interface e bibliotecas, existem assuntos relativos aos módulos internos desse pacote. Tais módulos se dividem em três grupos. Assim sendo, abordaremos o restante da interface nas subseções que tratam, respectivamente, da interface referente ao cadastro do Paciente; da lista de CID e lista de medicamento do Centro de Saúde e, por fim, do Encontro Domiciliar. Essas subseções tratarão de assuntos específicos dos respectivos módulos.

\section{Interface Paciente}

A interface referente ao Cadastro do Paciente é responsável pela captura e consulta dos dados de identificação e socioeconômicos do paciente, além dos dados do cuidador. Os dados dessas entidades são, na sua maior parte, texto livre, o que prejudica a usabilidade do sistema, pois a entrada de dados nos dispositivos móveis torna-se lenta e cansativa. Não podemos esquecer que os dispositivos móveis em questão possuem, na melhor das hipóteses, um teclado limitado (com teclas pequenas e desconfortáveis para uma digitação longa). Fizemos um trabalho, junto com a equipe de profissionais de saúde, para minimizar o uso de campos com texto livre. Por exemplo, religião, escolaridade e outras informações cadastradas foram implementadas como componentes que não precisam ser digitados, mas sim escolhidos através de um componente de seleção de uma lista pré-definida. 


\section{Interface da Lista CID e de Medicamentos do Centro de Saúde}

O Catálogo Internacional de Doenças, conhecido pelo acrônimo CID [Org04], contém uma listagem das doenças que foram catalogadas pela Organização Mundial de Saúde (OMS). Ele usa um sistema hierárquico de categorias e subcategorias que auxiliam o profissional de saúde a identificar com uma maior facilidade e precisão a doença que procura. Cada doença tem um código que é formado com elementos da categoria e da subcategoria ao qual pertence. No Borboleta, estamos utilizando o mesmo sistema hierárquico, porém com menos níveis entre a categoria e a doença, assim, consome-se um menor volume de recurso de armazenamento do dispositivo e agiliza-se o processo de seleção por parte do usuário do sistema.

Além do CID, existe também a lista de medicamentos que são oferecidos pelo Centro de Saúde, que é preenchida pelos profissionais de saúde e usada em vários lugares do sistema. Porém, nesse caso, ela é apenas utilizada para consulta.

\section{Interface do Encontro Domiciliar}

A interface referente ao cadastro de encontros domiciliares segue a modelagem descrita na seção 5.4.1. As telas foram projetadas seguindo as orientações da equipe de profissionais de saúde que, testando a versão preliminar do sistema, consideraram que a divisão em muitas telas prejudicava a legibilidade e a facilidade de uso do sistema. Foi assim, pesquisando alternativas, que encontramos a biblioteca gráfica LWUIT disponibilizada recentemente pela Sun Microsystems, que tem sido uma boa caixa de ferramentas para otimizar a interface do Borboleta.

O Encontro Domiciliar relaciona-se com quase todas as partes do sistema, afinal é ao redor dele que gira o foco do Borboleta. Assim sendo, a lista do CID e a lista de medicamentos são utilizadas dentro do Encontro. O CID é usado no registro da Situação Clínica e o medicamento é utilizado na conduta de prescrição de medicamento. Dessa forma, as listagens são otimizadas para funcionar dentro dos cadastros.

\subsubsection{Integração com o Sistema Central}

O pacote de integração com o Sistema Central do Borboleta é responsável por receber e enviar os dados para o Sistema de Apoio à Gestão Unificada de Informações de Saúde (SAGUISaúde) [DCK $\left.{ }^{+} 08\right]$. Para isso, foi escolhido o formato de XML para realizar a integração. O Borboleta interage em três processos com o SAGUISaúde:

- Importar Tabelas de Apoio - Processo de integração usado para que as tabelas de apoio utilizados no sistema sejam carregadas. Exemplos de tabelas de apoio incluem catálogo de doenças (CID), medicamentos, procedimentos etc.

- Importar Pacientes - Nesse processo o SAGUISaúde transmite os dados referentes aos pacientes selecionados do banco de dados central para o do dispositivo móvel.

- Exportar Pacientes - Transferência dos dados coletados do Borboleta para o banco de dados central do SAGUISaúde.

A comunicação entre o Borboleta e o SAGUISaúde é feita por meio de XML usando o protocolo HTTP implementado pelo Java ME. As Figuras 5.8 e 5.9 mostram a sequência de importação e exportação de dados entre o Borboleta e o SAGUISaúde. 


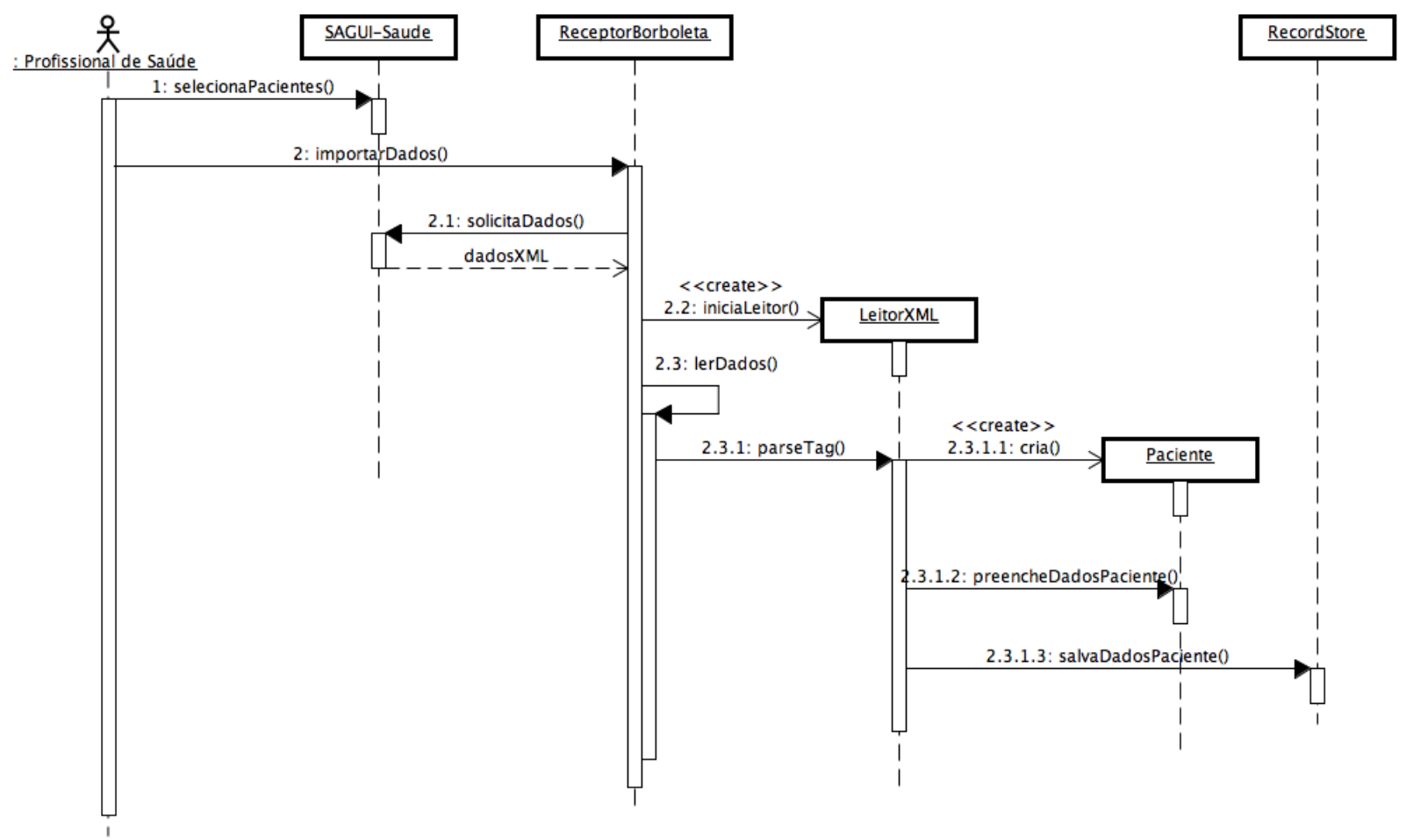

Figura 5.8: Importação de Dados do SAGUISaúde para o Borboleta

O processo apresentado na Figura 5.8 se inicia com o profissional escolhendo no SAGUISaúde os dados dos pacientes que vão ser copiados para o sistema móvel. Depois disso, no Borboleta, ele requisita a importação de dados, o Borboleta, por sua vez, solicita ao SAGUISaúde um XML com os dados requisitados e manda uma resposta HTTP para o sistema móvel. Dentro do Borboleta esse XML inicia o processo de parsing, que é realizado pelo método lerDados (). Esse método inicia um LeitorXML, essa classe é responsável por ler uma entidade do sistema, por exemplo, Paciente ou Encontro ou qualquer outra que seja enviada pelo XML. A classe LeitorXML instância uma classe da entidade lida, no exemplo da Figura 5.8, Paciente. Então essa classe é persistida no RecordStore.

O processo de exportação dos dados dos pacientes, apresentado na Figura 5.9, se inicia com o Profissional de Saúde pedindo a execução da exportação de dados. Assim se inicia a montagem do XML. O método montaXML chama o método toXMLElement de cada registro de paciente. O método toXMLElement pertence a todas as classes de dados e é responsável por gerar o código XML responsável pela entidade, se uma entidade tem outras entidades como atributos seus respectivos métodos toXMLElement são chamados. Depois do XML pronto o método de exportação de pacientes envia o XML para o SAGUISaúde e assim finaliza o processo. A Figura 5.10 mostra como é a visualização dos dados de um Encontro no SAGUISaúde. 


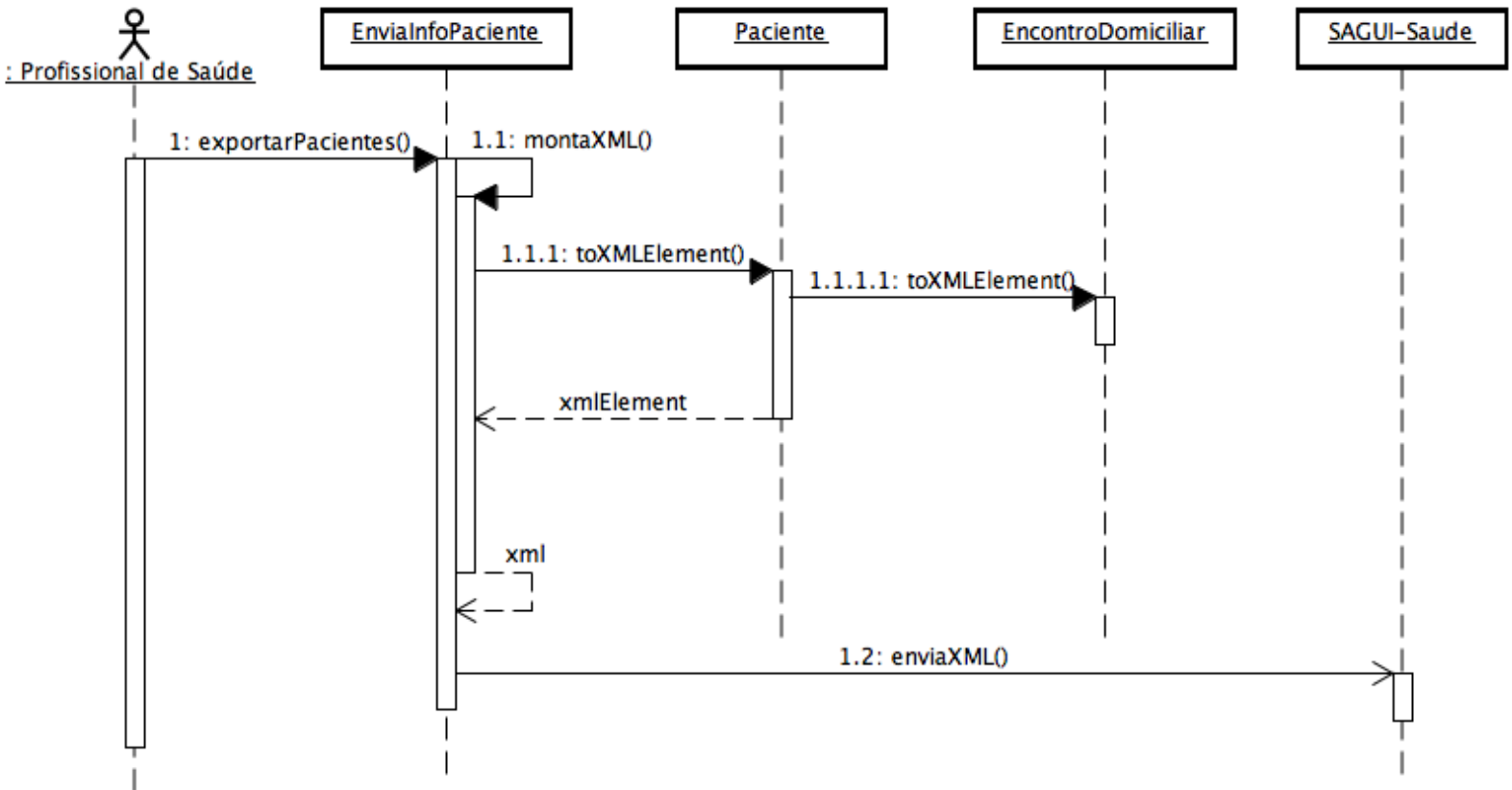

Figura 5.9: Exportação de Dados do Borboleta para o SAGUISaúde

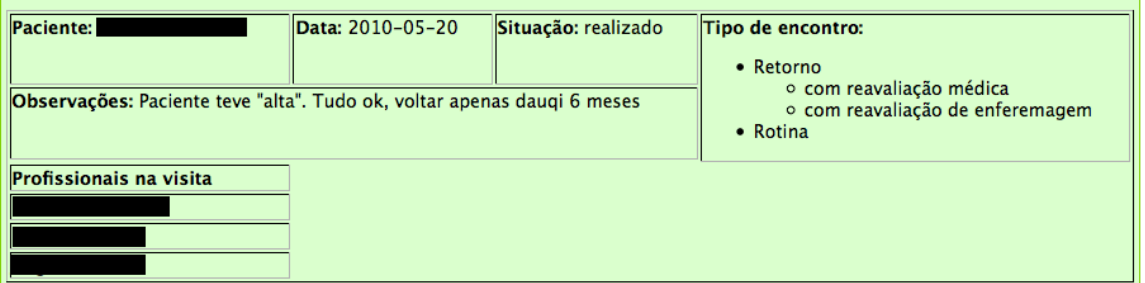

Dados Específicos

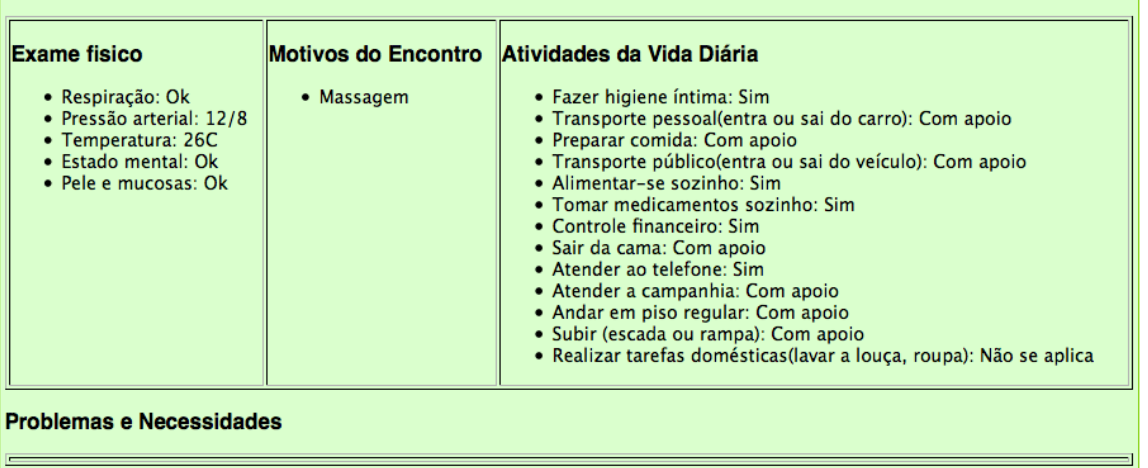

Programação Final

Retorno da APD: Retorno em 6 meses

Profissionais indicados para retorno:

Figura 5.10: Página de visualização do Encontro Domiciliar no SAGUISaúde 


\section{Capítulo 6}

\section{Implementação}

Neste capítulo, descrevemos o desenvolvimento do projeto Borboleta, abordando as metodologias adotadas, dificuldades encontradas e outras questões referentes a como o projeto vem sendo implementado. Primeiramente, é importante ressaltar que o Borboleta utiliza as metodologias de desenvolvimento comuns entre os desenvolvedores do grupo de sistemas de software do IME/USP que há uma década utiliza métodos ágeis tais como Programação eXtrema (XP) [BA04, AM02], conforme citado na Seção 5.4.2. Questões de como a Programação eXtrema foi implantada no projeto e uma análise dos pontos positivos e negativos são abordados na Seção 6.1.

O Borboleta é uma aplicação desenvolvida em Java sobre a plataforma Java ME CLDC [SUN09], como já citado no Capítulo 5.3. Decidimos utilizar o Java ME devido a sua difusão entre os dispositivos móveis, a grande maioria deles aceitam aplicativos desenvolvidos para Java ME. A especificação CLDC se destina a dispositivos móveis com recursos limitados. Isso torna mais abrangente a gama de dispositivos que podem executar o Borboleta e, geralmente, já vem instalada nos dispositivos uma máquina virtual Java que aceita aplicações que usam essa especificação. Por estarmos lidando com uma plataforma móvel, dificuldades que não temos em plataformas convencionais aparecem. Os recursos da plataforma móvel são bem limitados, principalmente com relação ao que é disponibilizado na plataforma padrão, Java SE. Parte da dificuldade já foi abordada na Seção 5.4.2, porém outras questões relacionadas a esse tema e a outros recursos do Java ME serão abordadas na Seção 6.3.

\subsection{Metodologia de Desenvolvimento}

Tentamos implementar a metodologia de Programação eXtrema em sua totalidade, realizando adaptações como, por exemplo, a utilização de um cliente proxy, que é uma adaptação para situações nas quais o cliente tem limitação de tempo e horário e não pode estar com os desenvolvedores do projeto todo o tempo. Além dessa adaptação, ocorreram outras, porém foram pontuais, por um período de tempo limitado e depois foram abandonadas, pois foram tomadas para suprir uma situação que a equipe estava vivendo. Talvez, a principal dessas adaptações temporárias foi a que Auer et al. [AM02] chama de Lone Wolf, na qual uma única pessoa faz o trabalho todo sozinha, pois não tem uma equipe disponível no momento.

Sobre outros os aspectos da metodologia, XP pode ser resumida em três fases: planejamento, desenvolvimento e entrega. O planejamento ocorre ao observar necessidade de alteração no software, ou por surgimento de funcionalidades novas ou por correções/adaptações de funcionalidades existentes; de forma simples, as alterações são mapeadas e selecionadas para o desenvolvimento. 
Para o registro inicial dessas funcionalidades nós usamos cartões de cartolina, onde são registradas brevemente o que é requisitado. Com isso em mãos, pudemos acompanhar e dividir de tarefas entre as equipes de desenvolvimento. Para facilitar o gerenciamento, os cartões foram transcritos para uma ferramenta chamada XPlanner [Mor], que ajuda a gerenciar o desenvolvimento das funcionalidades. Caso seja uma correções ou sugestões em funcionalidades já existentes, não criamos cartões, nós registramos o ocorrido na ferramenta Trac [Sof], que é um sistema de bugtracking. Durante o processo de desenvolvimento, a especificação da funcionalidade é aprimorada com a ajuda do cliente, no nosso caso um cliente proxy, fazendo parte do desenvolvimento e analisando o resultado do software sempre que possível.

Além disso, usamos a técnica de programação em pares que reduz o número de erros de desenvolvimento e aprimora o foco dos desenvolvedores no sistema. Além disso, os testes de unidade e de aceitação executando a sempre que necessário garantem que não sejam inseridas falhas nas funcionalidades durante a implementação. A fase de entrega ocorre quando fechamos uma versão e entregamos ao cliente, que, por sua vez, realiza mais testes para verificar se confere plenamente com as funcionalidades especificadas. Tivemos como meta minimizar o tempo entre as versões, fazendo com que o processo total dure em média um mês, no entanto, infelizmente, na maioria dos casos, essa meta não foi atingida e a entrega de novas versões ao cliente tipicamente aconteceu a cada três ou seis meses, dependendo do término do desenvolvimento das funcionalidades prioritárias para aquela versão. Para o controle de versões utilizamos a ferramenta Subversion [Tig].

\subsection{Desenvolvimento da Interface Gráfica do Sistema Móvel}

Como na Seção 5.4.2, a interface do Borboleta mudou de arcabouço de interface, do LCDUI (padrão do Java2ME) para LWUIT (biblioteca com diversos ganhos com relação a componentes e apresentação). Mas, ao alterar o arcabouço, seria necessário mudar todas as telas do sistema. Aproveitamos a oportunidade para reformular a navegação e a forma de trabalhar com o PDA, já que a equipe de saúde tinha apontado dificuldades no uso do sistema devido à forma como a interface foi construída. A seguir mostraremos como remodelamos as telas do sistema, junto com os profissionais de saúde, evitando assim reimplementações desnecessárias na interface.

\subsubsection{Construindo a nova interface}

Quando decidimos trocar a biblioteca gráfica também já sabíamos que remodelaríamos a interface inteira do sistema móvel. Para fazermos essa remodelagem, adotamos uma técnica onde desenhamos em cartões as telas do sistema. Nós já tínhamos as funcionalidades enumeradas e uma ideia básica do que seria. Assim, junto com uma pessoa da equipe de saúde, desenhamos nos cartões as telas do borboleta.

Os desenhos não precisavam ter detalhes minuciosos sobre os dados, bastava apenas que eles nos guiassem na hora de ajeitar os componentes nos formulários e como faríamos a organização deles. Utilizamos Post-its de cor laranja para mostrar o conteúdo dos menus daquele formulário; não colocamos em todos, apenas nos relevantes, como no caso do Encontro. Apesar dos desenhos terem ficado rústicos e com várias rasuras, eles guiaram bem o desenvolvimento da interface nova.

A Figura 6.1 mostra algumas das telas projetadas nos cartões.

Para o projeto de telas ainda elaboramos um diagrama que mostra os fluxos de navegação no 


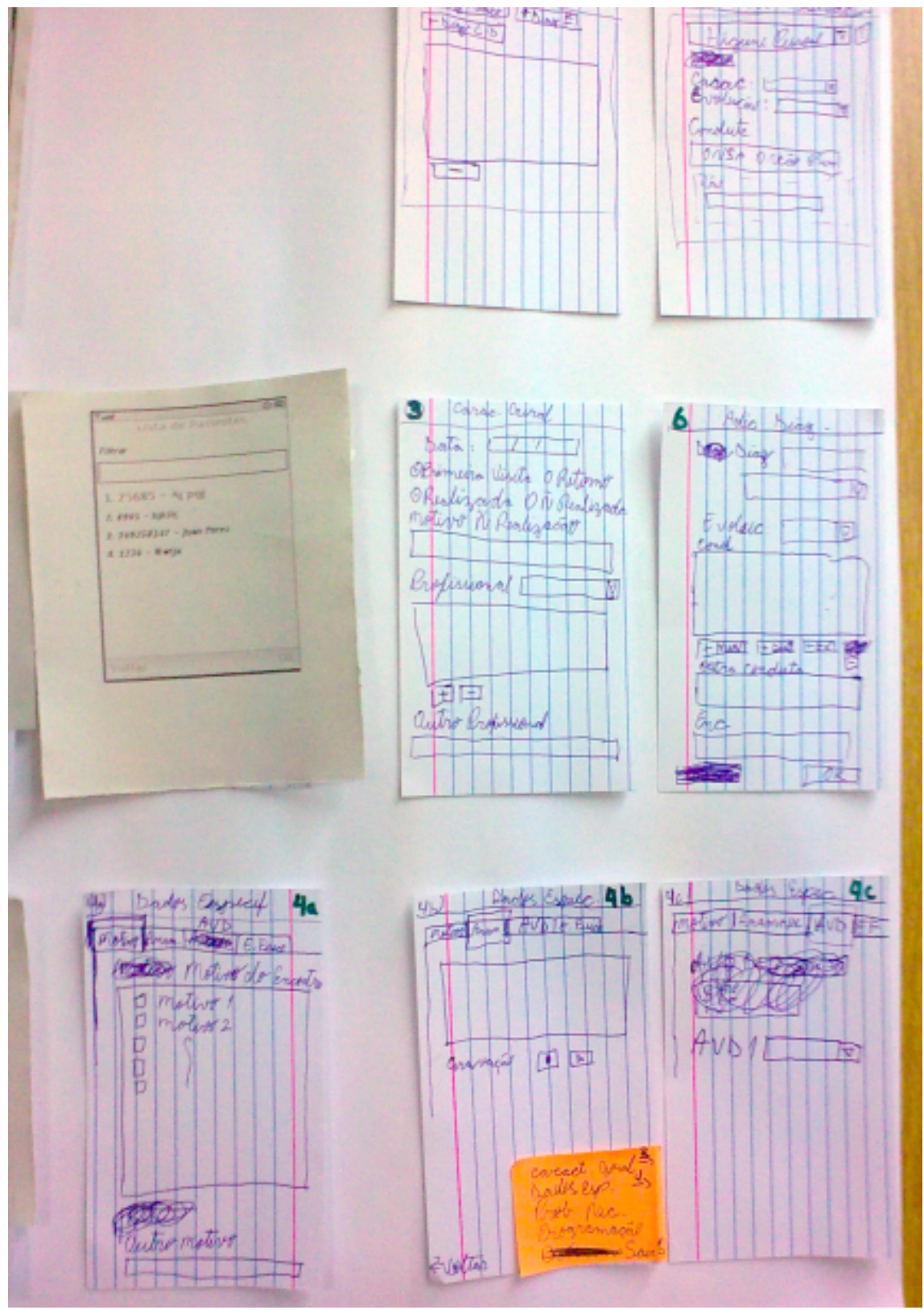

Figura 6.1: Mural com os cartões que representam as telas do Borboleta

sistema móvel. A Figura $6.2{ }^{1}$ mostra esse diagrama, as caixas representam as telas do Borboleta e os caminhos são as ações disponíveis em cada tela.

\subsection{Dificuldades de Desenvolvimento}

Durante o desenvolvimento, a equipe passou por algumas dificuldades, algumas são normais de um projeto, por exemplo, resolver algum bug inusitado; outras são problemas que requerem uma atenção especial. Um exemplo é o fato de o emulador usado para testar o aplicativo móvel na máquina de desenvolvimento apresentar um comportamento diferente da máquina virtual Java que está instalada no dispositivo móvel. Nesse caso, a equipe de desenvolvimento gastou muito tempo tentando encontrar o problema e qual o ponto exato onde estavam usando recursos do emulador

\footnotetext{
${ }^{1} \mathrm{O}$ diagrama abaixo se encontra ampliado no Apêndice B.1
} 


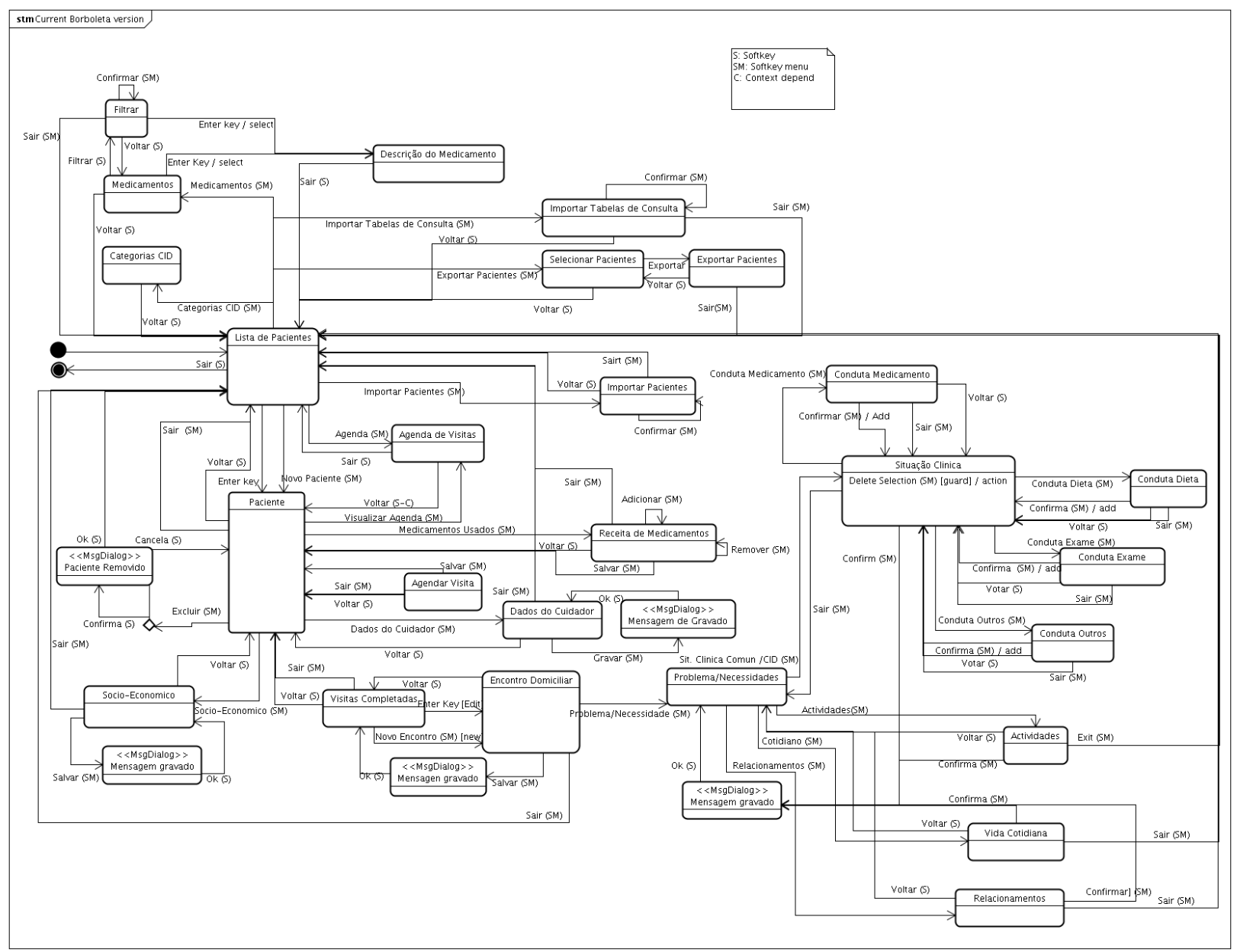

Figura 6.2: Diagrama de navegação do Borboleta

que não eram disponíveis na máquina virtual Java instalada no PDA ou telefone celular.

Outra dificuldade encontrada foi a divisão das equipes de desenvolvimento. No Borboleta, existiam duas equipes trabalhando com o sistema móvel, uma no IME-USP, outra na UNIFESP, em São José dos Campos, que tinha o trabalho mais focado na integração de recursos multimídia ao Borboleta $\left[\mathrm{CdCK}^{+} 09\right]$. A interação entre as equipes foi feita de duas formas. A primeira é o desenvolvimento em paralelo das duas equipes, trabalhando em funcionalidades diferentes, e a segunda é o desenvolvimento conjunto em "maratonas de programação" realizadas ao longo de alguns dias no IME ou na UNIFESP, quando toda a equipe trabalhou num mesmo conjunto de funcionalidades em um mesmo espaço físico.

Mais uma dificuldade foi o fato de tentarmos deixar o Borboleta o mais abrangente, com relação aos dispositivos que podem executá-lo. Tanto a equipe de desenvolvimento, quanto a equipe de saúde tentaram utilizar diversos tipos de dispositivos, porém apenas uma pequena gama de dispositivos foram aptos a executar o Borboleta, ainda mais com a utilização da biblioteca gráfica LWUIT. Depois de vários testes, chegamos a apenas duas gamas de dispositivos que satisfazem as exigências da equipe do projeto: os do fabricante HTC, com a Java VM JBed instalado e os celulares inteligentes do fabricante Nokia que utiliza uma Java VM própria. Atualmente, temos testado também a JVM feita pela Sun que tem como nome do projeto phoneME [Mic], ela está licenciada sob a GPL, porém só existe compilação para Windows/ARM que é a plataforma de hardware do dispositivo do fabricante HTC. Alguns experimentos preliminares mostraram também a possibilidade de executar 
o Borboleta em celulares OpenMoko e Android, mas para isso ocorrer realmente, mais trabalhos teriam que ser desenvolvidos.

A máquina virtual phoneME tem alguns prós e contras em relação à JBed, fornecida pelo fabricante. O principal problema é que ele muda totalmente a forma de trabalhar e redesenha toda a tela sem utilizar componentes fornecidos pelo sistema operacional, isso (somado ao uso do LWUIT) deixa o sistema com uma perda de desempenho considerável. Essa característica pode também ser analisada como um ponto a favor, já que isso deixa a forma de trabalhar mais padronizada ainda. Outro problema é que tem componentes muito feios, como componente de calendário. Agora como ponto positivo é a estabilidade e fidelidade da JVM em relação ao que esperamos da API, fora que observamos que a JVM é mais estável do que a JBed.

\subsection{Como o Borboleta funciona em campo?}

Até o momento da escrita desta dissertação, o Borboleta não entrou em ambiente de produção, portanto não temos dados de como os avanços deste aplicativo impactou o trabalho dos profissionais de saúde. No entanto temos feitos vários testes e ajustes para que essa meta se torne uma realidade. Por essa razão, nesta seção descreveremos como é o uso do Borboleta integrado com o SAGUISaúde durante o processo de registro de uma visita, desde o momento de carga dos dados no Centro de Saúde até a descarga deles, também realizada no centro, após o período de visita.

A primeira funcionalidade é a escolha dos pacientes que serão sincronizados com o Borboleta. Essa escolha é feita a partir do SAGUISaúde e respeita as políticas de inscrição de pacientes para o Programa de Atenção Primária Domiciliar do Centro de Saúde. A Figura 6.3 mostra a página Web onde é feita tal seleção. Note que os pacientes selecionados não tem relação com quem vai ser atendido no período da visita. Os nomes dos pacientes foram apagados da figura para respeitar sua privacidade.

Supondo que já tenha sido feita a escolha de pacientes, todo início de período de visita, o profissional de porte do dispositivo móvel sincroniza os dados com o servidor SAGUISaúde. A Figura 6.4 mostra a tela de importação usada para requisitar os dados do servidor e copiar para o celular. Depois de importado os dados dos pacientes, eles se encontram disponíveis na tela Lista de Paciente (como mostra a Figura 6.5), nesta tela o profissional pode filtrar os pacientes pelo nome e escolher qual paciente está sendo visitado. O que leva para a tela de Informação do Paciente que contém os dados detalhados dos pacientes conforme a Figura 6.6. Neste caso, ela já mostra também o menu presente, onde o profissional pode escolher a opção Lista de Encontros para visualizar a lista de encontros registrados para aquele paciente; o SAGUISaúde está configurado para enviar apenas os 3 últimos encontros, essa medida foi tomada devido à limitação de recurso de armazenamento no PDA. A Figura 6.7 mostra isso: as datas listadas são as datas de cada encontro realizado; os dados são de teste por essa razão as datas estão duplicadas. Pressionando o botão Novo no canto inferior esquerdo da tela, o profissional pode iniciar o registro de um novo Encontro.

A Figura 6.8 mostra o menu de divisões do Encontro; note que existem quatro botões, cada um deles leva para uma parte do registro da visita. A primeira parte do registro da visita é a Caracterização Geral (Figura 6.9); nesta área, é informado os dados básicos da visita, como a identificaçãos se o Encontro é o primeiro realizado com o paciente, motivação da visita e outros dados. Depois desses dados, o profissional pode começar a coletar os Dados Especificos desse encontro. Nessa 
tela, existem quatro abas onde ele pode registrar os seguintes dados: Motivo da visita, Anamnese, Atividade da Vida Diária, Exame Físico. A Figura 6.10 mostra a tela de Dados Específicos, com o foco na aba de Atividade da Vida Diária.

A próxima parte do Encontro a ser coletada é, talvez, a parte mais extensa da coleta que se chama Problemas e Necessidades. Nesta parte, são registrados as Situações Clínicas, Cuidados e Atividades do paciente, Aspectos do Cotidiano e Relacionamentos entre o paciente e a equipe de saúde, entre o paciente e o cuidador e uma avaliação final da equipe da APD. Vamos começar pela Situação Clínica, cuja a Figura 6.11 mostra a tela de listagem delas. Os botões Diag. Comum e Diag. CID são usado para registrar uma nova Situação Clínica. O primeiro usa a listagem de diagnósticos comuns e o segundo os diagnósticos usando a tabela CID. Pressionando um dos dois botões, o profissional é levado à tela de registro de Situação Clínica (Figura 6.12); aqui irei mostrar apenas a tela de diagnóstico comum, pois as duas formas de registro são semelhantes. Na tela de registro da Situação Clínica, pode-se escolher qual o diagnóstico observado do paciente, sua evolução e as condutas que a equipe de saúde prescreveu ao paciente, cujo o registro aparece na Figura 6.13. Após registrar as Condutas e finalizar o registro da Situação Clínica, o profissional pode retornar à tela de Problemas e Necessidades e prosseguir com o registro dos Cuidados e Atividades do paciente, conforme mostra a Figura 6.14 que expõe a listagem de tipos de cuidado que podem ser preenchidos (cujo a tela de registro está na Figura 6.15). Após o registro dos Cuidados e Atividades, o profissional pode cadastrar uma Condiçẫo de Vida Cotidiana, cuja tela pode ser vista na Figura 6.16. Depois, na Figura 6.17, vem o registro dos Relacionamentos.

Ao terminar com os registro dos Problemas e Necessidades o profissional passa para a coleta das informações de Programação Final. A Figura 6.18 mostra a tela onde os profissionais informam os dados sobre a próxima visita e qual a composição recomendada para a mesma. Assim, finaliza o registro de um Encontro Domiciliar. É importante ressaltar que os dados da visita são armazenadas duas vezes por minuto na memória do PDA, assim se o profissional tiver que parar a coleta e fazer algum procedimento a perda de dados é minimizada. Por fim, após o período de visitas, a equipe retorna ao Centro de Saúde e o responsável precisa sincronizar os dados coletados com o servidor. Dessa forma, ele realiza a operação de Exportação de dados dos Pacientes coletados, cuja tela pode ser vista na Figura 6.19. Então, os dados são passados para o SAGUISaúde e podem ser vistos como mostra a Figura 5.10 na Seção 5.4.3. 


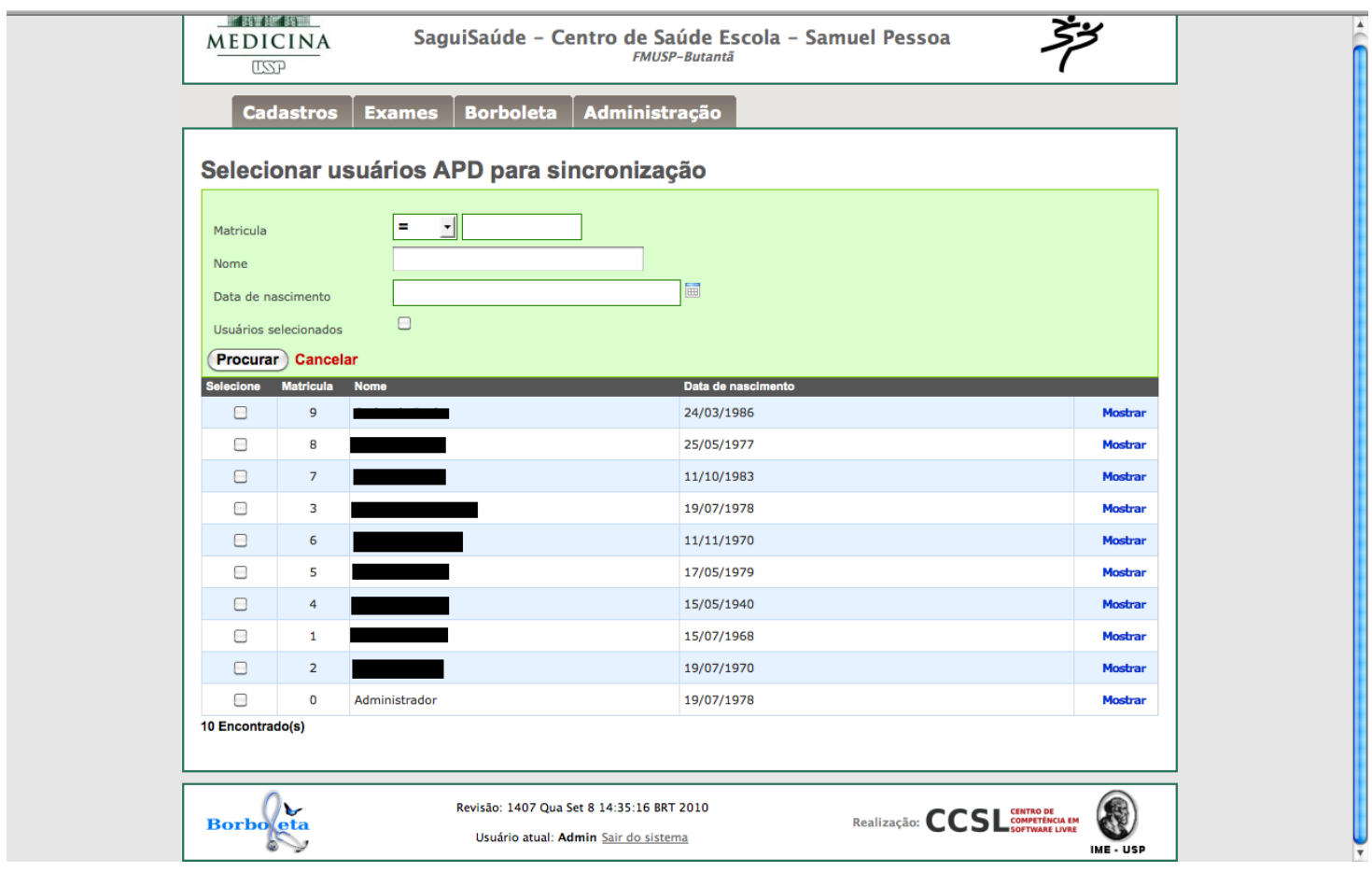

Figura 6.3: Tela do SAGUISaúde com a seleção dos pacientes que pertencem ao PAPD

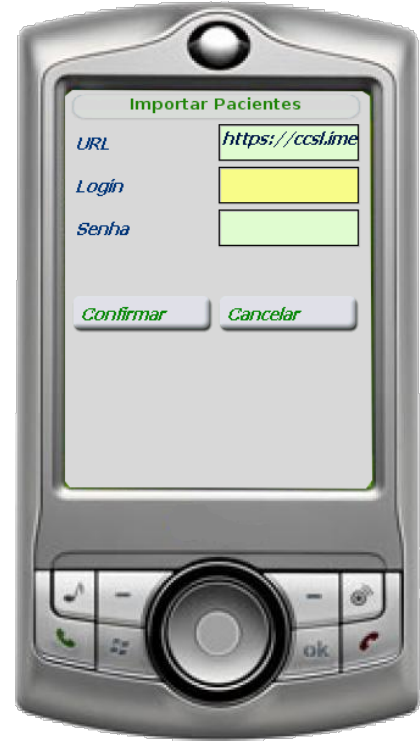

Figura 6.4: Tela do Borboleta de importação dos dados dos pacientes

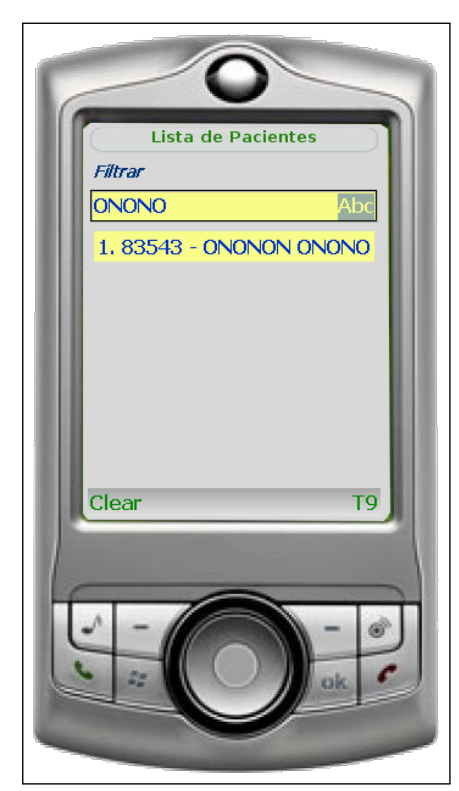

Figura 6.5: Tela Lista de Pacientes do Borboleta 


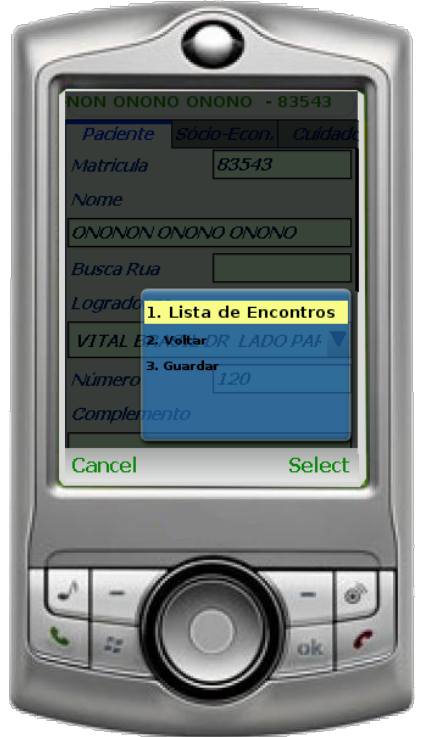

Figura 6.6: Tela de Informação do Paciente

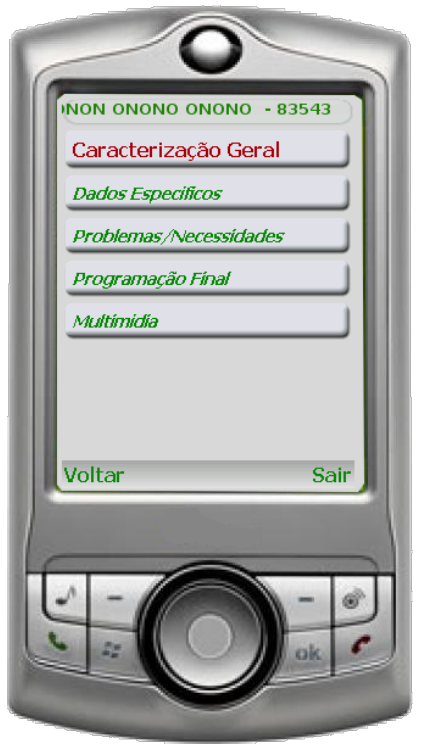

Figura 6.8: Tela de Menu do Encontro

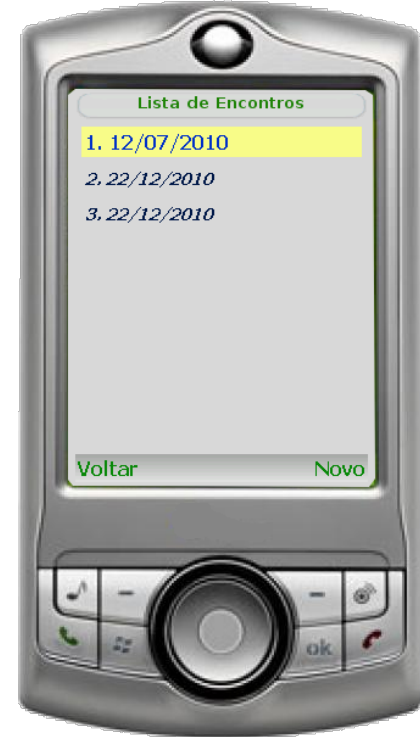

Figura 6.7: Tela de Lista de Encontro

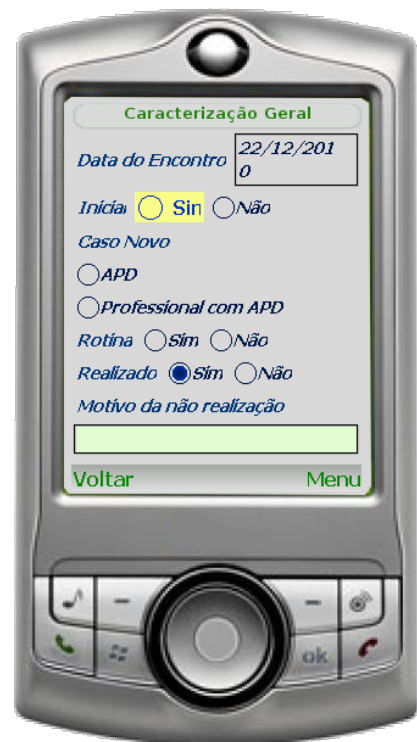

Figura 6.9: Tela de Caracterização Geral 

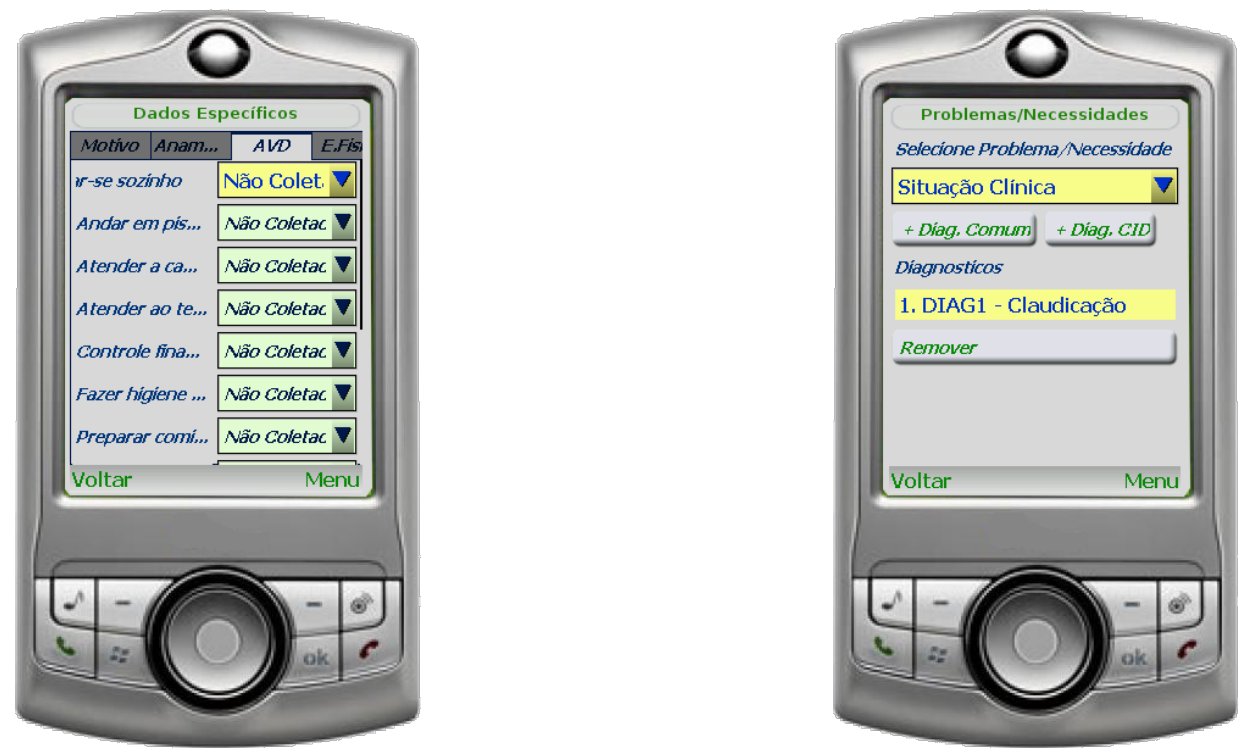

Figura 6.10: Tela de Dados Específicos do Encontro Figura 6.11: Tela de Listagem das Situações Clínicas

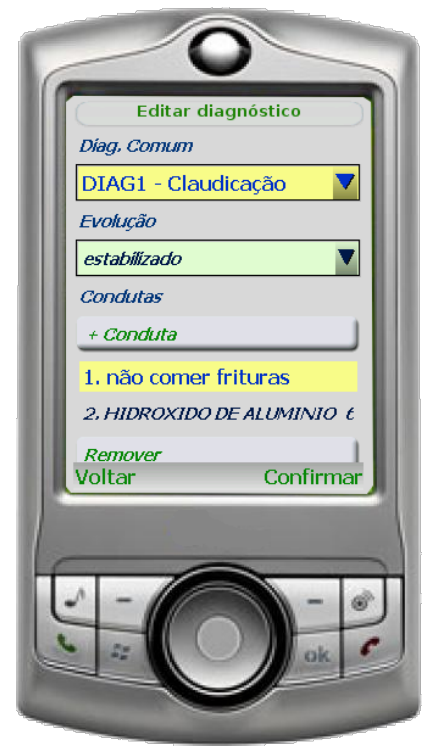

Figura 6.12: Tela de Registro da Situação Clínica - Figura 6.13: Tela de Dialogo de Registro de Conduta Diagnóstico Comum

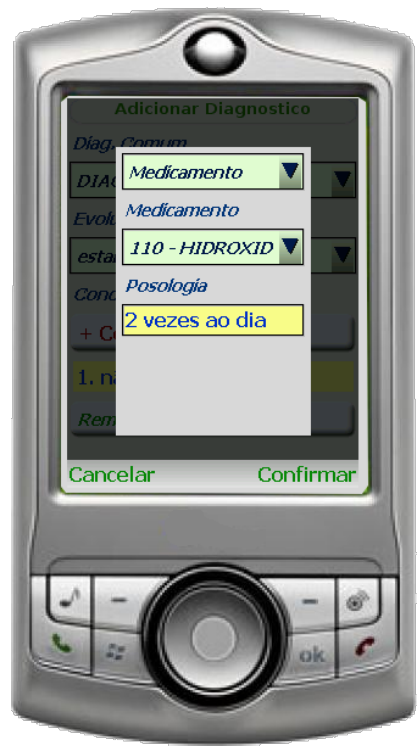

da Situação Clinica 

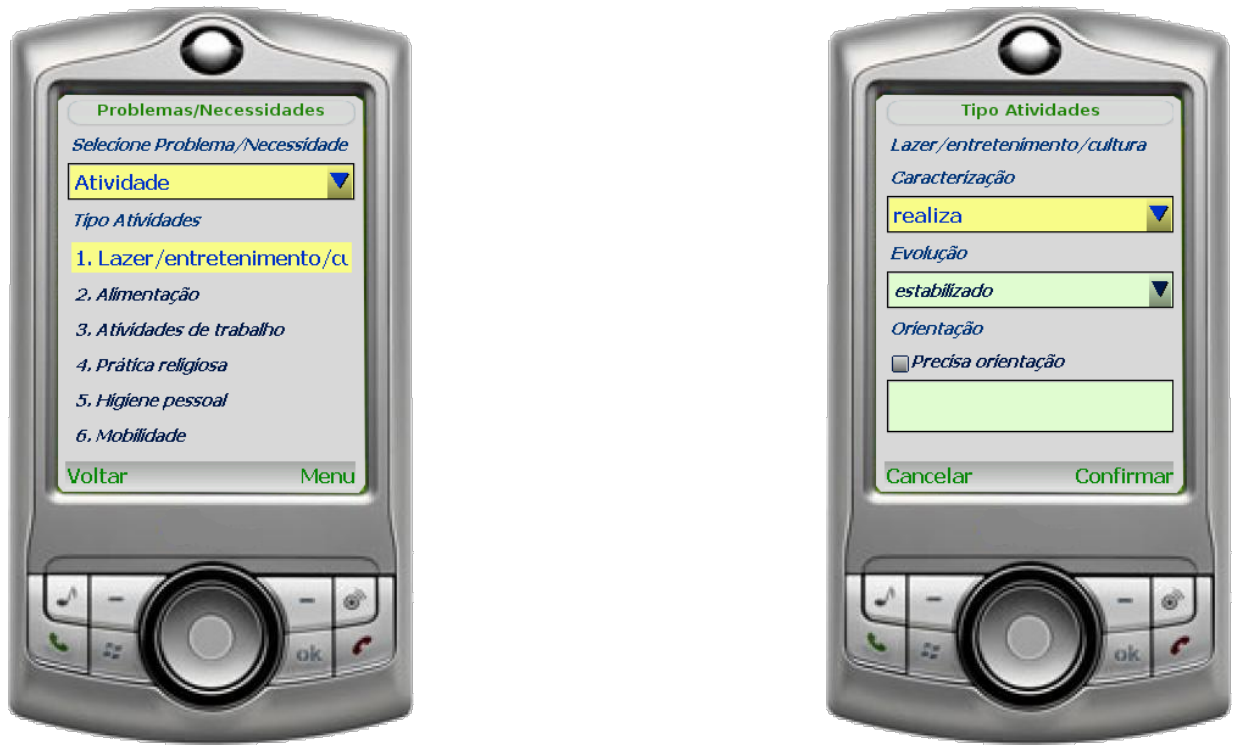

Figura 6.14: Tela de Listagem dos Cuidados e Ativi-Figura 6.15: Tela de Registro de um Cuidado ou dades Atividade
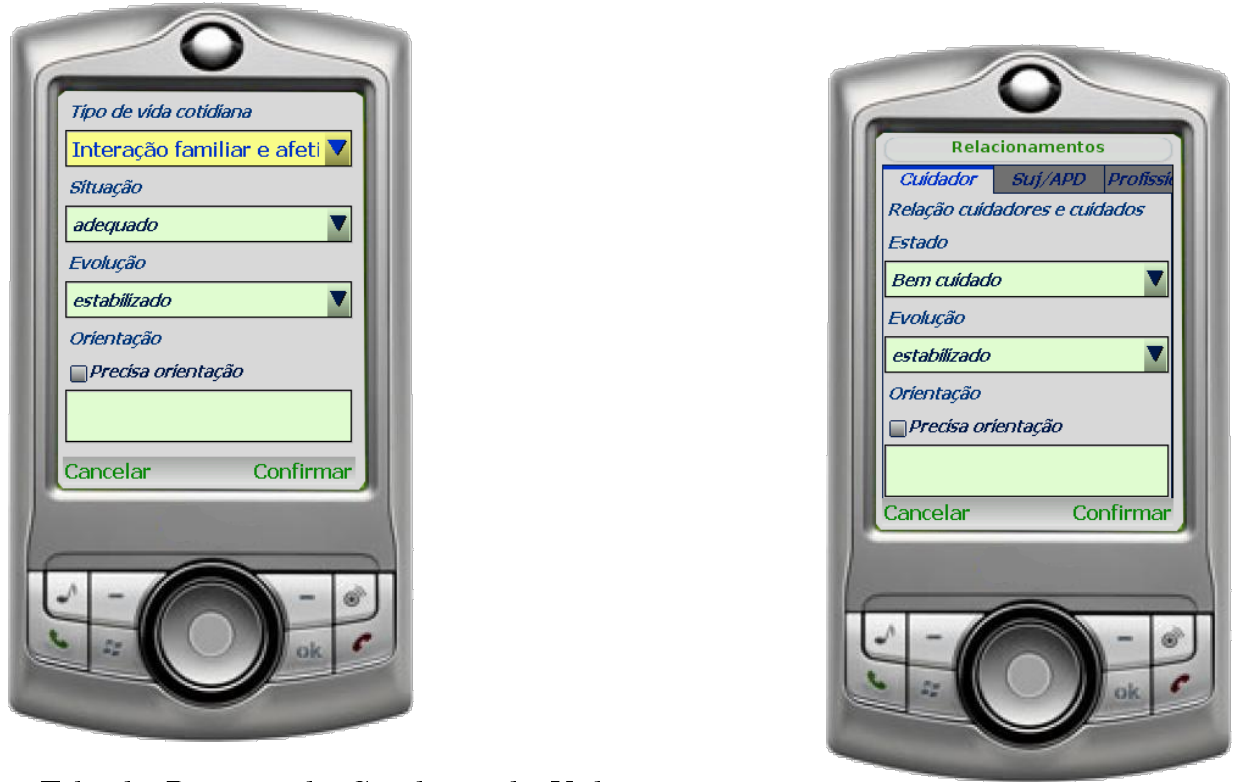

Figura 6.16: Tela de Registro de Condição de Vida Cotudiana

Figura 6.17: Tela de Registro dos Relacionamentos 

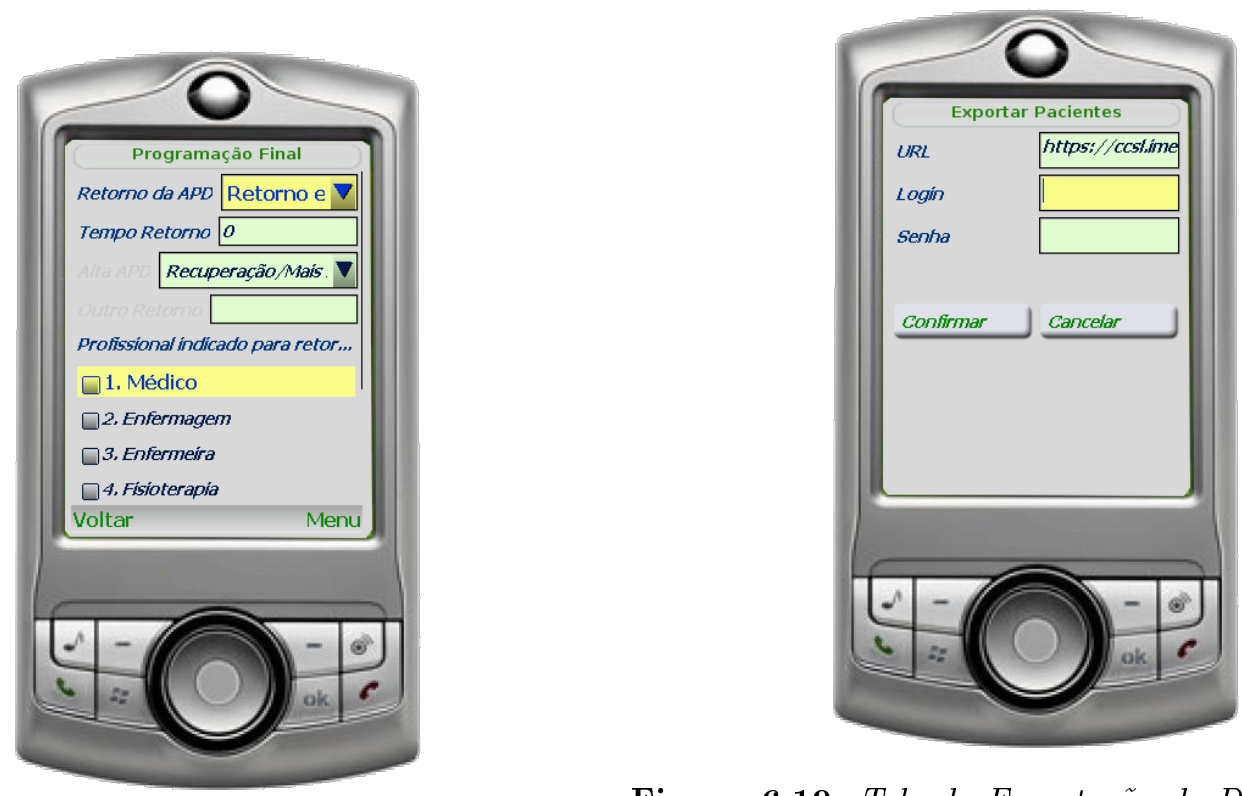

Figura 6.18: Tela de Registro da Programação Final cientes

Figura 6.19: Tela de Exportação de Dados dos Pa- 
54 Implementação 


\section{Capítulo 7}

\section{Conclusões e Trabalhos Futuros}

Concluímos aqui as questões levantadas na Seção 1.2 e discutidas ao longo deste trabalho. O primeiro ponto é sobre a análise de ferramentas e tecnologias móveis que poderiam ser utilizadas para desenvolver um sistema que auxiliasse a equipe de saúde a prestar o serviço de Atenção Primária Domiciliar. Neste quesito, pudemos ver que, por enquanto, para o nosso escopo, JavaME ainda é a melhor opção, ainda mais com o ganho de qualidade de IHM que a biblioteca LWUIT trouxe. Além disso, utilizar o conhecimento adquirido em outros projetos como OpenEHR e HL7 para guiar a modelagem do sistema agilizou a etapa onde tivemos que refazer a modelagem do Borboleta.

Uma das propostas do Borboleta foi reduzir a perda de informação gerada pela diferença de tempo entre encontro e o preenchimento do prontuário. A ideia do Borboleta de se adequar aos usuários do sistema móvel e simplificar o máximo possível a entrada de dados visa justamente trazer para a mesma hora do encontro, a captura dos dados da visita. Ainda temos que melhorar alguns fatores no sistema móvel, mas, segundo a equipe de saúde, a utilização está bem mais simples, o que deixa viável o preenchimento no local do encontro.

Outra questão que propomos é a redução de erros nos prontuários, com a modelagem atual do Borboleta e com a nova forma de coletar dados, dando preferência por dados que utilizam uma série de valores predefinidos. Assim, podemos usar mais comboboxes ou algum modo de inserção de dados que não precise de uma digitação extensa. Essa prática aumentou a quantidade e a qualidade dos dados que coletamos na visita.

Apesar de o Borboleta não ter entrado em produção, ele está em fase de teste com os profissionais de saúde e vem sendo atualizado de acordo com suas necessidades. Essas alterações são pontuais e não têm impacto na arquitetura do sistema, por exemplo, a inclusão de um campo, ou alteração na forma de tratar um determinado campo.

Por fim, esta dissertação mostrou como o Borboleta foi desenvolvido até o presente momento, no quesito de arquitetura e implementação, para resolver o problema da carência de tecnologia para o auxílio ao programa de Atenção Primária Domiciliar.

Toda a documentação e fontes do projeto Borboleta e SAGUISaúde se encontram na página do projeto, sob licença $B S D$.

\subsection{Contribuições e publicações durante o mestrado}

Com esse trabalho, queremos trazer uma solução para o auxílio ao Programa de Atenção Primária Domiciliar, tornando sua coleta de informações mais eficiente e o processo, como um 
todo, mais gerenciável. Porém, essa pesquisa não tem apenas contribuições práticas, mostrada pelo desenvolvimento do sistema, mas também gerou discussões e publicações em workshops e conferências, demonstrando a concepção e a evolução do Borboleta ao longo deste mestrado.

O primeiro artigo publicado durante esta pesquisa apresentou os conceitos básicos que permeiam o Borboleta e sua arquitetura inicial. Esse trabalho foi aceito no congresso internacional ACM-SAC'07 (XXIII ACM Symposium on Applied Computing), que é organizado pela conceituada organização ACM (The Association for Computing Machinery, Inc):

- Borboleta: A Mobile Telehealth System for Primary Homecare - Rafael Correia, Fabio Kon e Rubens Kon. Em XXIII ACM Symposium on Applied Computing. Fortaleza, Brasil, Março 2008.

Com a definição do modelo de arquitetura do Borboleta e sua interação com um sistema central, que foi chamado de SAGUISaúde. O modelo de ambos os sistemas foram concebidos e, no caso do Borboleta, readequado. Assim, tanto o sistema central, como o móvel, puderam trocar informações de forma mais eficiente. Esta adequação pode ser vista em dois trabalhos, também produzidos durante esse período de pesquisa de mestrado. Um mostrando a concepção da modelagem e o segundo focado mais na sincronização entre os sistemas:

- Análise e Modelagem Conceitual de um Sistema de Prontuário Eletrônico para Centros de Saúde - Helves H. Domingues, Rafael Correia, Fabio Kon, Rubens Kon e João Eduardo Ferreira. Em SBC - XIII Workshop de Informática Médica. Belém, Brasil, julho 2008.

\section{- Borboleta and SaguiSaúde - Open Source Mobile Telehealth for Public Home}

Healthcare - Gustavo Luiz Duarte, Rafael Correia, Pedro Leal, Helves H. Domingues, Fabio Kon, Rubens Kon e João Eduardo Ferreira. Em Med-e-Tel 2010, VIII International eHealth, Telemedicine and Health ICT Forum. Luxemburgo, Luxemburgo, abril 2010.

Outros dois trabalhos aceitos em congressos nacionais têm como tema a escolha do Borboleta como um software livre e, porque essa escolha é importante para a saúde pública, o outro trabalho aborda o uso de recursos multimídia em prontuários móveis. Ambos os assuntos impactam como o sistema é encarado e utilizado. Ambos trazem questões legais e de visão sobre a figura do Borboleta no cenário de computação móvel aplicado à saúde pública:

- Sistema Móvel Multimídia de Código Aberto para Atenção Primária de Saúde com Visitas Domiciliares - Rafael Correia, Arlindo Flávio da Conceição, Fabio Kon, Rubens Kon e José Ricardo Brandão. Em FISL - X Workshop de Software Livre. Porto Alegre, Brasil, julho 2009

- Projeto Borboleta: Ferramentas Móveis e Multimídia para Atenção Básica Domiciliar - Arlindo F. da Conceição, Rafael L. Pereira, João V. P. Rezende, Bruno N. M. Silva, Rafael J. P. Correia, Helves H. Domingues, Rubens Kon e Fabio Kon. Em CBIS - XI Congresso Brasileiro de Informática em Saúde. Campos do Jordão, Brasil, novembro 2008. 


\subsection{Trabalhos futuros}

Existem muitas linhas de trabalho que podem ser seguidas a partir da pesquisa descrita nesta dissertação. Uma delas é trazer o conceito de arquétipos, utilizado pelo OpenEHR, para uma plataforma móvel. Para esse desafio, existem questões relativas à adaptação do Borboleta a metadados definidos pelos profissionais de saúde utilizando a especificação do OpenEHR.

Outro trabalho é analisar o impacto que a versão de produção do Borboleta causará na forma de trabalho dos profissionais de saúde. Essa análise requer vários pontos a serem analisados, pontos esses que precisam ser discutidos com os profissionais de saúde, mas dois bem claros são a agilidade da captura de dados utilizando o dispositivo móvel e a quantidade de erros que os prontuários coletados apresentam. Um estudo desse porte teria um impacto positivo para a adoção de tecnologia móvel no campo da medicina preventiva, ainda mais para um serviço de saúde público.

\subsubsection{Proposta de um estudo do impacto do Borboleta}

Esta seção tem por objetivo levantar uma proposta de experimentação para medir o impacto do Borboleta no processo do Programa de Atenção Primária Domiciliar. Sabemos que o uso de dispositivos móveis e a digitalização dos prontuários já traz o benefício da facilidade de gerenciamento do processo. Porém, queremos propor a medição de outros aspectos nos quais o Borboleta também pode ter uma influência.

\section{Definição}

Esta proposta de experimento visa medir e analisar os ganhos e perdas do uso do sistema móvel Borboleta na rotina de uma equipe de saúde do Programa de Atenção Primária Domiciliar. Queremos testar se o uso da ferramenta desenvolvida traz ganhos em relação ao uso de prontuários em papel. Na Seção 3.2 são descritos os conceitos por trás do programa a ser analisado e seu processo utilizando prontuários em papel. Já na Seção 6.4 descrevemos como funciona o processo de uso do Borboleta em campo.

Portanto, queremos avaliar a diferença do uso de dispositivo móvel (com o Borboleta instalado) e os prontuários convencionais em papel, assim podemos avaliar quais os ganhos e perdas do uso de TI no contexto da Atenção Primária Domiciliar do ponto de vista da equipe de saúde.

\section{Hipóteses}

Queremos comparar dois processos para o Programa APD, o primeiro utilizando o método convencional com formulários em papel e o segundo utilizando o Borboleta. Assim, podemos levantar algumas hipóteses relacionadas a cada um dos processos:

1. Como apontado na Seção 1.2, queremos averiguar se o uso do Borboleta reduz a perda de informação dos prontuários. Nesta hipótese podemos incluir também verificação da existência de uma menor taxa de erros de prontuário com o uso da ferramenta móvel.

2. Outra hipótese é verificar se o tempo gasto com o preenchimento do Borboleta é menor que o gasto com o formulário em papel. 
Baseados nessas hipóteses informais, podemos estipular hipóteses mais formais e pensar como mediremos se tais afirmações são falsas ou verdadeiras. Os erros e perdas de informação serão somados para simplificar a análise.

1. - Hipótese Nula, $H_{0}$ - Não há diferenças entre usar o Borboleta e usar prontuário em papel com relação aos erros nos prontuários. Ou seja, os erros gerados por ambos processos são iguais e a perda de informação é a mesma. $H_{0}$ : $\operatorname{Err}($ Borboleta $)=\operatorname{Err}($ Papel)

Hipótese Alternativa, $H_{1}$ : $\operatorname{Err}($ Borboleta $)<\operatorname{Err}($ Papel $)$

Medidas necessárias: número de prontuários (Borboleta e formulário de papel) e número de erros e perdas de informação.

2. - Hipótese Nula, $H_{0}$ - O tempo médio de coleta dos dados utilizando o Borboleta e prontuário em papel é o mesmo. Ou seja, ambos os métodos demandam o mesmo tempo de coleta. $H_{0}$ : TempMedioColeta $($ Borboleta $)=$ TempMedioColeta $($ Papel $)$

Hipótese Alternativa, $H_{1}$ : TempMedioColeta(Borboleta) > TempMedioColeta(Papel)

Medidas necessárias: número de prontuários (Borboleta e formulário de papel) e tempo médio de coleta de ambos métodos. Precisamos lembrar que o tempo do formulário em papel precisa ser somado ao tempo de transcrição dos dados para o sistema digital do centro.

Dessas hipóteses, podemos tirar as seguintes variáveis independentes:

- Número de prontuários - Quanto mais prontuários coletados, melhor será avaliar a diferença das demais estatísticas. Um número razoável de prontuário (tanto de papel, quanto coletados pelo Borboleta) gira em torno de cem ou mais. Temos que levar em consideração todo o trabalho de correção para localizar erros nos prontuários. Os erros serão coletados a partir do prontuário presente no SAGUISaúde.

- Tempo gasto no preenchimento - Cada formulário, em ambas as tecnologias, tem um tempo de preenchimento. Precisamos medir esses tempos nos dois casos. Vale a pena lembrar algumas considerações. Pelo fato do Borboleta já ser um sistema digital, não é necessário coletar o tempo de transcrição do formulário para o sistema SAGUISaúde, enquanto nos formulários em papel, além do tempo de preenchimento do formulário em si, devemos contabilizar o tempo de transcrição do formulário em papel para o SAGUISaúde.

Como variáveis dependentes temos: quantidade de erros encontrados nos prontuários e o tempo médio de preenchimento dos formulários (tanto usando papel, quanto usando o Borboleta).

\section{Modelo do Experimento}

Este experimento tem o objetivo de medir o desempenho de dois modos de registrar os dados relevantes aos atendimentos domiciliares. Portanto, o objeto de pesquisa gira em torno dos registros médicos feitos, ou seja, prontuários. Os prontuários serão coletados durante um certo tempo até que cheguem ao número de cem atendimentos, para cada modo de coleta de dados. É interessante que sejam duas equipes distintas para realizar a pesquisa, pois o uso do sistema digital pode influenciar na coleta de dados em papel, e vice-versa. Cada equipe deve ter um responsável, no dia, por coletar os dados e esse profissional deve medir com um cronômetro o tempo que gasta preenchendo os 
dados dos formulários, mesmo que seja um dado pontal e que gaste poucos minutos; assim podemos refinar o experimento. Vale a pena lembrar que cada forma de trabalho tem suas diferenças e essas precisam, também, ser contabilizadas na cronometragem.

No caso do Borboleta, momentos como a sincronização deve ser contabilizado, tanto na captura dos dados quanto no envio para o SAGUISaúde. Já para o formulário em papel deve ser contabilizado o tempo de transcrição do prontuário para o SAGUISaúde, já que o mesmo será usado como base centralizadora de informação e também é nele que vai ser realizada a averiguação de erros nos prontuários.

Para uma comparação mais fiel entre os dois sistemas, é importante que ambos tenham os mesmos conteúdos. Dessa forma, é preciso formular um modelo de prontuário em papel com a mesma riqueza de conteúdo do Borboleta. No caso das situações clínicas, e outros dados que crescem indefinidamente no Borboleta, para o formulário em papel seria necessário replicar espaços para preenchimento (cinco para situação clínica e três para outros dados). O sistema Borboleta deverá ser instalado num dispositivo que execute com um desempenho bom, evitando tempo de espera por carga de formulário, com isso o usuário reduzirá a contagem do tempo gasto por ineficiência de hardware.

Para a segunda parte do experimento, verificar a confiabilidade dos métodos. O SAGUISaúde deve diferenciar se um prontuário foi transcrito de um formulário em papel ou sincronizado do Borboleta. Todas as validações referentes aos dados médicos devem ser retiradas; apenas validações cadastrais devem ser feitas, pois não estamos usando o sistema central como um facilitador do prontuário em papel e sim inserindo o tempo gasto de transcrição. O SAGUISaúde deve também ter um campo, aberto apenas para o corretor, informando a quantidade de erros encontrados no prontuário armazenado.

\section{Execução}

Seria bom ter duas equipes diferentes para realizar o experimento. Cada uma usando uma técnica diferente. Uma delas receberia um smartphone com o Borboleta instalado e outra, o formulário em papel. Cada uma coletaria cem prontuários e sincronizaria com o sistema central. Sabemos que existem dois tipos de visitas: caso novo e caso recorrente. Os casos novos devem ser equilibrados entre as duas equipes, pois costumam ter mais dados e demandar mais tempo de coleta. Além disso, o responsável pela coleta em cada grupo deve cronometrar o tempo gasto com o preenchimento do prontuário.

\section{Análise dos dados}

Com os dados coletados, podemos verificar as hipóteses levantadas anteriormente. A coleta e dados, a exposição e análises que podem ser retiradas desse experimento não serão descritas aqui, pois o objetivo desta seção é apenas dar um guia de como pode ser montado um experimento e uma sugestão de indicadores e variáveis que podem ser analisadas. Vale relembrar que uma comparação entre as duas formas de trabalho com o Programa APD apresentadas aqui seria uma forma interessante de validar cientificamente o nosso trabalho demonstrando, através de um experimento controlado, os benefícios do uso da tecnologia móvel para o ambiente de atenção primária domiciliar. 


\subsection{Considerações Finais}

Essa pesquisa, realizada durante quatro anos na área de computação móvel aplicada a dispensação de saúde, mostraram vários desafios que precisam ser transpostos. Cada vez mais a tecnologia chega em ambientes diversos trazendo uma melhora em tratar a informação. É gritante a evolução na tecnologia móvel e cada vez mais smartphones e tabblets tornam-se mais presentes na vida das pessoas. Com isso, a aceitação dessas tecnologias aumentará e, com a popularização delas, mais plataformas de desenvolvimento melhores e mais fáceis surgirão. Consequentemente, aplicações mais específicas, como o Borboleta, terão menos problemas para serem desenvolvidas, também pelo fato do poder de processamento dos dispositivos aumentarem. 
Apêndice A

Formulários APD 


\begin{tabular}{|c|c|c|}
\hline \multicolumn{3}{|c|}{$\begin{array}{c}\text { ATENDIMENTO DE ENFERMAGEM - FERIDAS } \\
\text { NO DOMICÍLIO } \\
\text { APD }\end{array}$} \\
\hline 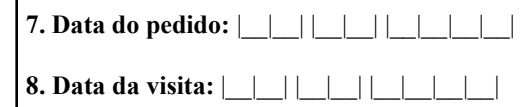 & 9. $N^{o}$ de matrícula & $\begin{array}{r}\text { Horário entrada: } \\
\text { Saída: }\end{array}$ \\
\hline 11. Visita para & L_ Pessoa & $L_{1}$ Contato $\mathrm{c} /$ \\
\hline
\end{tabular}

1. Resumo do caso e motivo da visita:

2. Plano de visita:

3. Avaliação do cuidado existente:

4. Avaliação do estado de saúde (referido e exame físico):

\section{Avaliação da ferida}

\begin{tabular}{|l|l|}
\hline a. Características do tecido & b. Características do exsudato \\
( ) granulação & ( ) seroso \\
( ) esfacelo & ( ) serosanguinolento \\
( ) necrose & ( ) sanguinolento \\
( ) epitelização & ( ) purulento \\
& ( ) ausente \\
\hline
\end{tabular}

c. Outros achados d. Cor da pele ao redor

Figura A.1: Formulário de Atendimento de Enfermagem 
Tem dificuldades em realizar as seguintes atividades?

Assinalar um $\mathrm{X}$ quando a resposta for afirmativa:

1. Fazer sua higiene intima

( ) Porquê?

Quem ajuda

2. Preparar a comida

( ) Porquê?

Quem ajuda

3. Alimentar-se sozinho

( ) Porquê?

Quem ajuda

4. Tomar sozinho os medicamentos ( $\quad$ Porquê?

Quem ajuda

5. Controlar seu dinheiro

( ) Porquê?

Quem ajuda

6. Sair da cama

( ) Porquê?

Quem ajuda

7. Atender o telefone

( ) Porquê?

Quem ajuda

8. Atender a campainha

( ) Porquê?

Quem ajuda

9. Andar em piso regular

( ) Porquê?

Quem ajuda

10. Subir (escada ou rampa)

( ) Porquê?

Quem ajuda

11. Realizar tarefas domésticas (lavar a louça, a roupa, varrer e tirar pó) ( )Porquê?

Quem ajuda

12. Transporte pessoal (entra ou sai do carro)

( ) Porquê?

Quem ajuda

13. Outros veículos (entra ou sai do veículo público) ( ) Porquê?

Quem ajuda

14.Outras atividades/tarefas verbalizadas pelo paciente

7.Avaliação da qualidade de vida:

Figura A.2: Formulário de Atendimento para Novo Paciente 


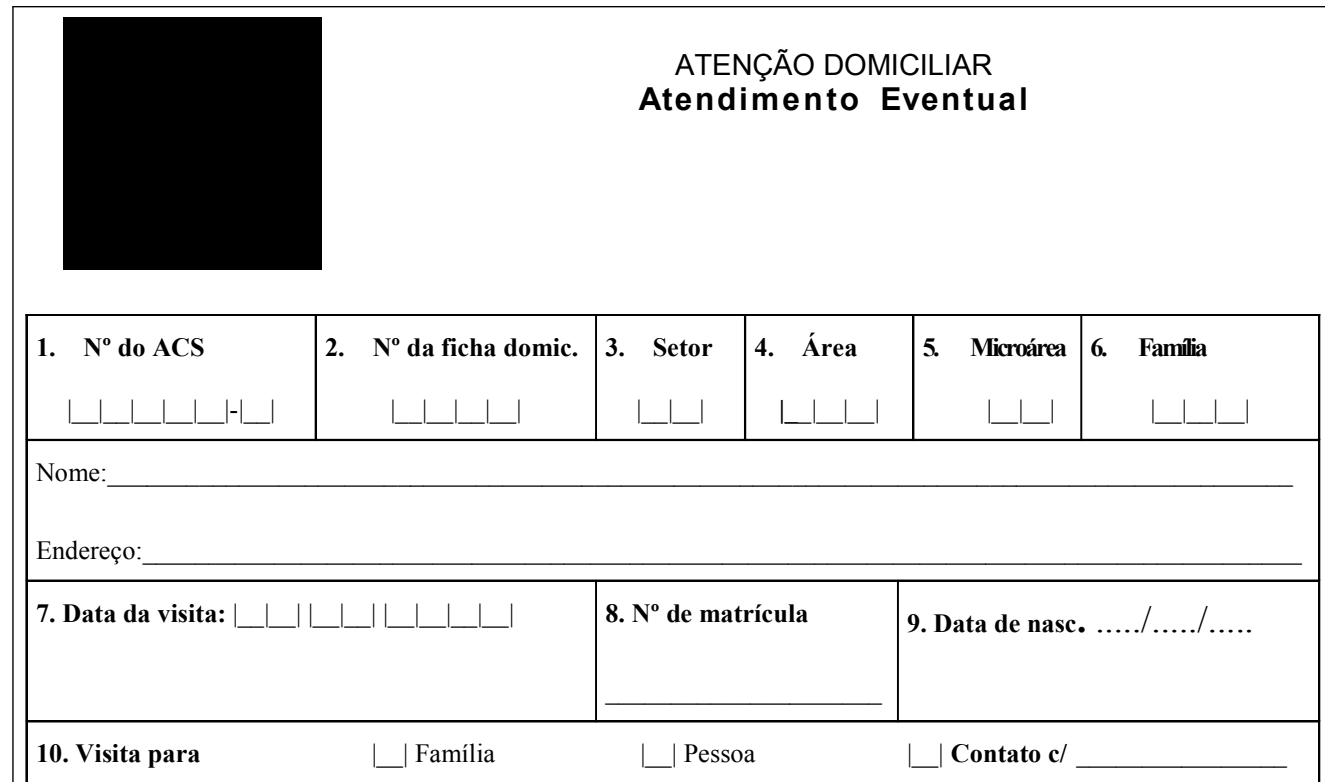

1. Motivo do atendimento:

2. Evolução do problema:

3. Avaliação do estado de saúde:

Figura A.3: Formulário de Atendimento Eventual 
9.Hipótese diagnostica/fatores de risco/problemas:

10.Conduta:

a) Medicamentos:

b) Procedimentos:

c) Orientações:

d) Cuidados:

e) Adaptações no ambiente:

f) Exames complementares:

g)Outros:

Figura A.4: Formulário de Atendimento Continuidade do Tratamento 
Apêndice B

Diagrama de navegação do Borboleta 


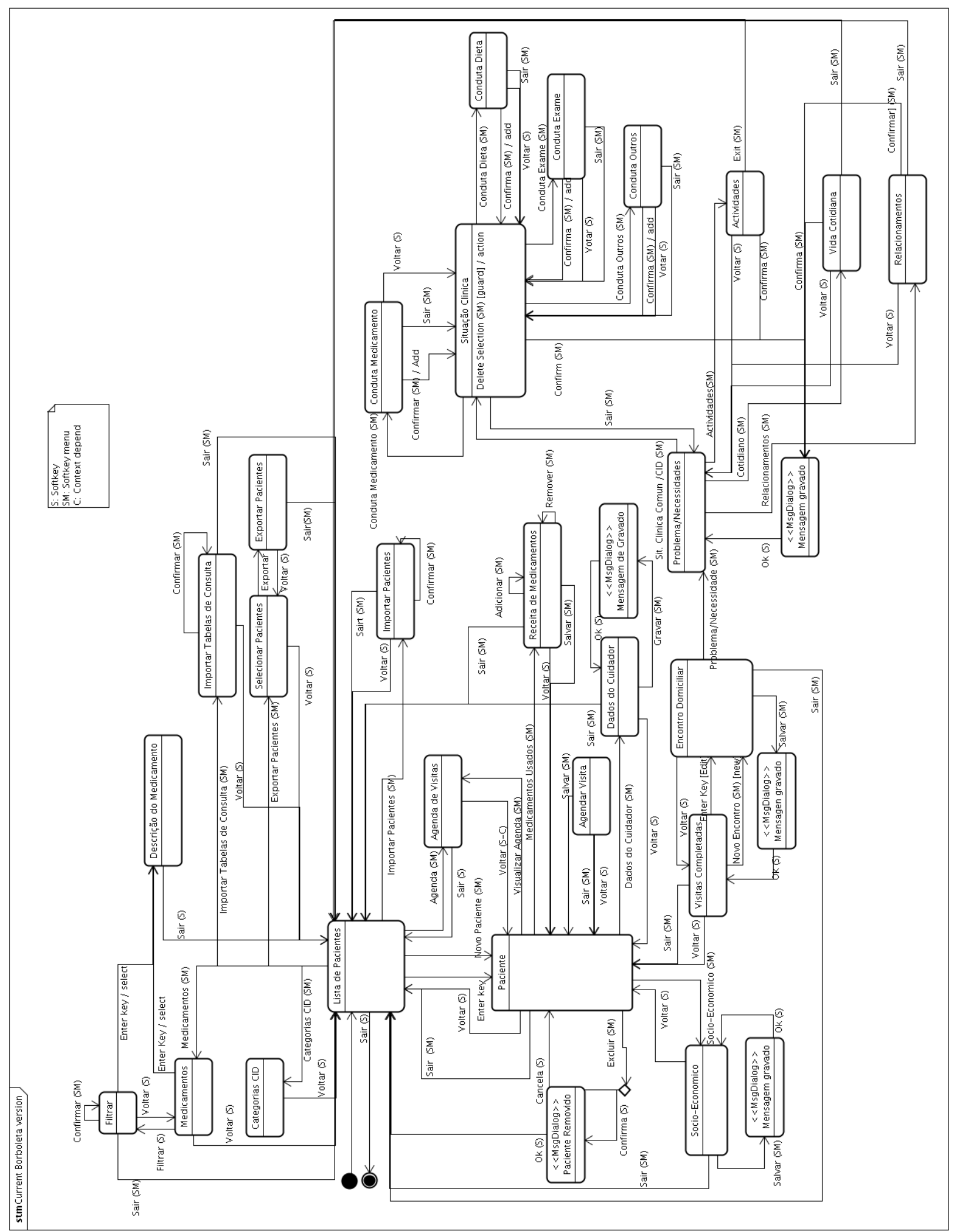

Figura B.1: Diagrama de navegação do Borboleta 


\section{Bibliografia}

[ABBH00] Elske Ammenwerth, Anke Buchauer, Bernd Bludau e Reinhold Haux. Mobile information and communication tools in the hospital. International Journal of Medical Informatics, 57:21-40, 2000. 11

[AM02] Ken Auer e Roy Miller. Extreme Programming Applied: Playing to Win. AddisonWesley, 2002. 43

[BA04] Kent Beck e Cynthia Andres. Extreme Programming Explained: Embrace Change, 2nd Edition. Addison-Wesley, 2004. 37, 43

[Bau05] Daniel C. Baumgart. Personal digital assistants in health care: experienced clinicians in the palm of your hand? The Lancet, 366(9492):1210-1222, October 2005. 11

[Bee98] George W. Beeler. HL 7 Version 3 - An object-oriented methodology for collaborative standards development. International Journal of Medical Informatics, (48):151-161, 1998. 14, 31

$\left[\mathrm{BEG}^{+} 03\right] \quad$ David W. Bates, Mark Ebell, Edward Gotlieb, John Zapp e H.C. Mullins. A Proposal for Electronic Medical Records in U.S. Primary Care. The Impact of Mobile Handheld Technology on Hospital Physicians Õ Work Practices and Patient Care: A Systematic Review, 10(1):1-10, Jan 2003. 3, 6, 33

[BH07a] Thomas Beale e Sam. Heard. An Ontology-based Model of Clinical Information. Medinfo 200\%: Proceedings of the 12th World Congress on Health (Medical) Informatics, páginas 760-764, 2007. 12, 31, 34

[BH07b] Thomas Beale e Sam Heard. openEHR Architecture: Architecture Overview. openEHR Fundation, 2007. 12, 13

$\left[\mathrm{BSB}^{+} 07\right] \quad$ R. Blaser, M. Schnabel, C. Biber, M. Bäumlein, O. Heger, M. Beyer, E. Opitz, R. Lenz e K.A. Kuhn. Improving pathway compliance and clinician performance by using information technology. International Journal of Medical Informatics, 76(2-3):151 - 156, 2007. Connecting Medical Informatics and Bio-Informatics MIE 2005. 9

$\left[\mathrm{BSM}^{+} 04\right] \quad$ R. Blaser, M. Schnabel, D. Mann, P. Jancke, K.A. Kuhn e R. Lenz. Potential prevention of medical errors in casualty surgery by using information technology. Em ACM Symposium on Applied Computing, páginas 285-290, 2004. 9

[CdCK $\left.{ }^{+} 09\right]$ Rafael Correia, Arlindo Flavio da Conceição, Fabio Kon, Rubens Kon e José Ricardo Brandão. Sistema Móvel multí́dia de Código Aberto para Atenção Primária de Saúde com Visitas Domiciliares. Em Em FISL - X Workshop de Software Livre, 2009. 10,46

[CKK08] Rafael Correia, Fabio Kon e Rubens Kon. Borboleta: A Mobile Telehealth System for Primary Homecare. Em ACM Symposium on Applied Computing, 2008. 3 
[CTHOC07] Aaron E. Carrol, Peter Tarczy-Hornoch, Eamon O'Reilly e Dimitri A. Cristakis. The Effect of Point-of-Care Personal Digital Assistant Use on Resident Documentation Discrepancies. Pediatrics, 113:450-454, 2007. 9

[dCaPaVPR ${ }^{+}$08] Arlindo F. da Conceição, Rafael L. Pereira, Jo ao V. P. Rezende, Bruno N. M. Silva, Rafael J. P. Correia, Helves H. Domingues, Rubens Kon e Fabio Kon. Projeto Borboleta: Ferramentas Móveis e Multimídia para Atenção Básica Domiciliar. Em CBIS - XI Congresso Brasileiro de Informática em Saúde, 2008. 29

[DCK $\left.{ }^{+} 08\right] \quad$ Helves Domingues, Rafael Correia, Fabio Kon, João Eduardo Ferreira e Rubens Kon. Análise e Modelagem Conceitual de um Sistema de Prontuário Eletrônico para Centros de Saúde. Em Workshop de Informática Médica, 2008. 19, 33, 39

[DCL $\left.{ }^{+} 10\right]$ Gustavo Duarte, Rafael Correia, Pedro Leal, Helves Domingues, Fabio Kon, Rubens Kon e João Eduardo Ferreira. Borboleta and SaguiSaúde - Open Source Mobile Telehealth for Public Home Healthcare. Em Med-e-Tel 2010, 2010. 10, 11,35

[DCR ${ }^{+}$08] Catherine M. DesRoches, Eric G. Campbell, Sowmya R. Rao, Karen Donelan, Timothy G. Ferris, Ashish Jha, Rainu Kaushal, Douglas E. Levy, Sara Rosenbaum, Alexandra E. Shields e David Blumenthal. Electronic health records in ambulatory care - a national survey of physicians. The New England Journal of Medicine, 359:50-60, 2008. 12

[DdAaB00] Departamente de Atenção Básica. Programa Saúde da Família. Revista de Saúde Pública, 34:316-319, 2000. 3

[dFdSAdS ${ }^{+}$06] Alaneir de Fátima dos Santos, Maria Beatriz Moreira Alkmin, Cláudio de Souza, Simone Ferreira Santos, Humberto José Alves e Maria do Carmo Barros de Melo. Advances in International Telemedicine and eHealth Around the World, volume 1, chapter BHTelehealth: a public telehealth model in Brazil, páginas 37-58. MediPage, 2006. 10

[dFM03] Heimar de Fátima Marin. O Prontuário Eletrônico do Paciente na Assistência, informação e conhecimento médico. Núcleo de Informática em Enfermagem UNIFESP, 2003. 3, 33

[dO07] Frédéric Matias de Oliveira. Telemedicima - conceitos, aplicações, aspectos éticolegais e desafios. Em Segundo Encontro Científico do ISLA, 2007. 4, 11

[dODD00] Yeda Aparecida de Oliveira Duarte e Maria José D'Elboux Diogo. Atendimento Domiciliar: Um Enfoque Gerontologico. Atheneu Editora, 2000. 20

[dS02] Renilson Rehem de Souza. Construindo o SUS. Dissertação de Mestrado, Universidade do Estado do Rio de Janeiro, 2002. 3

[dSCA07] Marco de Sá, Luís Carrico e Pedro Antunes. Defining personalized therapies for handheld devices. Em ACM Symposium on Applied Computing, páginas 163-164, 2007. 12

[DSD97] Richard S. Dick, Elaine B. Steen e Don E. Detmer. The Computer-Based Patient Record: An Essential Technology for Health Care, Revised Edition. Institute of Medicine of the National Academy of Sciences, 1997. 3, 33

[GFAG08] Bernardo Gonçalves, José G. Pereira Filho, Rodrigo V. Andreão e Giancarlo Guizzardi. ECG data provisioning for telehomecare monitoring. Em ACM Symposium on Applied Computing, 2008. 11 
[Hua09] Sike Huang. Mobile Telemedicine System based on IMS/SIP platform. Dissertação de Mestrado, KTH Royal Institute of Technology, 2009. 10, 11, 29

[Koc06] Sabine Koch. Home telehealth - Current state and future trends. International Journal of Medical Informatics, 75(8):565-576, 2006. 11

[KP88] Glenn E. Krasner e Stephen T. Pope. A cookbook for using the model-view controller user interface paradigm in Smalltalk-80. J. Object Oriented Program., $1(3): 26-49,1988.27$

[KWD06] Jospeh C. Kvedar, Richard Wootton e Susan L. Dimmick. Home Telehealth: Connecting Care Within the community. Royal Society of Medicine Press, 2006. 4

$\left[\mathrm{LBB}^{+} 07\right] \quad$ R. Lenz, R. Blaser, M. Beyer, O. Heger, C. Biber, M. Bäumlein e M. Schnabel. IT support for clinical pathways-Lessons learned. International Journal of Medical Informatics, 76(Supplement 3):S397 - S402, 2007. Ubiquity: Technologies for Better Health in Aging Societies - MIE 2006. 9, 10

[LSB ${ }^{+}$95] Steven Labkoff, Sandeep Shah, J Bormel, Y Lee e RA Greenes. The constellation project: experience and evaluation of personal digital assistants in the clinical environment. Em Proceedings of the 19th Annual Symposium on Computer Applications in Medical Care, páginas 678-682, 1995. 9

[MHG04] Robert H. Miller, John M. Hillman e Ruth S. Given. Physician's use of electronic medical records: Barriers and solutions. Journal of Healthcare Information Management, 18(1):72-80, 2004. 3

[Mic] Sun Microsystems. https://phoneme.dev.java.net/. 46

[MN10] Wagner Francisco Mezaroba e Evânio Ramos Nicoleit. Informática em Saúde - Protótipo para Representação de Informações demográficas em um S-RES baseado nas especificações openehr. Em Anais SULCOMP, 2010. 12

[Mor] Jacques Morel. http://www.xplanner.org/xplanner. http://www.xplanner.org/. 44

[Org01] World Health Organization. International Classification of Functioning, Disability and Health. World Health Organization, 2001. 21

[Org04] World Health Organization. International Statistical Classification of Diseases and Health Related Problems (The) ICD-10 Second Edition. World Health Organization, 2004. 17, 33, 39

[PGW09] Mirela Prgomet, Andrew Georgiou e Johanna I. Westbrook. The impact of mobile handheld technology on hospital physicians work practices and patient care: A systematic review. Journal of the American Medical Informatics Association, 16:792-801, 2009. 12

[SBW $\left.{ }^{+} 04\right] \quad$ Dirk Stengel, Kai Bauwens, Martin Walter, Thilo Kopfer e Axel Ekkernkamp. Comparison of Handheld Computer-Assisted and Conventional Paper Chart Documentation of Medical Records. The Journal of Bone and Joint Surgery, 86:553$560,2004.7$

[Sch99] Maria Regina Scholz. Deficiências e incapacidades de pessoas com doença arterial oclusiva crônica em membros inferiores. Tese de Doutorado, Universidade de São Paulo. Escola de Enfermagem, 1999. 21 
[SMO08] Meke I. Shivute, Blessing M. Maumbe e Vesper T. Owei. The emerging ict use patterns for health service delivery in africa: Evidence from rural and urban setting in namibia. Em IST-Africa 2008 Conference Proceedings, 2008. 12

[Sof $]$

Edgewall Software. Trac. http://trac.edgewall.org. 44

[SUN08] SUN. The Lightweight User Interface Toolkit (LWUIT), 2008. https://lwuit.dev. java.net. $10,20,28$

[SUN09] SUN. Java ME Technology API and Docs., 2009. http://java.sun.com/javame/ reference/apis.jsp. 19, 26, 27, 35, 43

[Tig] Tigris. Subversion. http://subversion.tigris.org. 44

[TLaMTRPL] Thiago Leão Moreira, Thiago Rossato e Priscila Lugon. http://floggy.sourceforge.net/. 37

[WCP06] Richard Wootton, John Craig e Victor Patterson. Introduction to Telemedicine. Rittenhouse Book Distributors, 2006. 4

$\left[\mathrm{WMP}^{+}\right.$03] Samuel J. Wang, Blackford Middleton, Lisa A. Prosser, Christina G. Bardon, Cynthia D. Spurr, Patricia J. Carchidi, Anne F. Kittler, Robert C. Goldszer andDavid G. Fairchild, Andrew J. Sussman, Gilad J. Kuperman e David W. Bates. A cost-benefit analysis of eletronic medical records in primary care. The American Journal of Medicine, 114(5):397-403, April 2003. 3

[ZBdPPM04] Cristine Zeni, Emerson Paulo Borsato, José Simao de Paula Pinto e Oswaldo Malafaia. Panorama do uso de computação móvel com conexão wireless. Em Anais do IX Congresso Brasileiro de Informática em Saúde, 2004. 11 